\title{
HYBRID SELECTIVE NON-CATALYTIC REDUCTION (SNCR)/SELECTIVE CATALYTIC REDUCTION (SCR) DEMONSTRATION FOR THE REMOVAL OF NOX FROM BOILER FLUE GASES
}

Final Technical Report

Reporting Period: 12/06/1996 - 04/30/1999

Author: Jerry B. Urbas

Report Issue Date: 05/14/1999

DE-FG22-96PC96256

GPU Generation, Inc. 1001 Broad Street

Johnstown, PA 15907

Fuel Tech, Inc.

P.O. Box 3031

Napierville, IL 60566

CONSOL, Inc. 4000 Brownsville Road Library, PA 15129

Cormetech, Inc. Treyburn Corporate Park 5000 Intenational Drive

Durham, NC 27712

Englehard Corporation

101 Wood Avenue

Iselin, NJ 08830 


\section{Disclaimer}

This report was prepared as an account of work sponsored by an agency of the United States Government. Neither the United States Government nor any agency thereof, nor any of their employees, makes any warranty, expressed or implied, or assumes any legal liability or responsibility for the accuracy, completeness, or usefulness of any information, apparatus, product, or process disclosed, or represents that its use would not infringe privately owned rights. Reference herein to any specific commercial product, process, or service by trade name, trademark, manufacturer, or otherwise does not necessarily constitute or imply its endorsement, recommendation, or favoring by the United States Government or any agency thereof. The views and opinions of authors expressed herein do not necessarily state or reflect those to the United States Government or any agency thereof. 


\section{Abstract}

The U. S. Department of Energy (DOE), Electric Power Research Institute (EPRI), Pennsylvania Electric Energy Research Council, (PEERC), New York State Electric and Gas and GPU Generation, Inc. jointly funded a demonstration to determine the capabilities for Hybrid SNCR/SCR (Selective Non-Catalytic Reduction/Selective Catalytic Reduction) technology. The demonstration site was GPU Generation's Seward Unit \#5 (147MW) located in Seward Pennsylvania. The demonstration began in October of 1997 and ended in December 1998. DOE funding was provided through Grant No. DE-FG22-96PC96256 with T. J. Feeley as the Project Manager. EPRI funding was provided through agreements TC4599-001-26999 and TC4599-002-26999 with E. Hughes as the Project Manager.

This project demonstrated the operation of the Hybrid SNCR/SCR NO control process on a full-scale coal fired utility boiler. The hybrid technology was expected to provide a cost-effective method of reducing $\mathrm{NO}_{x}$ while balancing capital and operation costs. An existing urea based SNCR system was modified with an expanded-duct catalyst to provide increased $\mathrm{NO}_{x}$ reduction efficiency from the SNCR while producing increased ammonia slip levels to the catalyst. The catalyst was sized to reduce the ammonia slip to the air heaters to less than 2 ppm while providing equivalent $\mathrm{NO}_{\mathrm{x}}$ reductions. The project goals were to demonstrate hybrid technology is capable of achieving at least a $55 \%$ reduction in $\mathrm{NO}_{x}$ emissions while maintaining less than $2 \mathrm{ppm}$ ammonia slip to the air heaters, maintain flyash marketability, verify the cost benefit and applicability of Hybrid post combustion technology, and reduce forced outages due to ammonium bisulfate (ABS) fouling of the air heaters.

Early system limitations, due to gas temperature stratification, restricted the $\mathrm{Hybrid}_{\mathrm{NO}}$ reduction capabilities to $48 \%$ with an ammonia slip of $6.1 \mathrm{mg} / \mathrm{Nm}^{3}(8 \mathrm{ppm})$ at the catalyst inlet. After resolving the stratification problem, the catalyst did not have sufficient activity in order to continue the planned test program. Arsenic poisoning was found to be the cause of premature catalyst deactivation. 


\section{Contents}

1. INTRODUCTION

2. OBJECTIVES

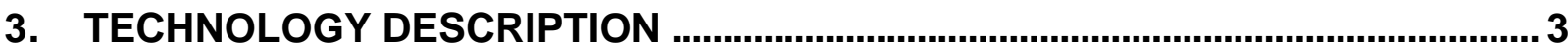

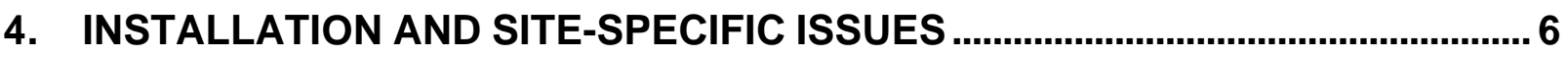

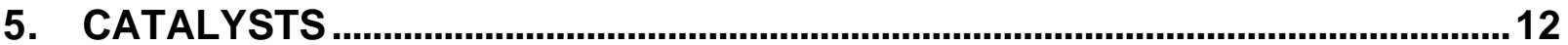

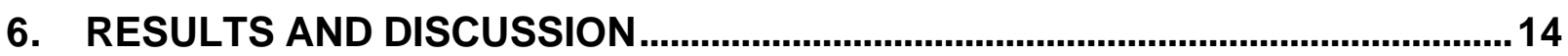

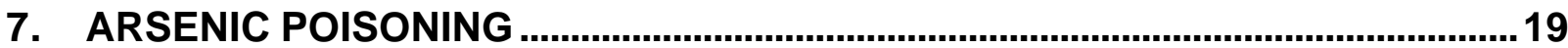

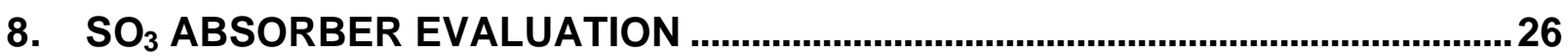

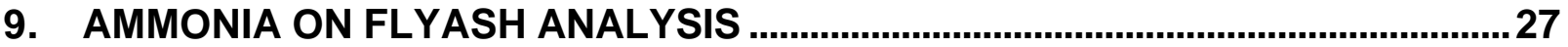

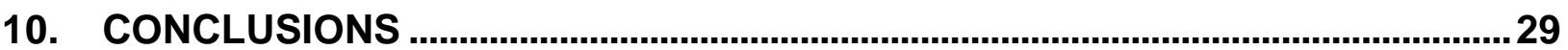

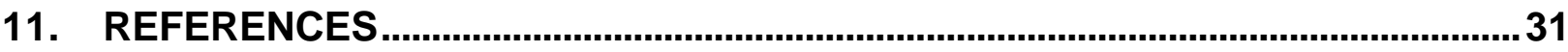

10. APPENDICES

A - ANALYSIS OF SCR SAMPLES REMOVED FROM SEWARD STATION .. A-1

B - SCR CATALYST PILOT PERFORMACE TEST REPORT ............................ B-1

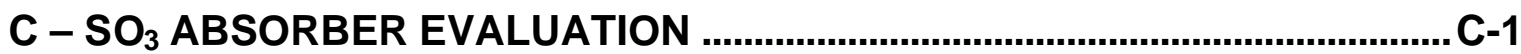

D - ANALYSIS OF SEWARD STATION FLY ASH SAMPLES........................... D-1

E - STANDARD METHOD No. 247 


\section{Figures}

1 CHEMICAL UTILITZATION

2 AIR HEATER INLET TEMPERATURE

3 AIR HEATER INLET \% OXYGEN

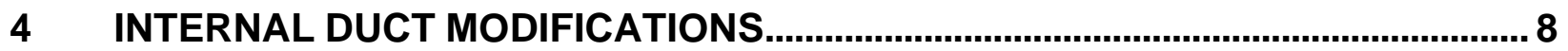

5 HYBRID LAYOUT CROSS-SECTION

6 COLD FLOW MODEL

7 CFD MODEL

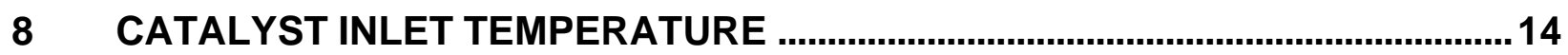

9 CATALYST INLET \% OXYGEN

10 MINIMUM CATALYST INLET TEMPERATURE VS. LOAD ................................15

11 ADDITIONAL MODIFICATIONS FOR TEMPERATURE BALANCING.................16

12 MINIMUM CATALYST INLET TEMPERATURE VS. LOAD BEFORE AND AFTER BYPASS INSTALLATION ..........................................................17

13 MINIMUM CATALYST INLET TEMPERATURE AND BYPASS DAMPER

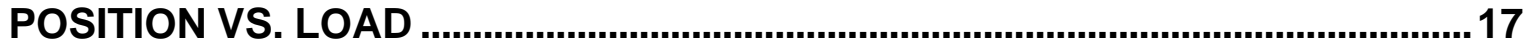

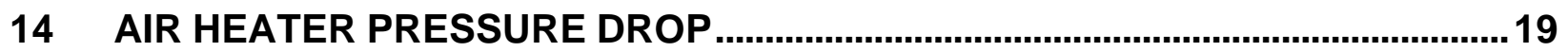

15 LOCATIONOF CATALYST “A” SAMPLES............................................................... 22

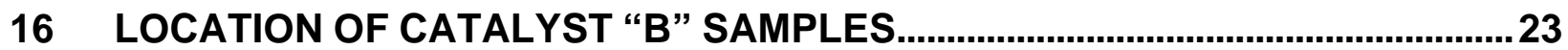




\section{Table}

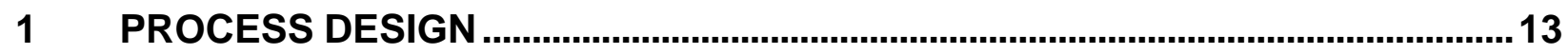

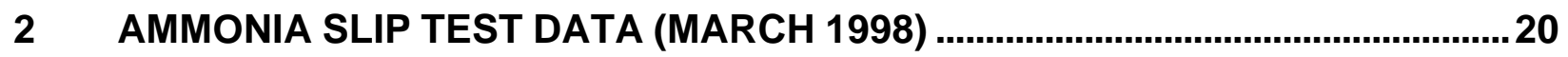

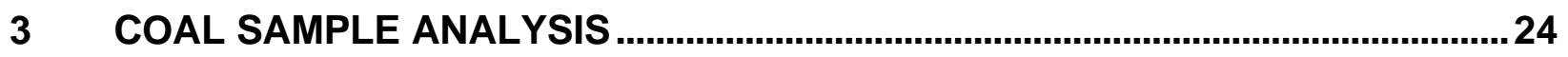

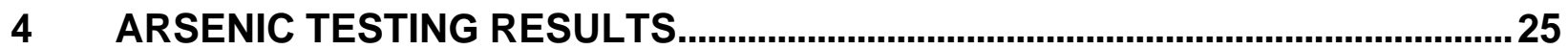




\section{1}

\section{INTRODUCTION}

Under the first phase of $\mathrm{NO}_{x}$ controls mandated by the Clean Air Act Amendments of 1990, low $\mathrm{NO}_{x}$ burners were required by Title IV, while low $\mathrm{NO}_{x}$ burners and overfire air were required in Pennsylvania in order to comply with Titte I (RACT). Additional technologies such as reburn, SNCR and deeper air staging have been further developed and demonstrated. In some instances, such as the SNCR on Unit \#5 at Seward Station, they have been installed and are being used to satisfy the requirements of RACT. Phase II provisions for Title I and Title IV will lower the allowed emissions in 1999 and 2000 respectively. This will require additional capital expenditure in order to comply. For selected units, a combination of technologies may provide a cost-effective means for compliance. Hybird combinations of SNCR and SCR are a flexible method to obtain moderate to deep reductions of $\mathrm{NO}_{x}$ at cost ranges typically below those of a fullscale SCR retrofit. By combining the two technologies, the result is a more costeffective technology than the sum of the parts, and it provides the best characteristics from each technology. 


\section{2}

\section{OBJECTIVE}

The original SNCR system on Seward \#5 has been operated at reduced efficiency to produce less than $1.52 \mathrm{mg} / \mathrm{Nm}^{3}(2 \mathrm{ppm})$ ammonia slip at the inlet of the air heaters. The ammonia slip was kept under this level in order to minimize the effect of ammonium bisulfate (ABS) fouling. The formation of ABS occurs when excess ammonia vapors from the SNCR process combines with the $\mathrm{SO}_{3}$ in the flue gas. It then condenses in the intermediate air heater baskets and plugs the passages between the plates, subsequently increasing the pressure drop across the air heaters. Operating at this level of ammonia slip reduces the overall $\mathrm{NO}_{x}$ reduction capabilities of the SNCR. The SNCR system is capable of reducing $\mathrm{NO}_{x}$ emissions from a baseline of 1093 to 656 $\mathrm{mg} / \mathrm{Nm}^{3}(0.75$ to $0.45 \mathrm{lb} / \mathrm{MMBtu}$ ) with an ammonia slip level between 3.8 and 6.1 $\mathrm{mg} / \mathrm{Nm}^{3}$ (5 and $8 \mathrm{ppm}$ ). Based on extensive operating experience, it has been determined that ammonia slip levels must be maintained below $1.52 \mathrm{mg} / \mathrm{Nm}^{3}(2 \mathrm{ppm})$ to allow continuous unit operation without washing air heaters at time intervals of less that four to six weeks. The Hybrid SNCR/SCR was designed to reduce the ammonia concentration in the flue gas to below $1.52 \mathrm{mg} / \mathrm{Nm}^{3}$ (2 ppm), while also allowing the existing SNCR system to be operated in a more optimum/efficient mode. The main objectives of this demonstration, which will interest utilities faced with Phase II requirements, are as follows:

- Provide proof of concept of the Hybrid process with eastern bituminous coal

- Determine the cost/benefit and applicability of Hybrid technology

- Verify that an overall $\mathrm{NO}_{x}$ reduction of at least $55 \%$ can be achieved

- Maintain ammonia slip levels of less than $1.52 \mathrm{mg} / \mathrm{Nm}^{3}$ (2 ppm) after three years

- Achieve a projected catalyst life of at least three years

- Verify the performance capabilities of two different types of catalyst (monolithic and plate/wash coat)

- Maintain flyash marketability

- Develop a gas conditioning system for stripping $\mathrm{SO}_{3}$ from extracted flue gases. The system will be used in conjunction with an ammonia monitor.

- Determine if ammonia concentrations in the flyash can be correlated with physical or chemical characteristics, such as particle size or loss on ignition (LOI).

The last two objectives are not directly related to the Hybrid demonstration, but they were included as part of the DOE grant. They were funded separately by the DOE, while the Hybrid demonstration was funded by the EPA and administrated by the DOE. 


\section{TECHNOLOGY DESCRIPTION}

\section{Hybrid Background}

Hybrid SNCR/SCR $\mathrm{NO}_{x}$ reduction systems can be engineered in many different configurations depending upon the level of overall $\mathrm{NO}_{\mathrm{x}}$ reduction desired and the configuration of the existing unit. Both factors combined lead to differences in catalyst dimensions and, therefore, the contribution of the catalyst to total capital cost. The different types of hybridized SNCR/SCR can be fit into one of three major categories. They are as follows:

- Catalytic air heater baskets

- "In Duct" SCR with existing or expanded duct dimensions

- Combination of air heater and "In Duct" SCR

Variations to the above list can be made by either using excess ammonia slip from the SNCR system as the reductant for the SCR, or by installing an ammonia injection grid (AIG) ahead of the SCR. For the purposes of this paper, the term "Hybrid" will be reserved for a combination of SNCR and "expanded duct" SCR with the reductant for the catalyst being supplied by the SNCR.

A survey (ref 1) was conducted on the above combined technologies, which listed the potential benefits and drawbacks of combining the technologies. It primarily reported from a technological feasibility viewpoint where a specific requirement for SCR is presumed. It is important, however, to view the potential application of hybridized SNCR/SCR from an economic standpoint, particularly in the case where combustion modifications have already been employed. Items that need to be considered when performing such a review are:

- Desired level of $\mathrm{NO}_{x}$ reduction

- $\mathrm{NH}_{3}$ constraints, (regulatory, and/or operational)

- Volume of catalyst that can be installed based on existing plant physical constraints

- Face velocity requirements from the catalyst vendors

- Available pressure drop with existing fans

- Structural steel and ductwork modifications required for support of the catalyst

- Guaranteed life of catalyst at specified ammonia slip levels

- $\mathrm{NH}_{3}$ distribution and flow requirements

- Existing $\mathrm{NO}_{\mathrm{x}}$ emissions baseline

- Remaining life of the unit 
The total capital requirement will increase as the catalyst size and retrofit complexity increases. The key to minimizing lifecycle $\mathrm{NO}_{x}$ reduction costs is to find the appropriate balance between annualized capital charges and operating costs for the remaining life of the system. The challenge for SCR retrofit is to minimize capital requirement while the challenge for SNCR is to minimize the reagent requirements. Designing Hybrid systems suggests optimization of these costs over the lifecycle for a specific level of $\mathrm{NO}_{\mathrm{x}}$ reduction.

\section{Chemical Utilization}

In post-combustion $\mathrm{NO}_{x}$ control processes, $\mathrm{NO}_{x}$ reduction is achieved at a given Normalized Stoichiometric Ratio or NSR. NSR refers to the ratio of chemical reductant applied to the amount of $\mathrm{NO}_{\mathrm{x}}$ existing in the flue gas. With SCR, ammonia is typically the reductant and it is applied at an NSR of one for deep reductions, i.e. one mole of $\mathrm{NH}_{3}$ applied for each mole of $\mathrm{NO}_{x}$. If only a $75 \% \mathrm{NO}_{x}$ reduction is required, the $\mathrm{NH}_{3}$ NSR would be approximately 0.75 . In non-catalytic systems, the reductant is applied in broader ranges of NSR because of relatively lower $\mathrm{NO}_{x}$ reduction efficiencies compared to catalytic systems. In commercial practice, NSRs range form 0.6 to 2.0. When urea is used for SNCR systems, a NSR of 1.0 means 0.5 mole of urea is applied for 1.0 mole of $\mathrm{NO}_{x}$, because there are two moles of nitrogen for reaction in every mole of urea. Chemical utilization is a quantification of $\mathrm{NO}_{\mathrm{x}}$ reduction efficiency expressed by:

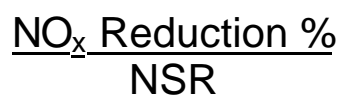

That is, if each 1- mole of injected urea or ammonia reduces $\mathrm{NO}_{x}$ to the theoretical maximum amount, utilization is $100 \%$. This level of chemical utilization is approached in SCR systems, but in a SNCR system, the values range from 30-60\%. In commercial post-combustion $\mathrm{NO}_{x}$ control systems, maximizing utilization, all other things being equal, minimizes lifecycle operating costs.

Figure 1 schematically depicts the enabling effect of downstream catalyst on SNCR performance in a hybrid system. SNCR NO reduction occurs in a defined temperature window, roughly bell-shaped, with maximum $\mathrm{SNCR} \mathrm{NO}$, reduction occurring at the top, or plateau of the bell. In a commercial "stand-alone" SNCR, the system is operated within the slope area on the right side of the temperature window curve (ref 2). In this region, the hot side of the performance maximum, ammonia slip is very low or nonexistent. This is often an operating constraint imposed by the source owner. In contrast, the SNCR component of the hybrid system operates best at the plateau, which is in a lower temperature region. In this region, SNCR NO${ }_{x}$ reductions are maximized and some ammonia slip is produced. The ammonia slip that is produced is available for additional $\mathrm{NO}_{x}$ reductions with a downstream catalyst system. When operated in this manner, SNCR NO reduction is maximized (compared to its stand-alone performance) and additional $\mathrm{NO}_{x}$ reductions are realized from the catalyst, which is fueled by the SNCR generated ammonia slip. 
Hybrid systems can be designed to operate in the cooler zone to the left side of the slope. This will produce more ammonia slip than the other regions. In this scenario, SNCR NO reductions are less than maximal and SCR $\mathrm{NO}_{x}$ reductions increase until limited by catalyst space velocity. Overall system $\mathrm{NO}_{x}$ reductions beyond $75 \%$ would typically require this type of operation, and it would require catalyst reactor dimensions that would not be possible to fit into existing duct spaces. Hybrid systems can be designed to maximize SNCR performance while "existing duct" SCRs are used to control the ammonia slip. Reagent utilization for the Hybrid systems can increase dramatically compared to a stand-alone SNCR.

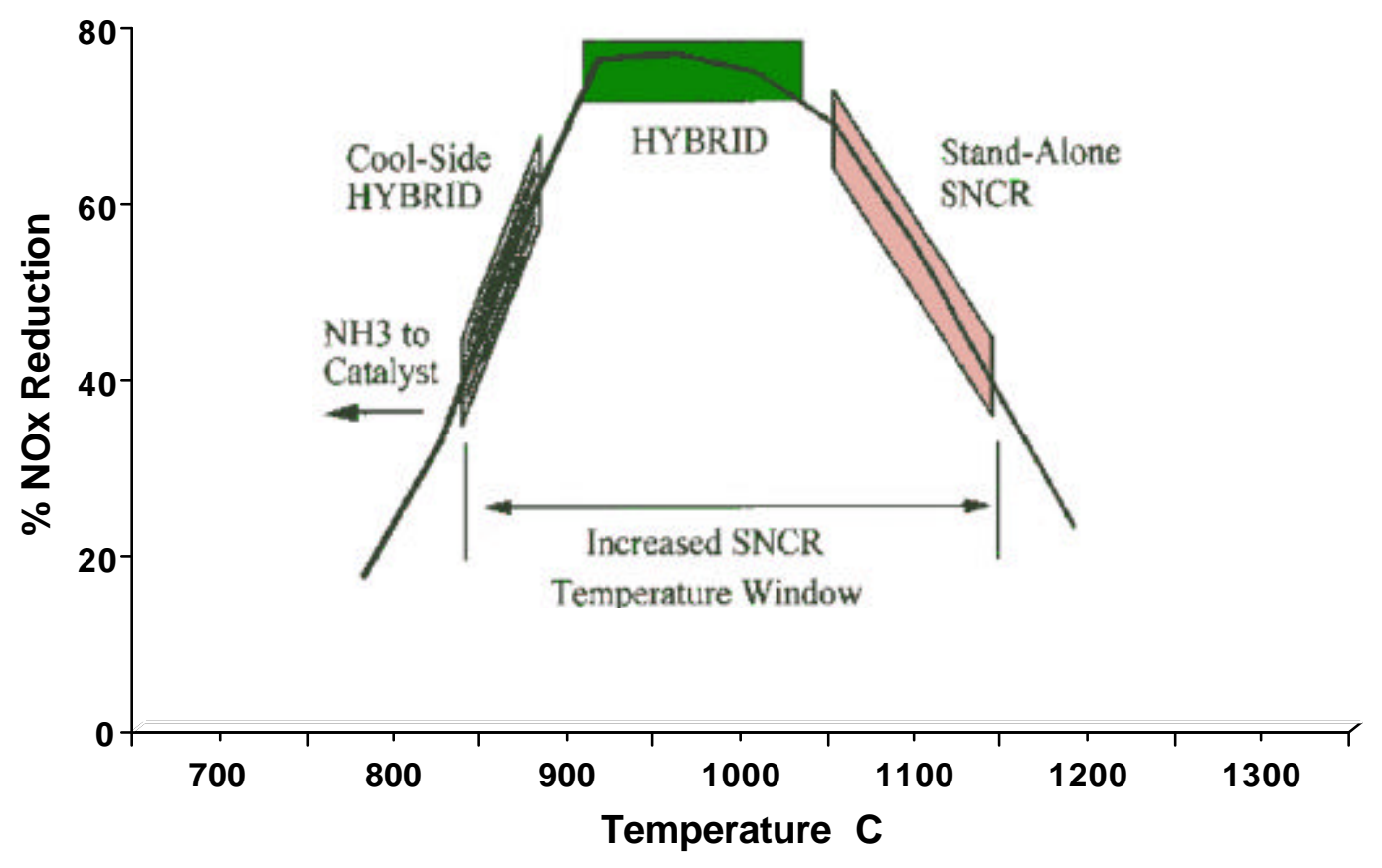

FIGURE 1 - Chemical Utilization 


\section{INSTALLATION AND SITE-SPECIFIC ISSUES}

A full-scale demonstration of Hybrid SNCR/SCR technology was performed by GPU Generation Inc. at the Seward Generating Station, Unit \#5. The system was designed and furnished by Fuel Tech (formerly Nalco Fuel Tech). Modifications that were required for the installation of the Hybrid system were performed during a scheduled outage from September 8, 1997 to October 5, 1997. The baseline testing of the system was to occur during early November with additional testing after 6 months and 1 year. The unit is rated at $147 \mathrm{MW}$ gross generating capacity and it has a urea based SNCR system that has been in operation since June of 1995. The unit's 1990 baseline $\mathrm{NO}_{\mathrm{x}}$ emission rate was $1093 \mathrm{mg} / \mathrm{Nm}^{3}$ (0.75 lb/MMBtu). The existing SNCR system reduced the emissions from this baseline to a rate of $656 \mathrm{mg} / \mathrm{Nm}^{3}(0.45 \mathrm{lb} / \mathrm{MMBtu})$ while minimizing the ammonia slip level to approximately 3.8 to $6.1 \mathrm{mg} / \mathrm{Nm}^{3}$ (5 to $8 \mathrm{ppm}$ ). At this level of ammonia slip, ABS fouling of the air heaters prevented continuous operation of the system. Additional system tuning, operational changes and control changes were made to minimize or eliminate ammonia spikes and other intermittent high levels of ammonia slip. Based on the data that was generated during this time period, it was determined that an ammonia slip level of less than $1.52 \mathrm{mg} / \mathrm{Nm}^{3}(2 \mathrm{ppm})$ was required to minimize air heater fouling to an acceptable level. This value of ammonia slip was the key to the design of the Hybrid SNCR/SCR for Seward Unit \#5.

Due to the air heater fouling under normal operation of the SNCR, the system must be operated at reduced efficiency, approximately $729 \mathrm{mg} / \mathrm{Nm}^{3}$ (0.50 lb/MMBtu), to produce less than $1.52 \mathrm{mg} / \mathrm{Nm}^{3}(2 \mathrm{ppm})$ ammonia slip at the inlet of the air heaters. As a result, as much as $75 \%$ of the urea is injected into the furnace where utilization is relatively low. The remaining portion of the urea is injected behind the pendant superheater tubes located above the furnace arch. Chemical injection into the upper zone is performed with multi-nozzle lances. These lances are capable of providing good chemical distribution and high chemical utilization.

During the development and design phases of the Hybrid project, consideration was given to the following:

- Ammonia slip control, SNCR to SCR - Urea, which is used as the reductant in the SNCR process, undergoes thermal decomposition to generate ammonia and HNCO to react with the $\mathrm{NO}_{x}$ in the flue gas. Correct placement of the reagent droplets introduces the proper level of reactivity in an environment that provides the correct kinetics for the reduction of $\mathrm{NO}_{\mathrm{x}}$. As with any chemical oxidation-reduction reaction, the reaction is not complete. The residual ammonia, which does not react with the $\mathrm{NO}_{x}$ in the flue gas, is used as the reductant feed for the SCR. Control of this phenomenon allows the proper amount of ammonia slip to pass to the SCR 
providing additional $\mathrm{NO}_{x}$ reductions and control of the ammonia slip to the air heaters.

- Gas Temperatures - Temperature of the flue gas through the catalyst must be maintained above $302^{\circ} \mathrm{C}\left(575^{\circ} \mathrm{F}\right)$ in order to avoid condensing of $A B S$ and thus avoiding masking and deactivation of the catalysts. Relatively low temperatures are normal for full load operation on this unit. The average bulk temperatures are 328 ${ }^{\circ} \mathrm{C}\left(623^{\circ} \mathrm{F}\right)$ and $317^{\circ} \mathrm{C}\left(602^{\circ} \mathrm{F}\right)$ for the "A" and "B" sides respectively. FIGURE 2 illustrates that the gas temperature distribution from the center of the unit to the outside walls originally had a temperature gradient of approximately 32 to $38^{\circ} \mathrm{C}(90$ to $100^{\circ} \mathrm{F}$ ). FIGURE 3 shows the corresponding $\mathrm{O}_{2}$ levels. This data indicates that the flue gas temperatures are directly related to the $\mathrm{O}_{2}$ levels and point to the possibility of major areas of air in-leakage through the boiler water walls. As part of the cold flow modeling study for this project, static mixing channels and flue gas crossover piping were designed to help minimize the large temperature gradient across the ducts. The location of these items can be seen in FIGURE 4. In addition to these modifications, the sidewalls were inspected for major air in leaks and repaired as required during the scheduled September 1997 outage

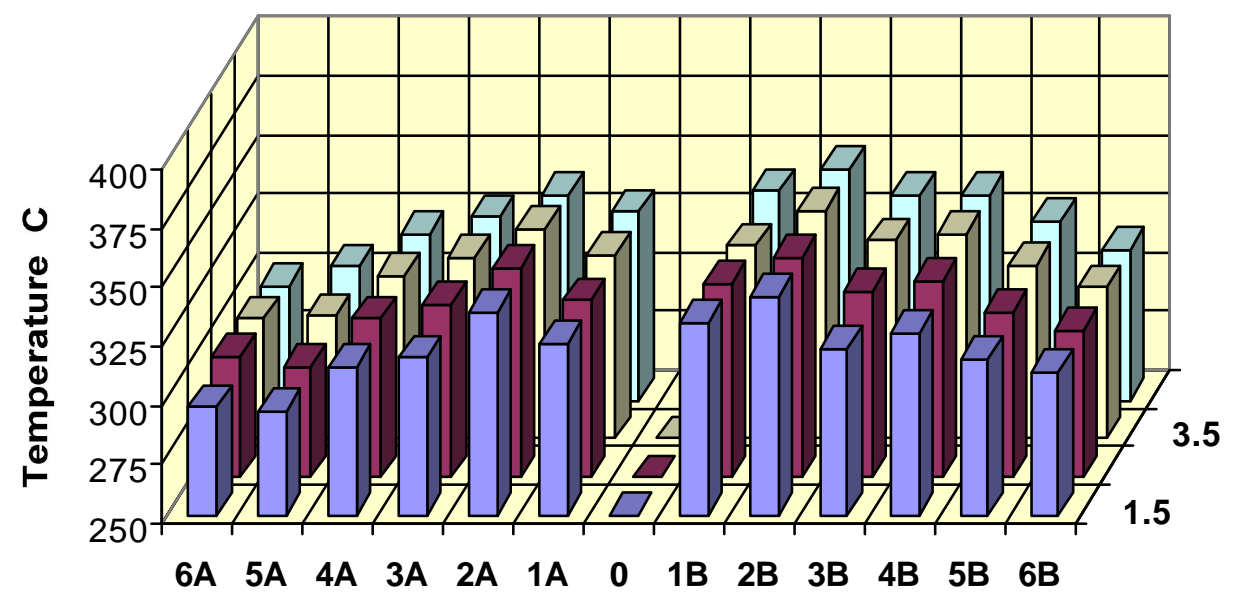

FIGURE 2 Air Heater Inlet Temperature

(Prior to Hybrid) 


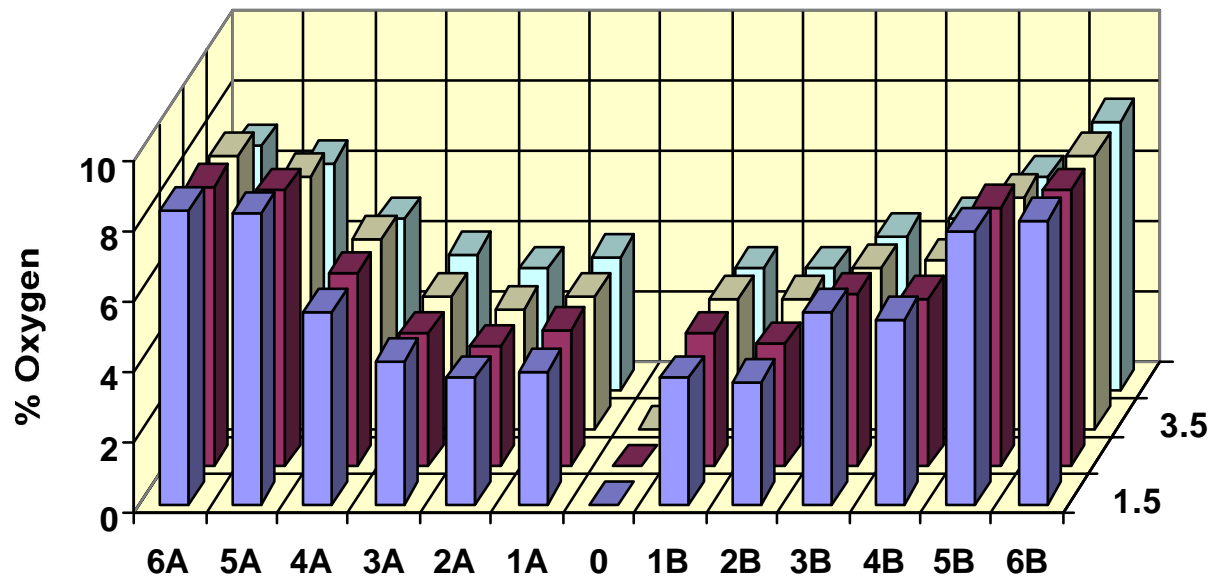

FIGURE 3 Air Heater Inlet \% Oxygen

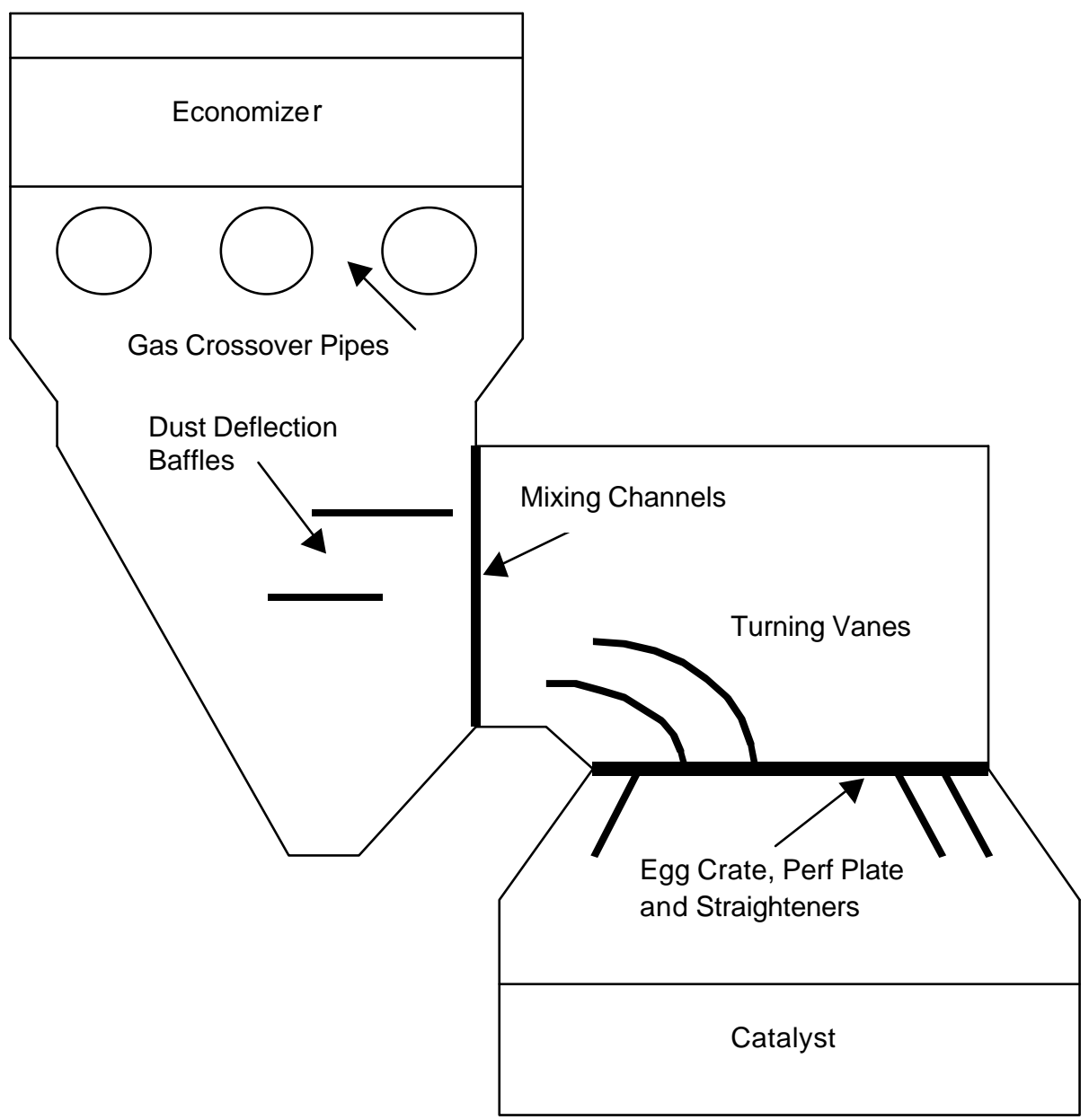

FIGURE 4 Internal Duct Modifications 
Erosion - Each catalyst vendor (monolith and solid metal/wash coat) has its own unique strategy for combating the erosive effects of flyash at high velocities. The monolith type is equipped with a hardened leading edge, which absorbs the initial erosive effect. The solid metal substrate type allows for erosion of the leading edges to the base metal, which in turn acts as a flow-straightening device to manage the angle of attack of the ash on the balance of the material.

- Available Space - The available space for the catalyst reactor vessel was considered and final placement was determined to be in the two sections of vertical ductwork between the economizer outlet and the air heater inlet as shown in FIGURE 5. The maximum amount of space was used between the existing duct location and the boiler house north wall. In addition, the ducts were expanded to the outside of their original east and west boundaries. The available area was sufficient to achieve acceptable velocity profiles while providing enough catalyst volume to achieve the goals of increased $\mathrm{NO}_{x}$ reduction efficiency from the existing SNCR and the ability to maintain the ammonia slip level below $1.52 \mathrm{mg} / \mathrm{Nm}^{3}$ (2 ppm).

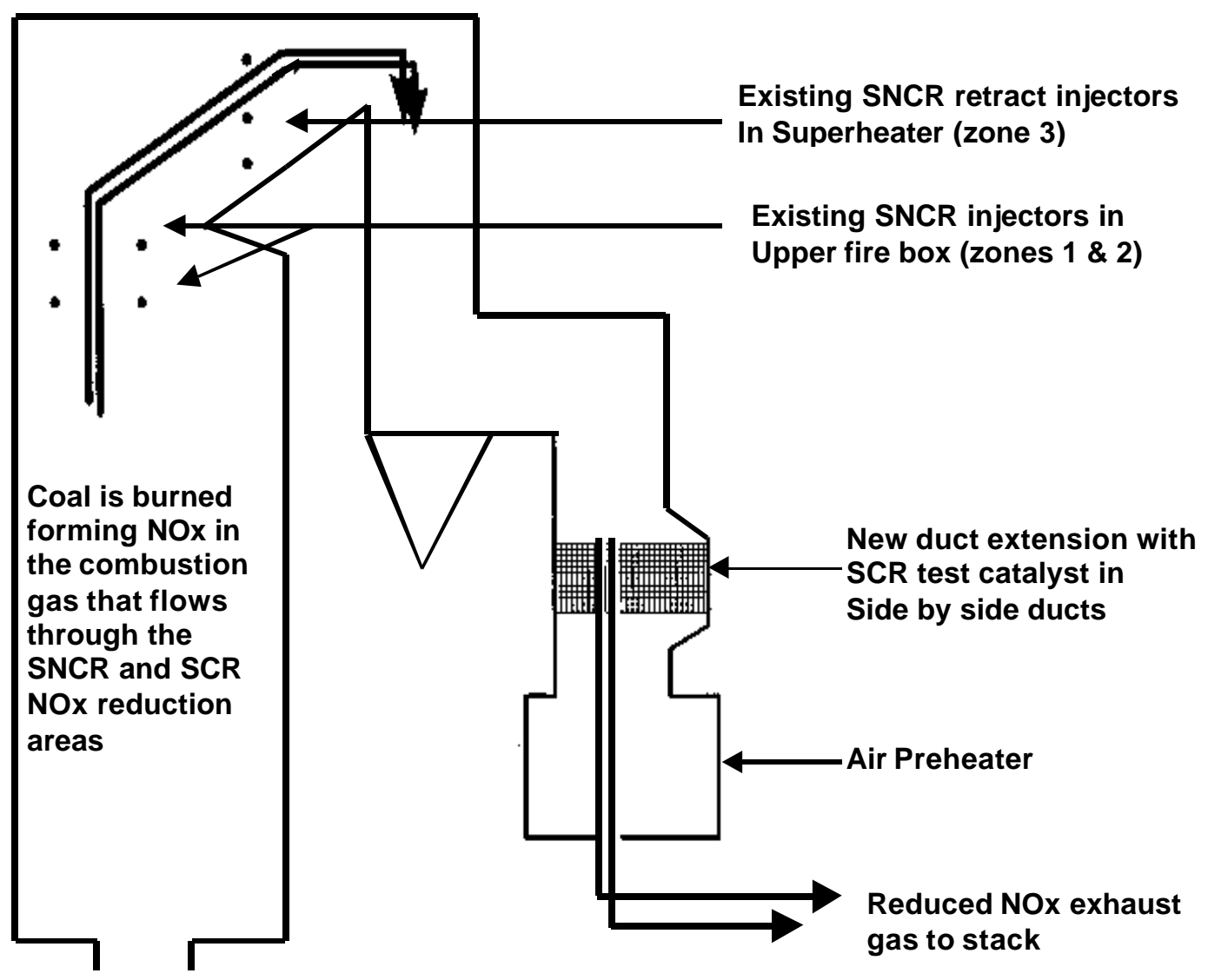

FIGURE 5 Hybrid Layout Cross-Section 
- Flue Gas Velocities - The face velocity of the flue gas entering the catalyst is approximately $6.8-6.1 \mathrm{~m} / \mathrm{sec}(19-20 \mathrm{ft} / \mathrm{sec})$. This is approximately $33 \%$ greater than the velocities used for full-scale SCR installations. A cold flow model study was performed to balance the flows into the two catalysts ducts to within $\pm 5 \%$ of theoretically equal, to insure flow is normal to the catalyst face and to equalize the velocity distribution through each catalyst within a RMS deviation less that $10-15 \%$ of mean velocity. FIGURE 6 shows the $1 / 8^{\text {th }}$ scale model that was constructed and used by NELS Consulting for this work. In addition, Fuel Tech performed a CFD modeling study, which predicted some of the problems that were encountered. As can be seen in FIGURE 7, there was an area of high velocity located on the boiler side of the vertical duct between the economizer hoppers and the catalyst.

Streamlines forming a recirculation zone located along the back wall of the new duct can also be seen. FIGURE 4 shows the location of the turning vanes, egg crate flow straightener, perforated plate and miscellaneous flow straighteners that were installed to help meet the velocity and flow requirements stated above.

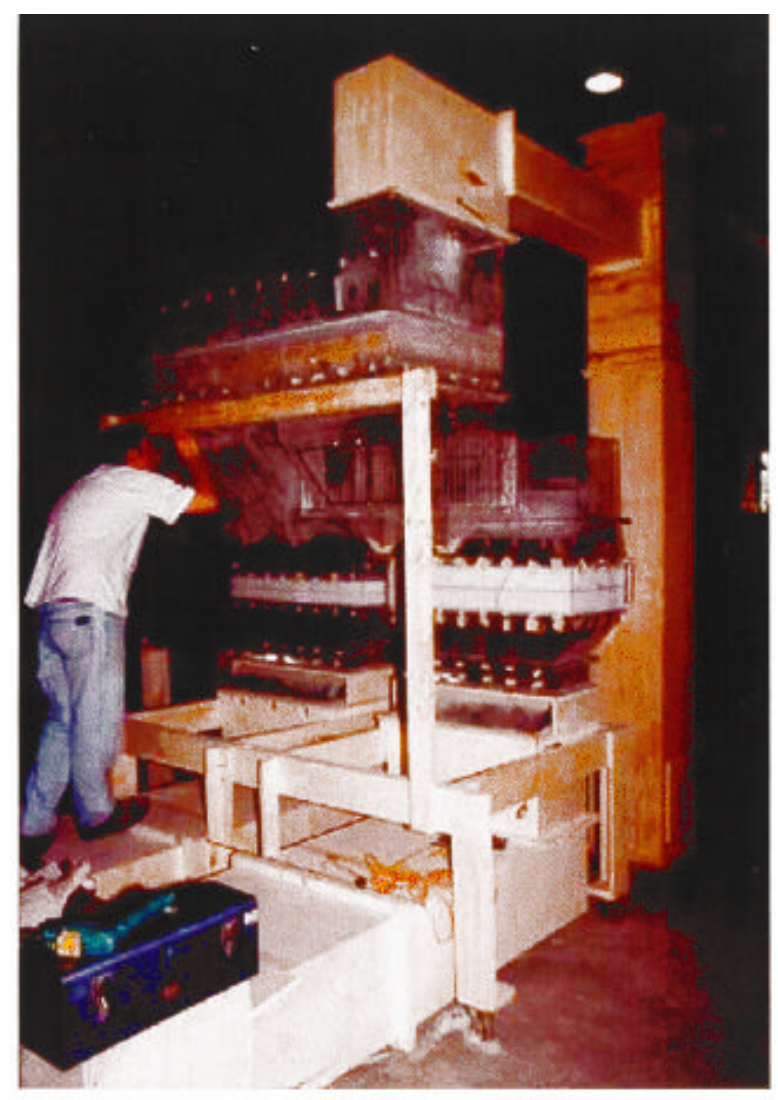

FIGURE 6 Cold Flow Model

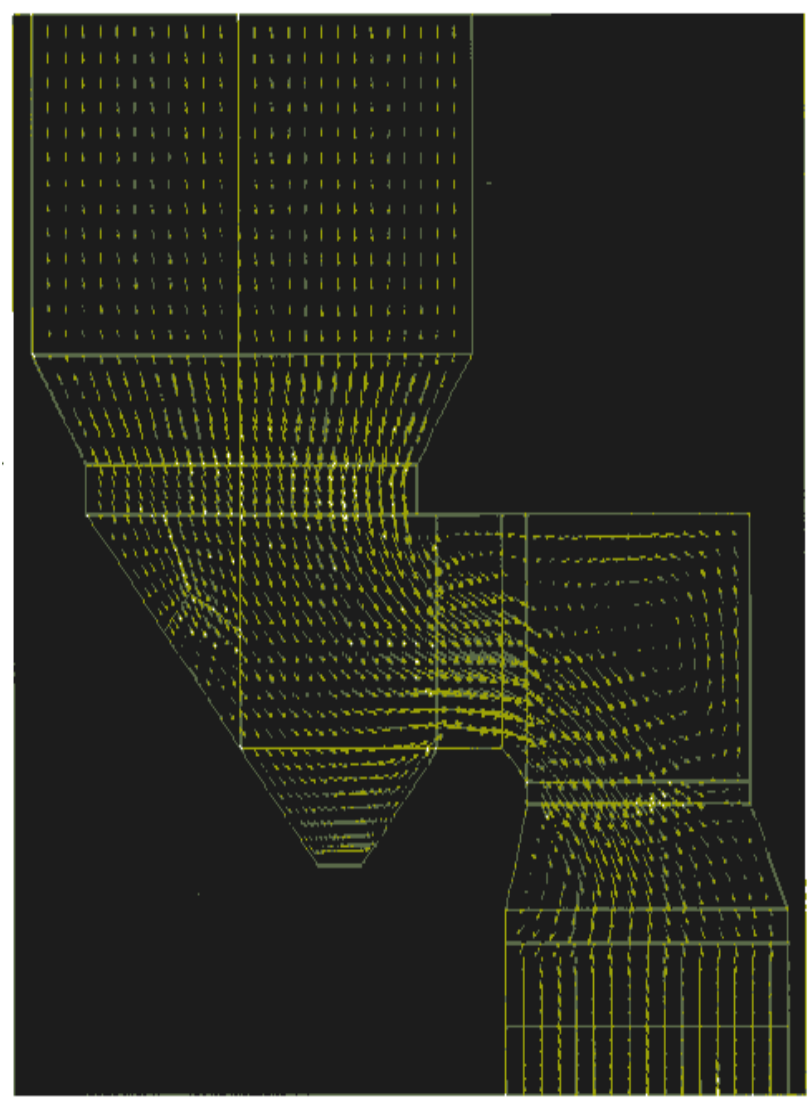

FIGURE 7 CFD Model

- Ash Loading - The ash loading between the two ducts was not balanced due to conditions created by the four corner tangential-fired boiler. The dust loading between the "A" and "B" ducts were 1602 and $2523 \mathrm{~kg} / \mathrm{hr}$ (3531 and $5563 \mathrm{lb} / \mathrm{hr}$ ) respectively. Even though there is a notable dust imbalance between the two ducts, 
the highest value is not abnormal for the ash loading range expected by the catalyst vendors. However, during the flow model study, it was discovered that the ash loading was being concentrated in the front portion of each duct. This was found to be primarily due to the installation of turning vanes at the inlet of the new ductwork. This problem was minimized with the installation of dust deflection baffles located below the economizer and upstream of the turning vanes. See FIGURE 4 for details.

- $\mathrm{SO}_{2}$ to $\mathrm{SO}_{3}$ Conversion - Because of current air heater sensitivities, the catalytic rate of $\mathrm{SO}_{3}$ generation is important. A guaranteed conversion rate of less than $1 \%$ was provided by one vendor and less than $0.5 \%$ was provided by the other vendor. The catalyst vendors have also specified a minimum operating temperature of 302 ${ }^{\circ} \mathrm{C}\left(575^{\circ} \mathrm{F}\right)$, above which ammonium salt formation and deposition in the catalyst pores will be avoided. Since economizer gas outlet temperatures will drop with unit load, the ammonia feed and $\mathrm{NO}_{x}$ reductions must also be adjusted to prevent $\mathrm{ABS}$ fouling of the catalyst.

- Water Contamination of Catalyst - Water can help accelerate the poisoning of a catalyst by transporting dissolved poisons from the flue gas and flyash into the pores of the catalyst. Flyash washed onto the catalyst will also mask the surface and prevent adequate penetration of the ammonia and $\mathrm{NO}_{\mathrm{x}}$ molecules into the active sites of the catalyst. In addition, sudden quenching of the catalyst could cause cracking of the catalytic material and accelerate erosion and deterioration of the catalyst. Seward Unit \#5 has a history of economizer and water wall tube leaks. In order to minimize any of the above effects from water contamination, thermocouples were installed on the mixing channels at the outlet of the economizer hoppers as an early leak detection system. Internal baffling for mixing and dust distribution were also designed and installed to potentially remove the majority of the larger water particles and direct them into the economizer hoppers. 


\section{5}

\section{CATALYSTS}

The use of Hybrid SNCR/SCR systems permits "tailoring" $\mathrm{NO}_{x}$ reduction and lifecycle costs to the potential future complex requirements of $\mathrm{NO}_{x}$ reduction. The total lifecycle cost of the modified SNCR/SCR NO reduction process is a function of chemical utilization, catalyst volume and capital requirement. Very high $\mathrm{NO}_{x}$ reductions (above $90 \%$ ) require a substantial catalyst volume. This system cannot be placed in existing or expanded duct dimensions and will always require, at the very least, major modifications. A modified SNCR/SCR system, providing between $50-60 \%$ pre-catalytic reduction, would require between $75-80 \%$ further $\mathrm{NO}_{x}$ reduction to achieve $90 \%$ overall. This would still demand $88 \%$ of the original catalyst volume. Similarly, for an overall $\mathrm{NO}_{\mathrm{x}}$ reduction of $75 \%$, a stand-alone SCR system requires approximately $88 \%$ of the original high $\mathrm{NO}_{x}$ reduction catalytic volume.

A modified SNCR/SCR process would conceptually be effective for an approximate $75 \%$ overall $\mathrm{NO}_{x}$ reduction system. Pre-catalytic SNCR reductions of $50-60 \%$ require only $38-50 \%$ SCR reductions, and no more than half of the original catalyst volume as designed for $90 \%$ reduction. This is also only $57 \%$ of the catalyst volume required for stand-alone SCR targeted at $75 \%$ reduction. An "In-Duct" catalyst may be used on a site-specific basis to fulfill this half-sized volume requirement.

The Seward Unit \#5 Hybrid SNCR/SCR was designed with the intent to reduce lifecycleoperating costs by increasing reagent utilization at modest catalyst capital requirements. The introduction of a catalyst allows the SNCR system to achieve a $53 \%$ reduction with $13.7-15.2 \mathrm{mg} / \mathrm{Nm}^{3}(18-20 \mathrm{ppm})$ of ammonia slip. The slip acts as the reducing agent for the SCR, which strips the ammonia from the flue gas while contributing an additional 6.3 $\% \mathrm{NO}_{x}$ reduction. The resulting overall $\mathrm{NO}_{x}$ reduction for the system becomes $56.7 \%$. Table 1 details the design data for the two catalysts that were evaluated on this project. 


\begin{tabular}{|c|c|c|c|}
\hline Description & Units & Catalyst "A" & Catalyst "B" \\
\hline Flue Gas Flow & $\begin{array}{l}\text { SCFH-wet } \\
\mathrm{Nm}^{3} / \mathrm{hr} \text {-wet }\end{array}$ & $\begin{array}{l}19,387,898 \\
519,438\end{array}$ & $\begin{array}{l}19,387,898 \\
519,438\end{array}$ \\
\hline Baseline $\mathrm{NO}_{\mathrm{x}}$ & $\begin{array}{l}\mathrm{mg} / \mathrm{Nm}^{3} \\
\mathrm{ppmvdc} \\
\mathrm{lb} / \mathrm{MMBtu}^{3} \\
\mathrm{mg} / \mathrm{Nm}^{3} \\
\mathrm{ppmvdc} \\
\mathrm{lb} / \mathrm{MMBtu}^{3}\end{array}$ & $\begin{array}{l}1093 \\
533 \\
0.75 \\
525 \\
256 \\
0.36\end{array}$ & $\begin{array}{l}1093 \\
533 \\
0.75 \\
525 \\
256 \\
0.36\end{array}$ \\
\hline $\mathrm{NO}_{x}$ Reduction & $\%$ & 52 & 52 \\
\hline Chemical Utilization & $\%$ & 40 & 40 \\
\hline NSR & - & 40 & 40 \\
\hline \multirow[t]{2}{*}{ Urea Flow } & L NO $x_{x} \mathrm{OUT}$ & 768 & 768 \\
\hline & gal $\mathrm{NO}_{x} \mathrm{OUT}$ & 203 & 203 \\
\hline \multirow[t]{2}{*}{ Final $\mathrm{NO}_{x}$ Desired } & $\mathrm{mg} / \mathrm{Nm}^{3}$ & 488 & 492 \\
\hline & ppmvdc & 238 & 240 \\
\hline Overall Reduction & $\%$ & 55.3 & 55 \\
\hline SCR Reduction & $\%$ & 7.0 & 6.3 \\
\hline \multirow[t]{2}{*}{$\mathrm{NH}_{3}$ at Catalyst Entrance } & $\mathrm{mg} / \mathrm{Nm}^{3}$ & 15.2 & 13.7 \\
\hline & ppmvdc & 20 & 18 \\
\hline \multirow[t]{2}{*}{$\mathrm{NH}_{3}$ Slip Requirement } & $\mathrm{mg} / \mathrm{Nm}^{3}$ & $<1.52$ & $<1.52$ \\
\hline & ppmvdc & $<2$ & $<2$ \\
\hline Space Velocity & $1 / \mathrm{hr}$ & 16,361 & 11,765 \\
\hline Specific Area & $\mathrm{m}^{2} / \mathrm{m}^{3}$ & 550 & 509 \\
\hline Area Velocity & $\mathrm{m} / \mathrm{hr}$ & 29.7 & 23.1 \\
\hline Catalyst Volume & $\begin{array}{l}\mathrm{m}^{3} \\
\mathrm{ft}^{3}\end{array}$ & $\begin{array}{l}33.6 \\
1,183\end{array}$ & $\begin{array}{l}46.8 \\
1643\end{array}$ \\
\hline Actual Duct Area & $\mathrm{m}^{2}$ & $\begin{array}{l}51.7 \\
556\end{array}$ & $\begin{array}{l}51.7 \\
556\end{array}$ \\
\hline Catalyst Depth & $\begin{array}{l}\mathrm{m} \\
\mathrm{ft}\end{array}$ & $\begin{array}{l}0.76 \\
2.50\end{array}$ & $\begin{array}{l}1.38 \\
4.53\end{array}$ \\
\hline Gas Temperature (design) & $\begin{array}{l}{ }^{\circ} \mathrm{C} \\
{ }^{\circ} \mathrm{F}\end{array}$ & $\begin{array}{l}316 \\
600\end{array}$ & $\begin{array}{l}316 \\
600\end{array}$ \\
\hline Flow @ Design Temp. & $\begin{array}{l}\mathrm{ACMH} \\
\mathrm{ACFH}\end{array}$ & $\begin{array}{l}1,102,790 \\
38,944,897\end{array}$ & $\begin{array}{l}1.102,790 \\
38,944,897\end{array}$ \\
\hline Flow Velocity & $\begin{array}{l}\mathrm{m} / \mathrm{sec} \\
\mathrm{ft} / \mathrm{sec}\end{array}$ & $\begin{array}{l}5.9 \\
19.5\end{array}$ & $\begin{array}{l}5.9 \\
19.5\end{array}$ \\
\hline Catalyst $\Delta \mathrm{P}$ & mBar & 2.5 & 4.25 \\
\hline & in $\mathrm{H}_{2} \mathrm{O}$ & 1.0 & 1.7 \\
\hline Final $\mathrm{NO}_{\mathrm{x}}$ & $\begin{array}{l}\mathrm{mg} / \mathrm{Nm}^{3} \\
\mathrm{ppmvdc} \\
\mathrm{lb} / \mathrm{MMBtu}\end{array}$ & $\begin{array}{l}488 \\
238 \\
0.335\end{array}$ & $\begin{array}{l}492 \\
240 \\
0.337\end{array}$ \\
\hline
\end{tabular}

* The data in this table is based on one catalyst vendor for the complete Hybrid SNCR/SCR. The demonstration will include one catalyst in duct " $\mathrm{A}$ " and one catalyst in duct "B".

TABLE 1 Process Design 


\section{6}

\section{RESULTS}

After installation of the catalyst, ductwork and the related equipment and controls in October 1997, full-scale operation of the Hybrid was not realized due to continued problems with low flue gas temperatures. The modifications noted previously did not help to reduce the temperature problem that was inherent with the original system. FIGURES 8 and 9 show the flue gas temperatures and the corresponding $\mathrm{O}_{2}$ levels after startup of the Hybrid. The relationship between the low flue gas temperatures and $\mathrm{O}_{2}$ levels was still apparent and very little changed from the original values shown in FIGURES 2 and 3.

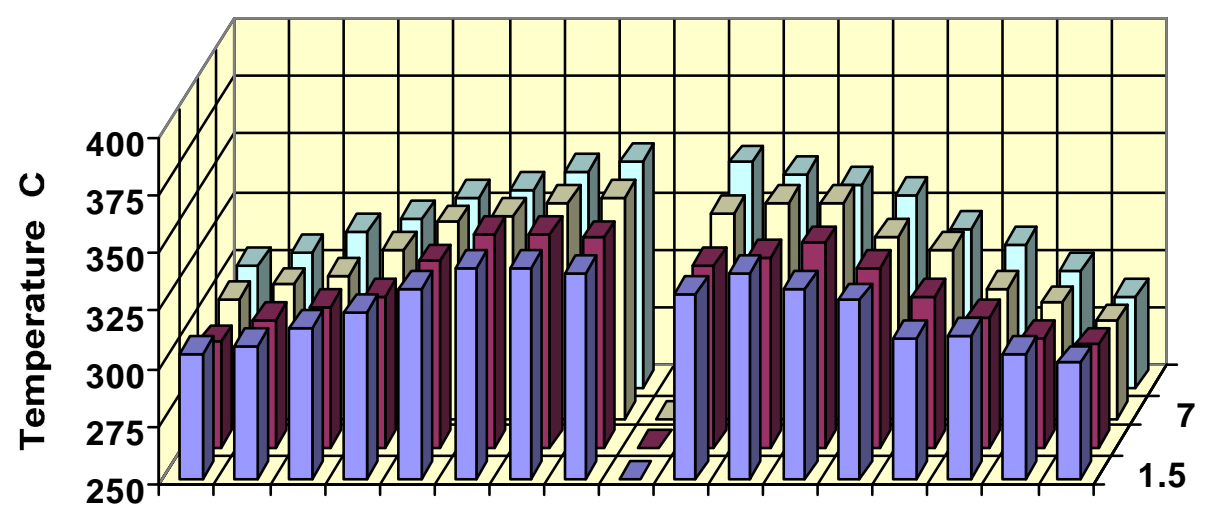

8A 7A 6A 5A 4A 3A 2A 1A 0 1B 2B 3B 4B 5B 6B 7B 8B

FIGURE 8 Catalyst Inlet Temperature

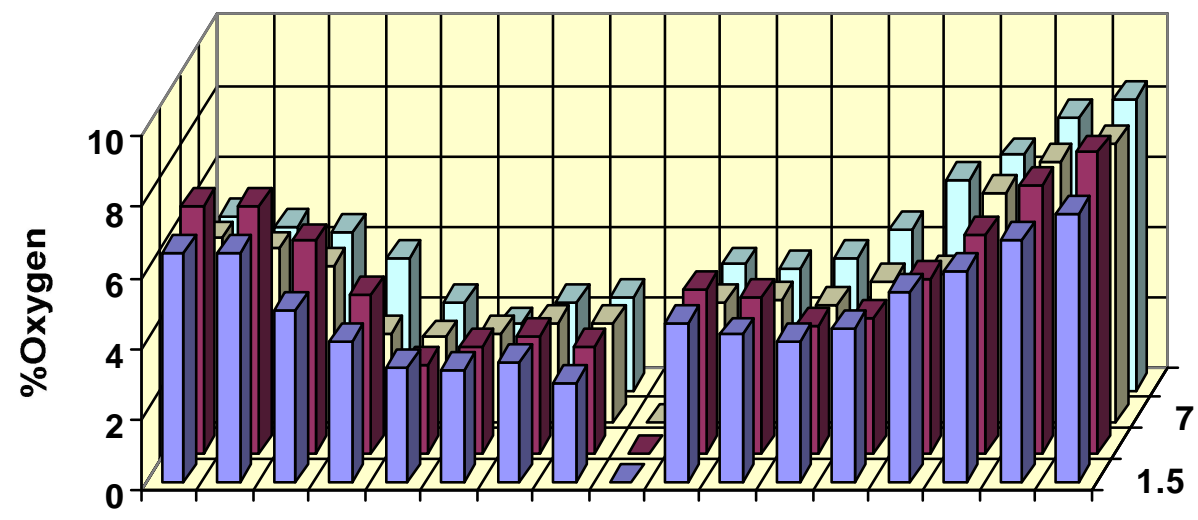

8A 7A 6A 5A 4A 3A 2A 1A 0 1B 2B 3B 4B 5B 6B 7B 8B

FIGURE 9 Catalyst Inlet \% Oxygen 
To better show the extent of the problem with low flue gas temperatures throughout the unit's load range, a plot of the minimum catalyst inlet temperatures versus load is shown in FIGURE 10. These temperatures were taken from a permanent thermocouple grid located below the catalyst bed. The minimum temperatures are located along the outside walls of the ductwork just as they were prior to the Hybrid installation.

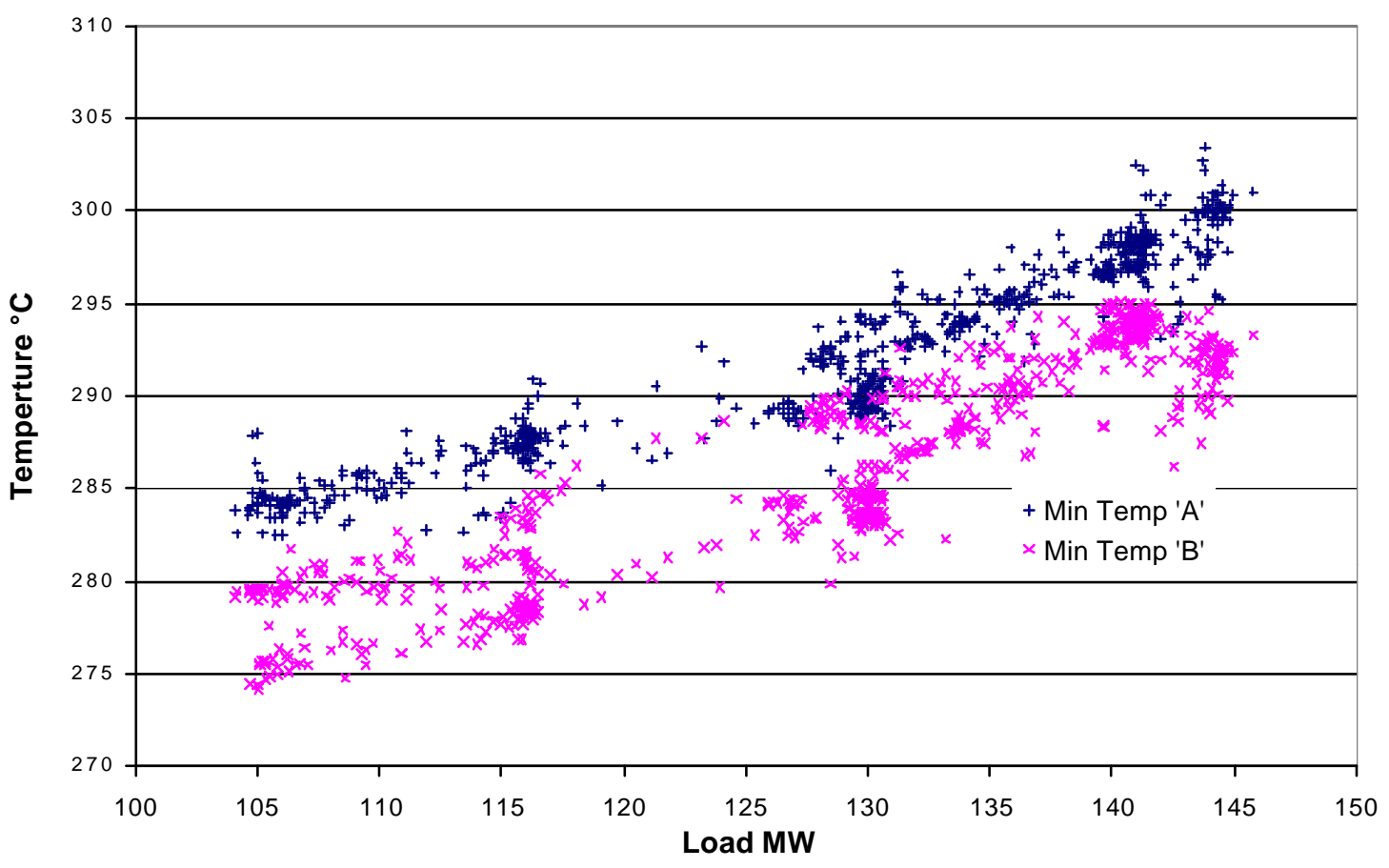

FIGURE 10 Minimum Catalyst Inlet Temperature vs Load

After tests were conducted to determine the actual condition of the catalysts, two options were selected to potentially help alleviate the low temperature problem. The first option was to inject a liquid refractory into the sidewalls of the boiler backpass. Based on the temperature and $\mathrm{O}_{2}$ relationship that was noted above for both the pre and post Hybrid installation, sidewall air in-leakage was very suspect. It was also a known fact that large gaps existed between the boiler waterwall tubing and the boiler casing. Although a large quantity of refractory was pumped into the "B" sidewall, and a lesser amount, into the "A" sidewall, the effect on the flue gas temperatures at the inlet to the catalysts was not noticeable. In parallel with the planning and the performance of the work noted, additional cold flow modeling was performed to devise better methods for mixing the flue gas within the ducts. The model work eventually provided the necessary data to size an economizer flue gas bypass that would adequately distribute additional hot flue gases to the areas of low temperatures along the sidewalls of the ductwork. In addition, a 1.25 mbar (1/2" wc) increase in pressure drop across the economizer was provided with the installation of restrictor plates between the previously installed gas crossover pipes. The increase in pressure drop was designed to force 


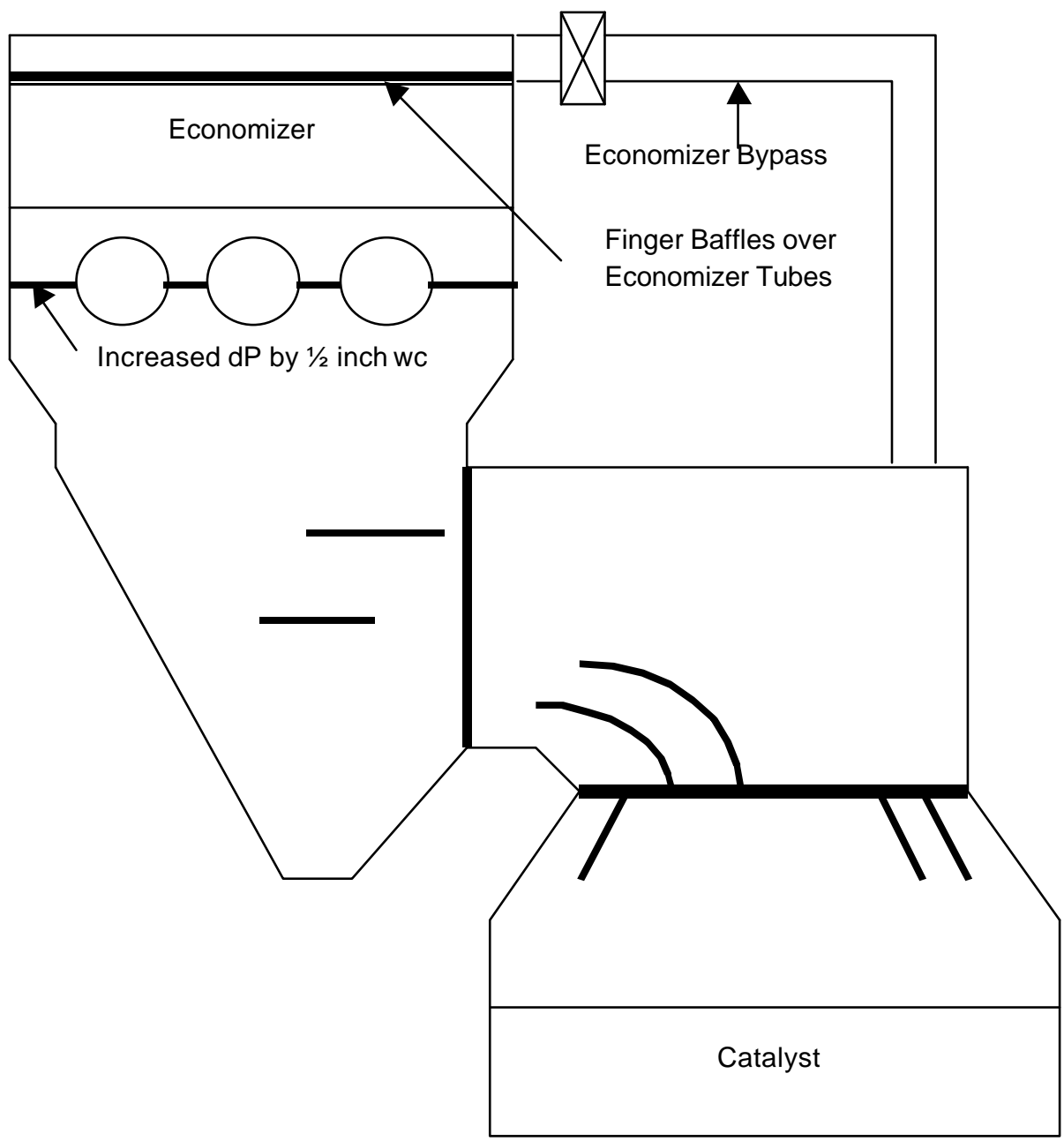

FIGURE 11 Additional Modifications for Temperature

additional hot flue gas through the existing crossover pipes. Also, finger baffles were installed on the top row of economizer tubes to direct the cooler gas along the sidewalls towards the center for mixing with the hotter gases. FIGURE 11 shows the location of the equipment that was installed during the scheduled May 1998 outage. The results of these modifications are shown in FIGURE 12. It shows the minimum flue gas temperature throughout the unit load range before and after the bypass installation. FIGURE 13 shows the minimum gas temperatures after installation of the bypass along with the corresponding bypass damper position. The opening of the bypass damper was controlled to reduce the required quantity of hot bypass gas, and thereby, minimizing thermal efficiency losses associated with the system. Sufficient gas bypassing was provided to allow the introduction of $13.7-15.2 \mathrm{mg} / \mathrm{Nm}^{3}(18-20 \mathrm{ppm})$ of ammonia slip into the catalysts at full load. Although the catalyst inlet slip must be reduced below $7.6 \mathrm{mg} / \mathrm{Nm}^{3}$ (10 ppm) at lower loads, the bypass provided sufficient hot gas to allow operation of the Hybrid at reduced and minimum load conditions. It should be noted that the quoted minimum required gas temperature of $302^{\circ} \mathrm{C}\left(575^{\circ} \mathrm{F}\right)$ is at the maximum ammonia slip level of $13.7-15.2 \mathrm{mg} / \mathrm{Nm}^{3}$ (18-20 ppm) into the catalysts. As 
the specified ammonia slip level is reduced, the minimum required gas temperature can also be reduced.

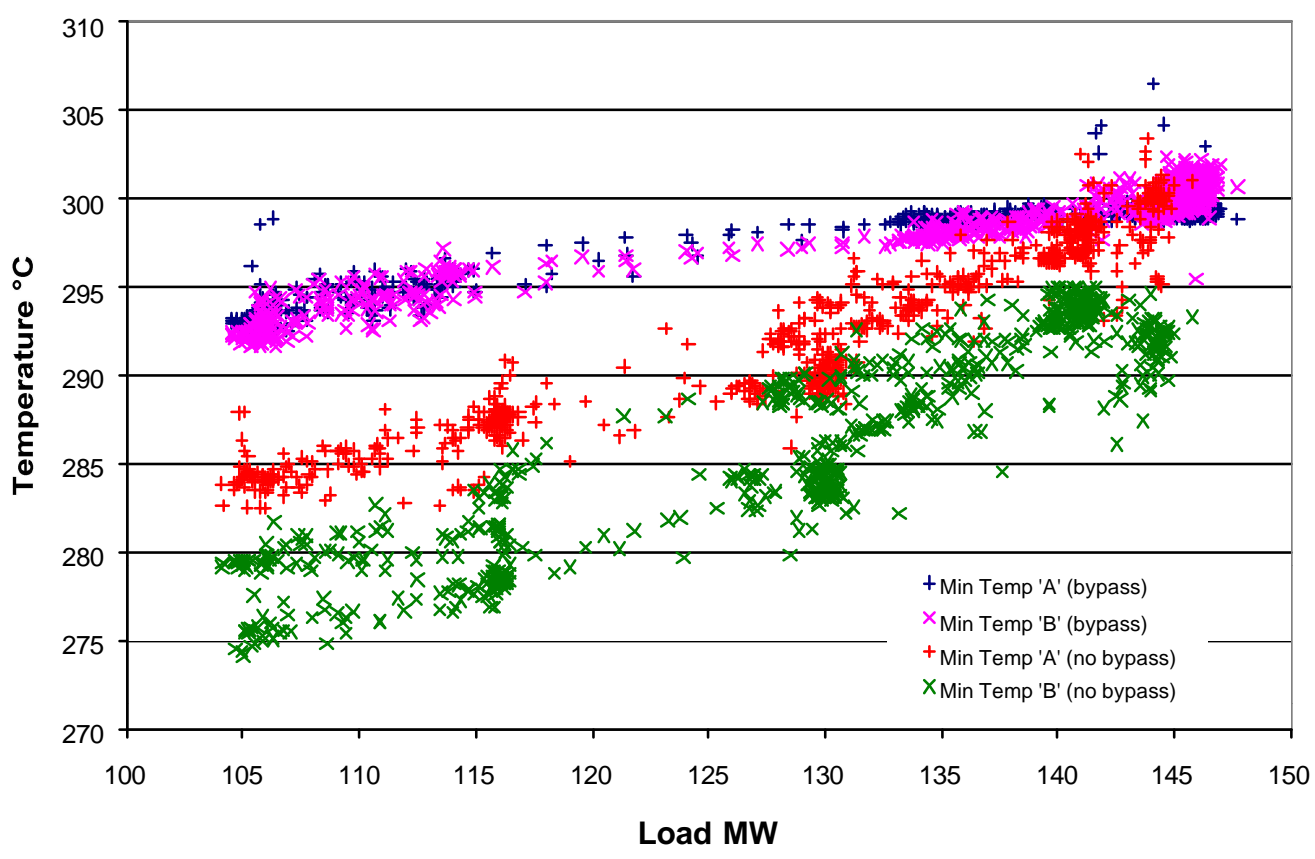

FIGURE 12 Minimum Catalyst Inlet Temperature vs Load (Before and After Bypass Installation)

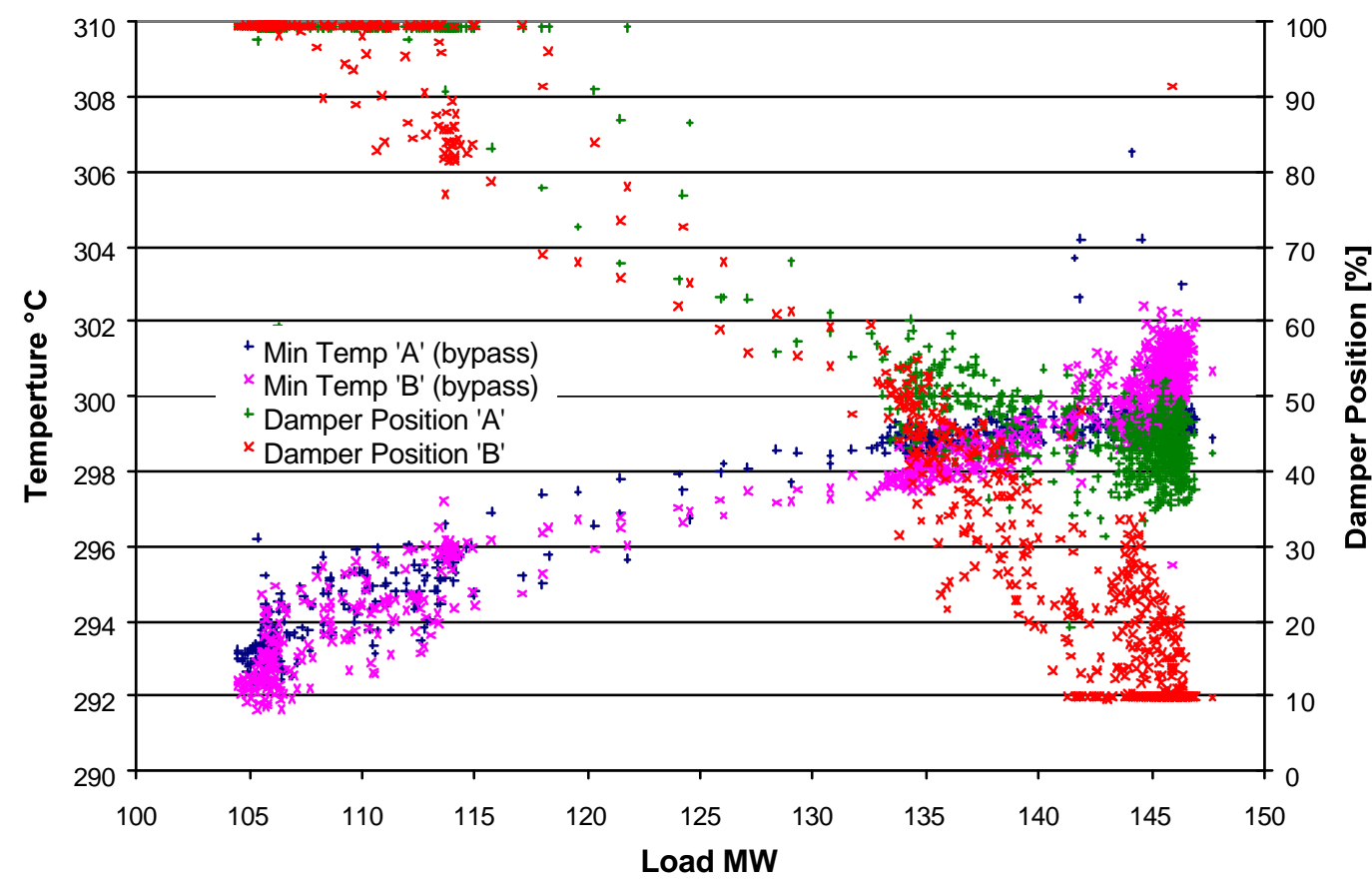

FIGURE 13 Minimum Catalyst Inlet Temperature and Bypass Damper Position vs Load 
After verification of sufficient flue gas temperature entering the catalyst, the ammonia slip level was slowly increased to approximately $7.6 \mathrm{mg} / \mathrm{Nm}^{3}(10 \mathrm{ppm})$ without incident. As the ammonia slip was increased beyond this level, the air heaters began to foul at a very accelerated rate. The unit was then removed from service to wash the air heaters.

To verify if the catalysts were fouling with $A B S$ or if they were being damaged or poisoned by the introduction of water from economizer and watewall tube leaks, samples of the catalysts were removed for testing in late March 1998. The results showed, at worst, the catalyst were $70 \%$ active after approximately 3250 hours of operation. Although the deactivation was faster than expected, the catalyst vendors estimated there was still sufficient catalyst activity to continue the demonstration. The tests also revealed arsenic was the main reason for the deactivation, and ABS fouling was not sufficiently present to cause a noticeable loss in catalyst performance.

Additional catalyst samples were removed for testing after approximately 4500 hours of operation. This was done during the forced outage taken to wash the air heaters on June 6,1998 . Testing of the new catalyst samples revealed they were between $50 \%$ and $70 \%$ active, and the wash coat on the plate type catalyst was significantly eroded away. As a result, it was concluded the catalyst did not have sufficient activity and/or surface area to support the performance required for the operation of the Hybrid system. The system is now operated in SNCR mode in order to provide less than 1.52 $\mathrm{mg} / \mathrm{Nm}^{3}(2 \mathrm{ppm})$ ammonia slip at the inlet of the catalyst and thereby minimizing the effects of $A B S$ fouling.

Based on these developments, the original scope of the associated testing program and the Hybrid cost/benefit analysis could not be completed. 


\section{7}

\section{ARSENIC POISONING}

Throughout the first four months of Hybrid operation, the differential pressures across the air heaters were acceptable and did not show any signs of increasing above the normal operating baselines. However, in February 1998, differential pressures increased approximately 2.5 to $5 \mathrm{mbar}$ ( 1 to 2 inches wc). During a boiler forced outage, the air heaters were washed and the original baselines were recovered without identifying the reason for the increased pressure drop. Several additional pressure drop excursions occurred through the end of April as illustrated below in Figure 14 (Ref.3).

Ammonia slip concentrations were taken in mid March to determine if the catalyst was performing as originally designed. The ammonia slips were measured at an inlet ammonia concentration level of approximately $6.1 \mathrm{mg} / \mathrm{Nm}^{3}(8 \mathrm{ppm})$. The catalyst outlet ammonia levels are given in TABLE 2.

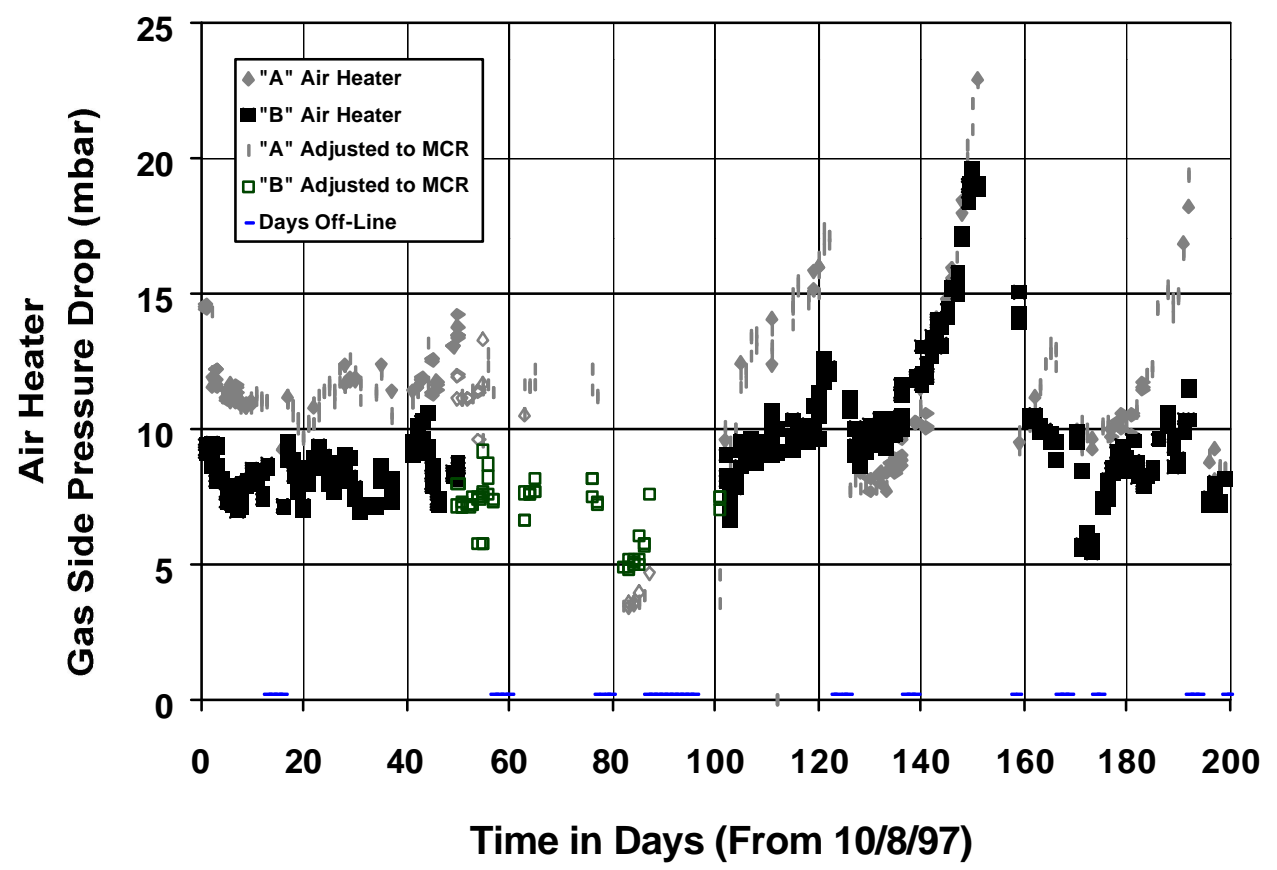

FIGURE 14 Air Heater Pressure Drop 


\begin{tabular}{|c|c|c|c|}
\hline Test Number & Port Location & $\begin{array}{c}\mathrm{NH}_{3} \text { Slip } \\
\mathrm{mg} / \mathrm{Nm}^{3} \text { (ppm) }\end{array}$ & Load \\
\hline \multicolumn{4}{|l|}{ March 16,1998} \\
\hline 16.01 & B7R & $0.23(0.30)$ & 130 's \\
\hline 16.02 & B8R & $0.15(0.20)$ & 130's \\
\hline 16.03 & A7R & $0.15(0.20)$ & 130 's \\
\hline 16.04 & A8R & $0.15(0.20)$ & 130 's \\
\hline 16.05 & $\mathrm{~B} 8 \mathrm{~F}$ & $0.15(0.20)$ & 130 's \\
\hline 16.06 & $\mathrm{~A} 8 \mathrm{~F}$ & $1.7(2.20)$ & 130's \\
\hline \multicolumn{4}{|l|}{ March 17-18, 1998} \\
\hline 17.17 & A8R & $0.46(0.60)$ & 105 \\
\hline 18.01 & A7R & $0.46(0.60)$ & 105 \\
\hline 18.02 & B8R & $0.30(0.40)$ & 105 \\
\hline 18.03 & B7R & $0.30(0.40)$ & 105 \\
\hline 18.04 & $\mathrm{~B} 8 \mathrm{~F}$ & $0.46(0.60)$ & 105 \\
\hline 18.05 & $\mathrm{~B} 7 \mathrm{~F}$ & $0.30(0.40)$ & 105 \\
\hline 18.06 & $\mathrm{~A} 8 \mathrm{~F}$ & $0.30(0.40)$ & 105 \\
\hline 18.07 & A7F & $0.30(0.40)$ & 105 \\
\hline \multicolumn{4}{|l|}{ March 18, 1998} \\
\hline 18.08 & A8F & $0.46(0.60)$ & 140 's \\
\hline 18.09 & A7F & $0.30(0.40)$ & 140 's \\
\hline 18.10 & $\mathrm{~A} 6 \mathrm{~F}$ & $0.30(0.40)$ & 140's \\
\hline 18.11 & A5F & $0.61(0.80)$ & 140 's \\
\hline 18.12 & $\mathrm{~A} 4 \mathrm{~F}$ & $0.53(0.70)$ & 140 's \\
\hline 18.13 & A3F & $0.46(0.60)$ & 140 's \\
\hline 18.14 & $\mathrm{~A} 2 \mathrm{~F}$ & $0.46(0.60)$ & 140 's \\
\hline 18.15 & $\mathrm{~A} 1 \mathrm{~F}$ & $0.46(0.60)$ & 140 's \\
\hline 18.16 & B1F & $0.23(0.30)$ & 140 's \\
\hline 18.17 & B2F & $0.30(0.40)$ & 140 's \\
\hline 18.18 & B3F & $0.30(0.40)$ & 140's \\
\hline 18.19 & $\mathrm{~B} 4 \mathrm{~F}$ & $0.38(0.50)$ & 140 's \\
\hline 18.20 & B5F & $0.46(0.60)$ & 140 's \\
\hline 18.21 & $\mathrm{~B} 6 \mathrm{~F}$ & $0.30(0.40)$ & 140 's \\
\hline 18.22 & B7F & $0.30(0.40)$ & 140 's \\
\hline 18.23 & $\mathrm{~B} 8 \mathrm{~F}$ & $0.38(0.50)$ & 140 's \\
\hline
\end{tabular}

TABLE 2 Ammonia Slip Test Data (March 1998) 
The test data in TABLE 2 indicates that the Hybrid system was performing as designed. Only one of the ammonia slip values was greater than $1.52 \mathrm{mg} / \mathrm{Nm}^{3}(2 \mathrm{ppm})$ with the remainder of the values being less than $0.61 \mathrm{mg} / \mathrm{Nm}^{3}(0.8 \mathrm{ppm})$. During a forced outage from March 22 to March 26 1998, samples of both catalysts were removed for testing and evaluation by the catalyst vendors. The main concern at that time was masking of the catalysts with ammonium bisulfate (ABS). This concern originated by operating the Hybrid system at lower flue gas temperatures than anticipated as a result of temperature stratification. Although the ammonia slip level into the catalyst was reduced to a maximum of 6.1 to $7.6 \mathrm{mg} / \mathrm{Nm}^{3}$ (8 to $10 \mathrm{ppm}$ ) at full load, $3.8 \mathrm{mg} / \mathrm{Nm}^{3}$ (5ppm) at mid load and less than $1.52 \mathrm{mg} / \mathrm{Nm}^{3}(2 \mathrm{ppm})$ at minimum load, the consequences of trying to control the slip as a function of minimum inlet flue gas temperature were unknown. Additional catalyst samples were also taken in June 1998 after the air heaters fouled while attempting to operate the Hybrid system at a maximum inlet ammonia slip of $13.7 \mathrm{mg} / \mathrm{Nm}^{3}$ (18 ppm). The results of the testing from both catalyst vendors are given in the following sections.

\section{CATALYST “A” LABORATORY TESTING RESULTS (Ref.4)}

As previously noted, the catalyst in the " $A$ " duct was designated as the "A" vendor catalyst. The catalyst modules consisted of metal plates, which were fabricated in the same manner as air heater heat exchange elements, and coated with a vanadia / titania catalyst wash coat. The catalyst bed included 12 modules approximately $0.76 \mathrm{~m}\left(2 \frac{1}{2}\right.$ ft) thick. See TABLE 1 for additional design information details.

March 25, 1998 Samples - A field inspection of the catalyst bed was made at this time, and one of the sample catalyst modules was removed for laboratory testing. A visual inspection of the catalyst bed revealed that it was in good physical condition with no signs of blockage. The location of the sample module is shown in FIGURE 15. At the vendor's laboratory, test samples were removed from the inlet, middle and outlet sections of the sample module for activity determination and an assessment of over all catalyst performance. The test samples indicated that erosion was occurring at the inlet and outlet zones, and to a minor extent, in the middle of the catalyst. At the inlet of the catalyst, approximately the first two inches of the catalytic wash coat was lost due to erosion. To a lesser extent, a similar erosion was experienced at the outlet of the catalyst. The total loss of catalytic material was estimated to be less that $15 \%$ and was not unexpected for this installation.

Catalyst activity testing was also conducted on the samples. When the results of the laboratory tests were corrected to the actual installed conditions, the catalyst bed was believed to be able to meet the original design conditions of $15.2 \mathrm{mg} / \mathrm{Nm}^{3}(20 \mathrm{ppm})$ of ammonia at the inlet and $1.52 \mathrm{mg} / \mathrm{Nm}^{3}(2 \mathrm{ppm})$ at the outlet.

June 6, 1998 Samples - Two additional sample modules were removed as a result of accelerated fouling of the air heaters which was created by increasing the ammonia slip 
at the catalyst inlet to $13.7 \mathrm{mg} / \mathrm{Nm}^{3}$ (18 ppm). The locations of the sample modules are also shown in FIGURE 15. As found with the previous module, there was no evidence of channel blockage throughout the length of either sample. An inspection of the individual plates from each module indicated that there was significant loss of catalytic material on all of the plates. The loss was estimated between 25 to $75 \%$ in the one module and 40 to $75 \%$ in the other module. Coupled with this physical loss of catalytic material was a reduction of activity for the catalytic material that remained. After correcting the test data to actual conditions the activity was determined to be less that $60 \%$. The combination of erosion and the reduction of catalytic activity reduced the overall activity of the catalyst bed to between 15 and $45 \%$.

Catalyst material was scraped from the plate samples and a chemical analysis was performed on the material by XRF (X-ray fluorescence). This testing revealed that there were high concentrations of arsenic in the catalyst. The March sample had $3.84 \%$ arsenic by weight and the two June samples had $2.05 \%$ and $2.76 \%$ arsenic by weight. This quantity of arsenic was determined to be responsible for the loss of activity in the remaining catalytic material. For a summary of the results see Appendix A.

Duct Dimension - 7.34 m x 3.52 m (24'1" x 11'-61/2")

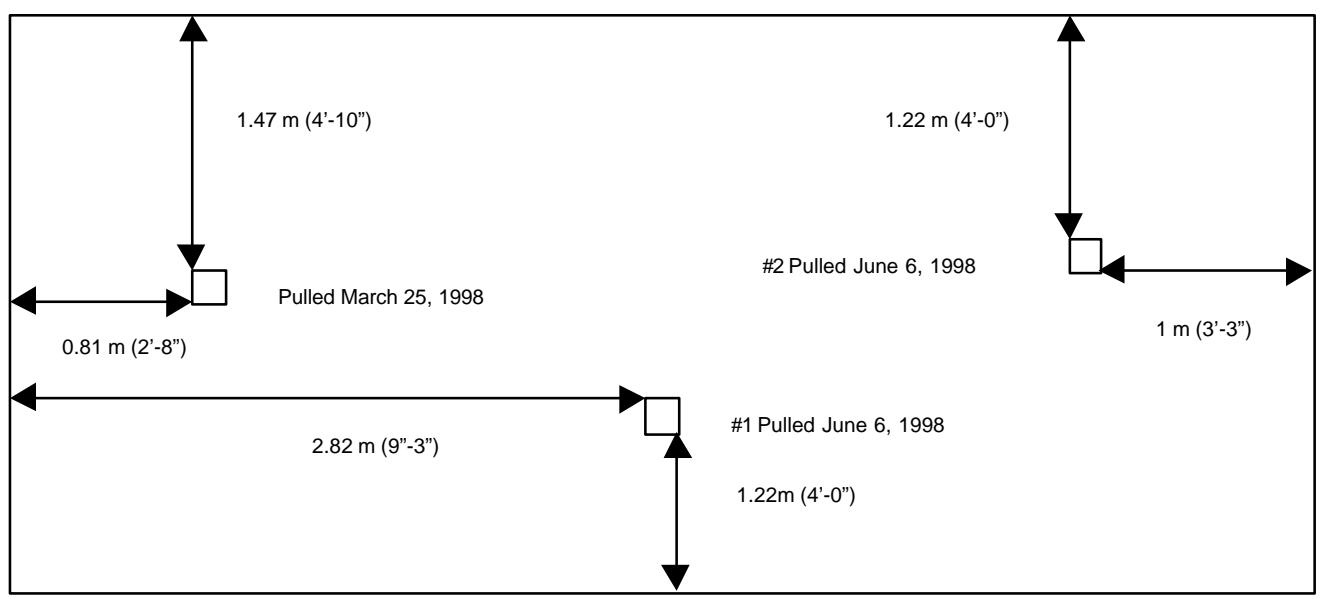

FIGURE 15 Location of Catalyst "A" Samples

\section{CATALYST “B” LABORATORY TESTING RESULTS (Ref. 5)}

Similar to the previous catalyst, the catalyst in duct "B" has been designated as the "B" vendor catalyst. The catalyst modules are of the extruded honeycomb titaniumtungsten-vanadium type. The catalyst bed includes 12 modules approximately $1.37 \mathrm{~m}$ $\left(4 \frac{1}{2} \mathrm{ft}\right)$ thick. See TABLE 1 for additional design information details.

March 25, 1998 Samples - A field inspection of the catalyst bed was made by vendor "B", and two catalyst samples were removed for laboratory testing and analysis. The 


\begin{tabular}{|l|l|l|l|}
\hline$\# 1$ & $\# 2$ & $\# 3$ & $\# 4$ \\
\hline$\# 5$ & $\# 6$ & $\# 7$ & $\# 8$ \\
\hline$\# 9$ & $\# 10$ & $\# 11$ & $\# 12$ \\
\hline
\end{tabular}

Boiler Side

\section{FIGURE 16 Location of Catalyst "B" Samples}

locations of the samples are shown in FIGURE 16. The field inspection revealed various stages of erosion on modules 1 through 4 . The erosion can be categorized by three main characteristics. The first is a rounding of cell edges at the entrance, with noticeable thinning of the walls. The second type includes worn-through walls at the catalyst inlet just below the hardened edge. The third type included a one by three-foot hole completely through the catalyst layer. The first two types of erosion appeared to be caused by a concentrated stream of flyash coming off the trailing edge of a flow straightener located just above the wear area. The large hole in the catalyst is believed to be a result of a small concentrated stream of flyash passing through the extreme right hand rear corner of the catalyst bed. Several velocity traverses and an in-duct cold flow velocity profile with a hand-held anemometer were performed to confirm that high flue gas velocities are not present in this area.

A higher degree of cell blockage was also being experienced in modules \#1 through \#4. Approximately $30 \%$ of the cells were blocked in the \#4 catalyst sample while approximately $5 \%$ of the cells were blocked in the \#10 sample. The higher blockage rate in the \#4 module is assumed to be caused by the same flow straightner that is creating the erosion problem noted above.

Performance testing of the two catalyst samples was performed, and the relative activity was compared to the pilot test data taken from the fresh catalyst sample tested in 1997. The final results showed that sample \#4 had a relative activity of 0.7 and sample \#10 had a relative activity of 0.56 . The design threshold for this project, which is the level of catalyst activity required to meet the original ammonia reduction capabilities, is 0.73 . It was therefore concluded that sufficient catalyst activity was not available from the subject catalyst to reduce the inlet ammonia slip from 15.2 to $1.52 \mathrm{mg} / \mathrm{Nm}^{3}$ (20ppm to $2 \mathrm{ppm})$.

Surface chemical analysis (QSA) by DC Arc Optical Emission Spectroscopy and Inductively-Coupled-Plasma Spectroscopy (ICP) was conducted to quantify the metal 
concentrations on the catalyst samples. The results indicated there was approximately $2 \%$ to $2.6 \%$ of arsenic by weight on the inlet surface of catalyst samples \#4 and \#10 respectively. The quantity of arsenic dropped to approximately $1.8 \%$ at the exit of the catalyst. The bulk material values for the arsenic were 0.9 to $1.6 \%$ on the inlet and $1.12 \%$ on the outlet. Comparing the relative activity of samples \#4 and \#10 and the corresponding surface arsenic concentrations with prior studies showed that the observed values correlated well with the prior studies. Therefore, the main cause of reduced catalyst activity was a result of arsenic poisoning.

June 6, 1998 Samples - Additional catalyst samples were removed on this date from modules \#1 and \#7 along with a chip from the new sample that was installed in module \#10 in March. Tests to determine the metal concentrations on these new samples were conducted as previously described above and showed similar level of arsenic concentrations in the catalyst. Additional performance testing has not been done on these samples. For a summary of the tests results see Appendix B.

\begin{tabular}{|c|c|c|c|}
\hline $\begin{array}{c}\text { SAMPLE } \\
\text { DATE }\end{array}$ & $\begin{array}{c}\text { ARSENIC } \\
\text { IN COAL } \\
\mu \mathrm{g} / \mathrm{g}(\mathrm{ppm})\end{array}$ & $\begin{array}{c}\text { ARSENIC } \\
\text { IN ASH } \\
\mu \mathrm{g} / \mathrm{g}(\mathrm{ppm})\end{array}$ & $\begin{array}{c}\text { CALCIUM OXIDE } \\
\text { IN ASH } \\
(\%)\end{array}$ \\
\hline & & & \\
\hline $6 / 10 / 98$ & 7.23 & 28.12 & 1.68 \\
$6 / 3 / 98$ & 8.38 & 29.54 & 1.92 \\
$5 / 27 / 98$ & 8.62 & 25.68 & 1.66 \\
$5 / 20 / 98$ & 8.86 & 35.89 & 1.69 \\
$5 / 13 / 98$ & 8.33 & 28.63 & 1.75 \\
$5 / 6 / 98$ & 8.15 & 30.38 & 1.6 \\
$4 / 29 / 98$ & 11.88 & 34.5 & 1.41 \\
$4 / 22 / 98$ & 9.38 & 41.09 & 1.57 \\
$4 / 15 / 98$ & 11.68 & 44.78 & 1.89 \\
$4 / 8 / 98$ & 8.95 & 32.74 & 1.54 \\
$4 / 1 / 98$ & 11.76 & 54.64 & 1.66 \\
$3 / 25 / 98$ & 7.66 & 30.8 & 2.07 \\
$3 / 18 / 98$ & 9.62 & 37.54 & 1.97 \\
$3 / 11 / 98$ & 7.51 & 32.99 & 2.26 \\
$3 / 4 / 98$ & 10.2 & 33.87 & 2.18 \\
$2 / 25 / 98$ & 9.91 & 39.86 & 1.8 \\
$2 / 18 / 98$ & 11.65 & 39.35 & 1.71 \\
$2 / 11 / 98$ & 12.27 & 39.1 & 1.92 \\
$2 / 4 / 98$ & 10.71 & 39.86 & 2.04 \\
$1 / 28 / 98$ & 10.38 & 38.47 & 2.25 \\
$1 / 21 / 98$ & 8.99 & 29.06 & 1.59 \\
$1 / 14 / 98$ & 10.96 & 40.1 & 1.41 \\
& & & 1.82 \\
MINIMUM & 7.23 & 25.68 & \\
MAXIMUM & 12.27 & 54.64 & \\
AVERAGE & 9.69 & 35.77 & \\
\hline & & & \\
\hline
\end{tabular}

TABLE 3 Coal Sample Analysis 


\section{COAL SAMPLE ANALYSIS}

After it was identified that arsenic poisoning was deactivating the catalysts, coal samples were retrieved as far back as they were available and sent to an independent laboratory for analysis. One random coal sample per week was analyzed from January 14, 1998 through June 10, 1998. Although the Hybrid began operation in October 1997, coal samples for the first three months of operation were not available. The results of the testing of the available samples shown in FIGURE 3 indicates that the arsenic in the coal ranged from 7.23 to $12.27 \mu \mathrm{g} / \mathrm{g}(\mathrm{ppm})$ and averaged $9.69 \mu \mathrm{g} / \mathrm{g}(\mathrm{ppm})$. The arsenic in the flyash ranged from 25.68 to $54.64 \mu \mathrm{g} / \mathrm{g}$ (ppm) with an average of $35.77 \mu \mathrm{g} / \mathrm{g}$ (ppm). The calcium oxide level in the flyash was also measured since it can help to reduce the gaseous arsenic levels in the flue gas. The calcium oxide levels ranged from 1.41 to $2.26 \mu \mathrm{g} / \mathrm{g}(\mathrm{ppm})$ with an average of $1.82 \mu \mathrm{g} / \mathrm{g}(\mathrm{ppm})$.

\section{ADDITIONAL TESTING RESULTS (Ref 6)}

The catalyst "B" vendor performed additional testing in order to determine the level of gaseous arsenic $\left(\mathrm{As}_{2} \mathrm{O}_{3}\right)$ in the flue gas stream and to see if it correlates with the quantity of arsenic found in the catalyst. The testing was performed in accordance with a modified version of EPA Method 108. The modification consisted of utilizing an instack filter to prevent the condensation of gaseous arsenic components of the flue gas on the filter. The tests were conducted in triplicate at two sampling points in the "B" duct at full and low load conditions. The test points were located above module \#3 and module \#9 identified in FIGURE 16. The average results of the three tests are summarized in TABLE 4.

\begin{tabular}{|l|c|c|c|}
\hline \multicolumn{1}{|c|}{ Sample Type } & Module \#3 & Module \#9 & Test Condition \\
\hline Gaseous As - $\mu \mathrm{g} / \mathrm{DSCM}$ & 1.71 & 1.54 & Low Load \\
\hline Gaseous As - $\mu \mathrm{g} / \mathrm{DSCM}$ & 1.43 & 1.64 & High Load \\
\hline $\begin{array}{l}\text { Particulate As - } \\
\mu \mathrm{g} / \mathrm{DSCM}\end{array}$ & 723 & 888 & Low Load \\
\hline $\begin{array}{l}\text { Particulate As - } \\
\mu \mathrm{g} / \mathrm{DSCM}\end{array}$ & 875 & 1018 & High Load \\
\hline
\end{tabular}

TABLE 4 Arsenic Testing Results

The results indicate a much lower amount of gaseous arsenic in the flue gas than anticipated based on the quantity of arsenic previously found in the fuel. See TABLE 4. Vendor "B" also conducted fuel and flyash analyses on samples collected during field testing and catalyst sample removal. The average fuel-bound arsenic was $14.75 \mu \mathrm{g} / \mathrm{g}$ (ppm) while the average flyash bound arsenic was $104 \mu \mathrm{g} / \mathrm{g}(\mathrm{ppm})$. In addition, the average free $\mathrm{CaO}$ was found to be approximately $0.5 \%$ by weight of the fly ash. 


\section{$\mathrm{SO}_{3}$ ABSORBER EVALUATION}

\section{Background}

The introduction of ammonia into the flue gas stream from the SNCR, SCR or Hybrid processes can promote downstream problems, which range from $A B S$ fouling to exceeding the permitted limits for ammonia emissions. A reliable ammonia monitor would be beneficial in helping to control the ammonia levels by allowing the operator to better tune the systems during initial set-up of the equipment and to allow continuous feedback control for the injection rate of ammonia or urea. There have been numerous tests of ammonia monitors dating back to 1992. However, poor performance and maintenance problems have plagued the many manufacturers of the equipment. One of the most common problems with the extractive type monitors has been ABS fouling of the gas extraction system and analyzer. In order to address the problem of ABS deposition, CONSOL, Inc. conducted a program that designed and tested an absorber to remove $\mathrm{SO}_{3}$ and prevent the unwanted reaction with the ammonia in the sample flue gas.

\section{Discussion and Results (Ref 7)}

The testing was performed using CONSOL's $1.58 \mathrm{GJ} / \mathrm{hr}$ (1.5 MMBtu/hr) pilot scale coal combustor as the flue gas source. Ammonia concentrations varying from 11.4 to 30.4 $\mathrm{mg} / \mathrm{Nm}^{3}$ (15 to $40 \mathrm{ppm}$ ) were introduced into the flue gas for simulation while the flue gas duct temperatures ranged from $282^{\circ} \mathrm{C}$ to $410^{\circ} \mathrm{C}\left(540^{\circ} \mathrm{F}\right.$ to $\left.770^{\circ} \mathrm{F}\right)$. Two types of absorber vessels, 316 stainless steel and quartz, were used during the testing. The stainless steel vessel was initially used, but tests on an empty vessel showed an $11 \%$ removal of ammonia. Subsequent testing of an empty quartz vessel showed no removal of ammonia. Only three tests were conducted with the stainless steel vessel. These were with a mixture of $\mathrm{CaO}$ (quicklime) and $\mathrm{Na}_{2} \mathrm{CO}_{3} / \mathrm{NaHCO}_{3}$ (sodium carbonate/sodium bicarbonate). After verifying that the stainless steel vessel was not completely inert in the presence of ammonia, a test with $\mathrm{CaO}$ was repeated with the quartz vessel. This test indicated that quicklime $(\mathrm{CaO})$ or a calcium based sorbent was not suitable for removal of $\mathrm{SO}_{3}$ since it also captured $43 \%$ of the ammonia. Six tests with a $\mathrm{Na}_{2} \mathrm{CO}_{3} / \mathrm{NaHCO}_{3}$ mix as the sorbent were conducted with the results indicating that none of the ammonia was captured by the Na-based sorbent.

Sampling tests were then conducted to determine the effectiveness of the Na-based sorbent for removal of $\mathrm{SO}_{2}$ and $\mathrm{SO}_{3}$. These results revealed that the sorbent was capable of removing from $94-98 \%$ of the $\mathrm{SO}_{3}$ and $100 \%$ of $\mathrm{SO}_{2}$ from the flue gas. For details of the test program and results see Appendix C. 


\section{AMMONIA ON FLYASH ANALYSIS}

\section{Background}

Three sets of flyash samples were taken from the airheater hoppers, inlet and outlet hoppers of the first precipitator and the inlet hoppers of the second precipitator on Unit \#5 at Seward Station. CONSOL, INC analyzed these samples in order to determine if any correlation could be made between the sample's ammonia concentration and the sample's physical and chemical characteristics.

In addition, CONSOL, Inc. was required to develop a rapid, low-cost field procedure for estimating the ammonia concentration in the flyash. The lack of an accurate and reliable ammonia monitor, as discussed in Section 8, reinforces the need for a quick and inexpensive method of determining the ammonia concentration in the flue gas as well as in the flyash. A relationship exists between the ammonia concentration in the flue gas and the ammonia concentration in the flyash. By monitoring the ammonia in the flyash, an operator can indirectly monitor the operation of their SCR, SNCR or Hybrid system. This would help to minimize any possible negative impacts caused by the formation of ammonium bisulfate (ABS). For those utilities that sell their flyash, the operator would also be able to monitor the flyash to determine if the ammonia concentrations are being maintained within the required specification limits.

\section{Discussion and Results (Ref 8 and 9)}

The ammonia concentration of the flyash samples were lower for the first set of samples obtained in October, 1998 (16-104 g/g) than in the second and third set of samples taken in January and February 1999 (49-616 g/g). CONSOL, Inc. contributed the difference to the fact that the October samples were stored longer than the second set of samples. An alternative reason for this difference could be variations in the actual ammonia slip being experienced at the time of the sampling. Operation of the SNCR is set to provide less than $1.52 \mathrm{mg} / \mathrm{Nm}^{3}$ (2 ppm) of ammonia slip at the exit of the boiler. However, since flue gas ammonia test were not performed to determine the concentration, the actual value is unknown. Based on the January and February sets of samples, a strong correlation was found between the ammonia concentration and the sulfur content. There was also a correlation between the ammonia concentration and the LOI. No apparent relationship was identified between the ammonia concentration and the particle size of the flyash. See Appendix D for details of the test program and the results.

A field test procedure to determine the ammonia concentration in the flyash was developed by CONSOL, Inc. The procedure involves leaching soluble ammonia from the flyash and determining the concentration via an ion-selective electrode (ISE). The 
procedure yields results comparable to ion Chromatoraphy (IC) with short-term and long-term precision of 1.3 and $4.5 \mu \mathrm{g} / \mathrm{g}(\mathrm{ppm})$, respectively, at the $100 \mu \mathrm{g} / \mathrm{g}(\mathrm{ppm})$ concentration level. The determination can be completed in less than one hour and requires approximately 15 minutes of labor per sample. It only requires a standard pH meter, ammonia specific-ion electrode, and ordinary laboratory equipment. For details of this procedure see Appendix E. 


\section{0 \\ CONCLUSIONS}

Although the demonstration of a Hybrid SNCR/SCR could not be completed as planned, valuable information has been obtained during this demonstration. The findings are as follows:

- Low flue gas temperatures and gas temperature stratification can be an inherent boiler problem for a SCR retrofit. The problems can be overcome with the installation of a properly designed economizer bypass to raise the bulk flue gas temperature to the required level and also by the proper design of static mixers and other devices to help produce a more homogeneous flue gas mixture. A homogeneous gas mixture is also required to obtain uniform concentrations of $\mathrm{NO}_{x}$ at the catalyst inlet. This will help to enhance the $\mathrm{NO}_{x}$ reduction capabilities of the catalyst.

- Non-uniform dust loading as well as concentrated dust streams need to be properly identified and addressed during the testing and design stages of the project. A uniform velocity distribution should not be confused with a uniform dust loading, and therefore, must be addressed separately. Uniform dust and velocity distributions will help prevent erosion and blockage of the catalyst.

- In order to define the input parameters to a Hybrid or SCR, a proper test program needs to be developed and executed prior to specifying the equipment. This would include identifying the distribution of the flue gas constituents, temperature and velocity profiles, dust loading and a complete fuel analysis for all expected fuels.

- The quantity of gaseous arsenic in the flue gas needs to be identified and provided to the catalyst vendors for proper sizing of the catalyst. This value can drastically effect the size and cost of the SCR if it is expected to meet the required guarantees.

- Since EPA Method 108 was utilized to obtain the gaseous arsenic data, and the values were orders of magnitude lower than expected. Another testing method may need to be investigated or modifications to Method 108 may be required. Any test results that utilizes different testing methods should be compared to results from Method 108.

- The Hybrid process does work since we were able to obtain approximately 568 $\mathrm{mg} / \mathrm{Nm}^{3}$ (0.39 lb/MMBtu) with an ammonia slip of 6.1 to $7.6 \mathrm{mg} / \mathrm{Nm}^{3}$ (8 to $10 \mathrm{ppm}$ ) entering the catalyst. The full capabilities of the Hybrid system could not be realized 
due to the problems encountered with low gas temperatures and arsenic poisoning of the catalyst.

- More research is needed to insure that catalysts, which are utilized in Hybrids and SCR's, can cost-effectively work with US coals. This would include a complete study of arsenic poisoning, the formation of gaseous arsenic and strategies for dealing with it.

- A mixture of $\mathrm{Na}_{2} \mathrm{CO}_{3}$ and $\mathrm{NaHCO}_{3}$ was proven to be an acceptable sorbent for a $\mathrm{SO}_{3}$ absorber. It showed no reaction with the ammonia in the flue gas, and it captured $100 \%$ of the $\mathrm{SO}_{2}$ and an average of $96 \%$ of the $\mathrm{SO}_{3}$.

- A strong correlation was found to exist between the ammonia concentration and the sulfur content in the flyash. A correlation was also observed between the ammonia concentration and the LOI in the flyash. However, no apparent relationship exists between the ammonia concentration and the particle size of the flyash. 


\section{1}

REFERENCES

1. Jantzen, T. and Zammit, K., "Hybrid SCR," presented at EPRI/EPA NO $O_{x}$ Symposium, Kansas City, 1995.

2. U.S. Patent $4,780,289$, issued 1998

3. Counterman, Wayne, ABB Air Preheater, Corp., 1998

4. Catalyst "A" Vendor, "Analysis of SCR samples removed from Seward Station, July 27, 1998.

5. Catalyst "B" Vendor, "GPU/Genco Seward Station Unit 5 Duct B, SCR Catalyst Pilot Performance Test Report," June 26, 1998. (Confidential)

6. Catalyst "B" Vendor, "Stationary Source Sampling Report Reference No. 16907," December 11, 1998. (Confidential)

7. Rosenhoover, W. A. and Cairns, G. L., " $\mathrm{SO}_{3}$ Absorber Evaluation" CONSOL, Inc., March 1999.

8. Brandes, S. D., "analysis of Seward Station Fly Ash Samples", CONSOL, Inc., March 1999.

9. CONSOL, Inc., "Titled The Determination of Ammonia in Fly Ash Using an Ammonia Specific Ion Electrode", CONSOL, Inc. Standard Method No. 247, April 1, 1998. 
APPENDIX A 


\title{
Analysis of SCR samples removed from Seward Station
}

\author{
Report prepared for Nalco Fuel Tech
}

\author{
By \\ Engelhard Corporation
}

July 27, 1998

Information in this report is covered by a Confidentially Agreement between Nalco Fuel Tech and Engelhard.

Questions regarding this report should be directed to Stan Mack (732 205 6174) or Joe Patchett (732 205 6072) 


\section{Background}

In November 1997 approximately 600 cubic feet of PNX SCR catalyst were installed in the A duct at the GPU/Penelec generating station in Seward, Penn. This catalyst along with a competitor's catalyst were installed down stream of a Nalco Fuel Tech SNCR system to control ammonia slip from the SNCR reactor to prevent air heater fouling.

As part of the original catalyst order, some catalyst modules contained smaller (approximately 6 x 6 inches x module length) sample modules. One of these sample modules was sampled on March 25, 1998 after about 6 months of operation

In April of 1998 Nalco and GPU adjusted the SNCR system to give an ammonia slip of about $10 \mathrm{ppm}$. The goal was to achieve higher NOx control by allowing greater ammonia slip for the SCR reaction. Shortly after increasing the ammonia slip, the pressure drop across the airheater increased and quickly became unacceptable. The boiler was brought down for an airheater cleaning and the catalyst was available for inspection on June 06, 1998.

Stan Mack inspected the catalyst bed and removed two samples on June 6, 1998. A meeting was held at Seward station on June 10th. This meeting provided more information on the catalyst's performance and established a plan for catalyst testing and analysis. Data collected at the plant during SNCR system operation was subsequently disseminated by Nalco.

This report covers Engelhard's analysis of the catalyst samples removed June 6th and compares these results to the earlier sample.

\section{$\underline{\text { Testing and Evaluation }}$}

The as received catalyst module was open and a visual examination of individual plates was conducted. The extent of catalyst erosion was documented using a digital camera. Samples approximately 1 inch wide by 5 inches long were cut from flat plates. Four samples were taken, one each from the inlet and middle and two from the outlet. These samples were evaluated for ammonia removal under these conditions.

Test conditions:

$$
\begin{aligned}
& \mathrm{SV}=22,000 \mathrm{hr}^{-1} \\
& \mathrm{NO}=150 \mathrm{ppm} \\
& \mathrm{NH}_{3}=26 \mathrm{ppm} \text { or } 30 \mathrm{ppm} \\
& \mathrm{O}_{2}=\mathrm{H}_{2} \mathrm{O}=10 \% \\
& \text { Temperatures }=270 \mathrm{C}(518 \mathrm{~F}), 300 \mathrm{C}(572 \mathrm{~F}) \text { and } 320 \mathrm{C}(608 \mathrm{~F})
\end{aligned}
$$

The sample test holder simulates a plate spacing of $5 \mathrm{~mm}$.

Where possible, results of these tests were compared to our model predictions. This comparison gives an indication of changes in the catalyst activity with time. From the test conditions above, these predictions are corrected for space velocity, plate spacing and $\mathrm{NH}_{3}$ concentration.

Chemical analysis of catalyst removed from the supporting plates was done by X-ray fluorescence (XRF). Two types of analyses were done, a standardless "scan" which identified components present in concentrations greater than about $75 \mathrm{ppm}$ and quantitative determination, using a NBS traceable standard. 
$\underline{\text { Results and Discussion }}$

\section{Extent of Catalyst Erosion}

The location of sample modules removed on March 25 and June 6th are shown in Figure 1. All of the samples have been taken from a region about 3 feet from a reactor wall. The approximate inside dimensions of the A side reactor are $22 \times 12 \mathrm{ft}$.

\section{Figure \\ Sample times and locations Seward Station}

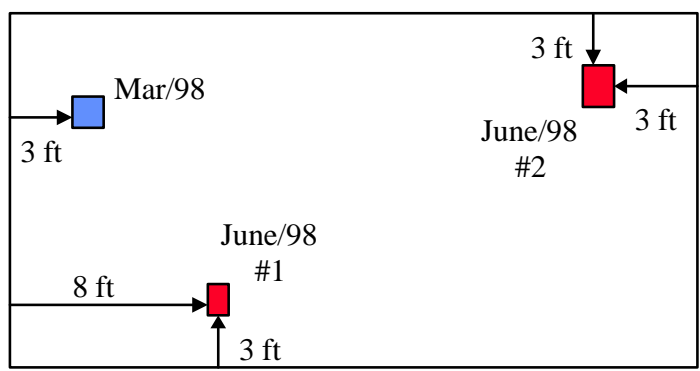

Boiler A Duct

As received, the sample modules taken June 6th were intact and showed no evidence of channel blockage on the inlet face. One side of the module was opened and individual plates were removed for examination. There was no evidence of any channel blockage within these sample modules. It appears that the combination of plate spacing, soot blower design and soot blowing frequency is sufficient to maintain open catalyst channels.

Figures 2 and 3 are digital photographs of catalyst plates from the sample module taken on March 25th. There was about 2 inches of catalyst loss at the inlet and similar erosion pattern was observed on the exit face, but to a lesser extent. Through out the length of the module there was evidence of catalyst abrasion. In a few isolated regions catalyst loss had exposed the underlying metal support. The over all the extent of catalyst erosion is estimated at about $15 \%$. At that time we determined that this level of erosion was typical, but that only future samples would determine if the erosion has stabilized.

Figure 2

SCR Plate Inlet is on the left Sampled March 25th.

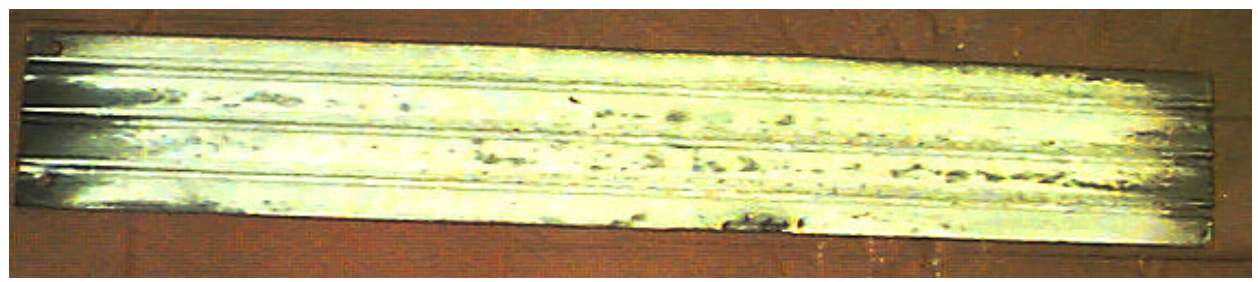


Figure 3

SCR plate, Inlet is on the left

Sampled March 25th

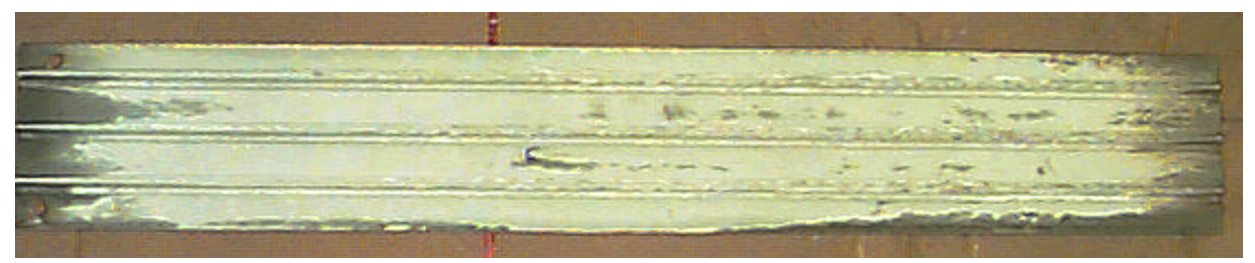

Figures 4 and 5 are digital photographs of plates from the sample module taken at location \#1 on June 6th. It is evident in these photographs that significantly greater catalyst erosion has occurred. The extent of catalyst loss is estimated between 40 to $70 \%$. These levels of catalyst loss will significantly degrade the system performance regardless of the remaining catalyst's activity.

Figure 4

SCR plate, Inlet is on the right

Sampled June 06, Location \#1

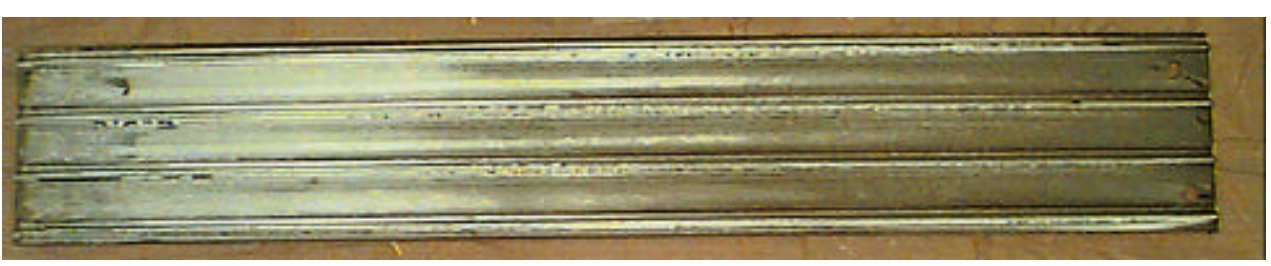

Figure 5

SCR plate, Inlet is on the right Sampled June 6, Location \#1

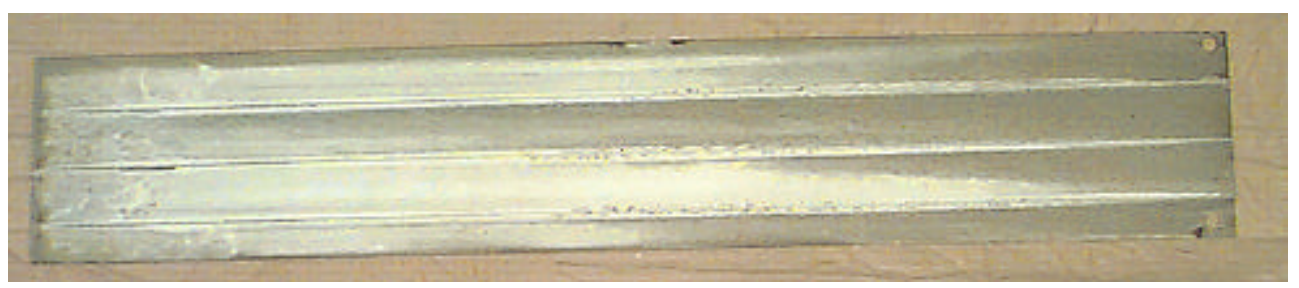

Similarly Figures 6 and 7 are photographs of plates taken from location \#2 on June 6th. These photographs also show significant catalyst loss, estimated between 25 to $75 \%$. 
Figure 6

SCR Plate, Inlet is on the right

Sampled June 6, Location \#2

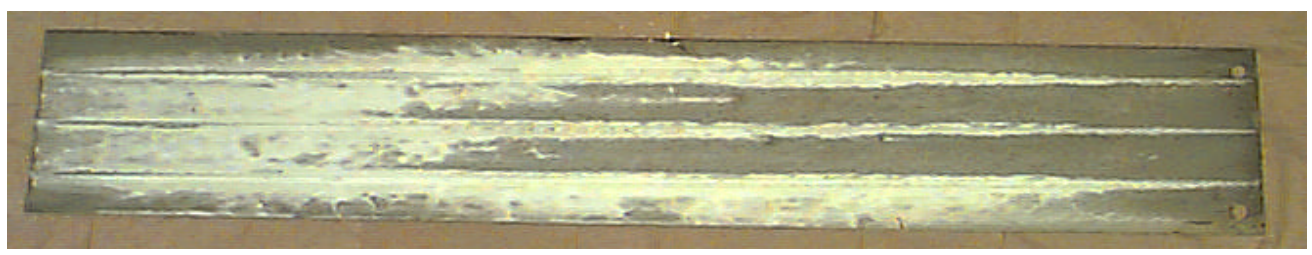

Figure 7

SCR Plate, Inlet is on the right

Sampled June 6, Location \#2

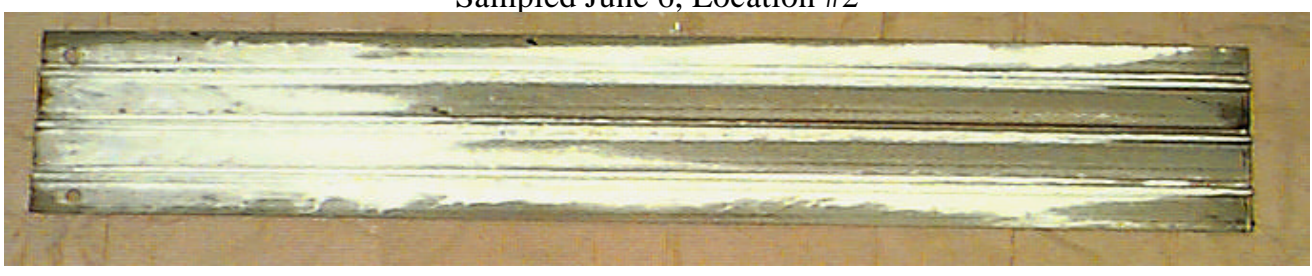

Comparing the catalyst appearance in June to sample taken in March shows continued and quite significant catalyst loss. The extent of catalyst is greater than expected at the design operating conditions. Based on the March and June samples, it appears that catalyst loss has not stabilized and should be expected to continue. Catalyst loss greater than $30 \%$ will cause a degradation in the overall system performance.

\section{Catalyst Activity}

Table 1 summarizes changes in the concentration of ammonia and NO measured during bench testing for samples taken on March 25th. These are the same data as were reported earlier. These samples, about 5 inches long, were cut from individual plates.

Table 1

The change in $\mathrm{NO}$ and $\mathrm{NH}_{3}$ concentration, in ppm, for samples from the inlet, middle and outlet portions of the sample module. These values represent the change from the inlet concentrations.

\begin{tabular}{|c|c|c|c|c|c|c|}
\hline Sample & \multicolumn{2}{|c|}{$270 \mathrm{C}$} & \multicolumn{2}{c|}{$300 \mathrm{C}$} & \multicolumn{2}{c|}{$320 \mathrm{C}$} \\
\hline Location & $\Delta \mathrm{NO}$ & $\Delta \mathrm{NH}_{3}$ & $\Delta \mathrm{NO}$ & $\Delta \mathrm{NH}_{3}$ & $\Delta \mathrm{NO}$ & $\Delta \mathrm{NH}_{3}$ \\
\hline & & & & & & \\
\hline Inlet & 1 & 12 & 1 & 12 & 3 & 20 \\
\hline Middle & 14 & 21 & 16 & 19 & 18 & 23 \\
\hline Outlet A & 4 & 16 & 6 & 18 & 3 & 20 \\
\hline Outlet B & 1 & 12 & 1 & 12 & 3 & 20 \\
\hline
\end{tabular}

Based on inlet $\mathrm{NO}=150 \mathrm{ppm}$ and $\mathrm{NH}_{3}=26 \mathrm{ppm}$

The uncertainty in the ammonia measurement is about $+/-2 \mathrm{ppm}$ for the inlet and outlet concentrations. These levels of uncertainties can lead to a high relative error at low concentrations. Despite washcoat removal from the 
inlet and outlet samples, there was still $46 \% \mathrm{NH}_{3}$ removal at temperatures of 300 and $270 \mathrm{C}$ and $77 \%$ removal at 320 C. A greater amount of catalyst on the outlet A sample lead to greater SCR activity. The sample from the middle of the bed has between 70 to $88 \%$ ammonia conversion over the range of temperatures studied. The SCR reaction seems to account for most of the ammonia removal based on a comparison of the changes in the ammonia and NO concentrations.

Table 2

Changes in NO and ammonia concentrations Sampled June 6th, Location \#1

\begin{tabular}{|c|c|c|c|c|}
\hline Sample & \multicolumn{2}{|c|}{$270 \mathrm{C}$} & \multicolumn{2}{c|}{$320 \mathrm{C}$} \\
\hline Location & $\Delta \mathrm{NO}$ & $\Delta \mathrm{NH} 3$ & $\Delta \mathrm{NO}$ & \multicolumn{2}{c|}{} \\
\hline & & & 2 & 14 \\
\hline Inlet & 2 & 19 & 17 & 16 \\
\hline Middle & 13 & 15 & 12 & 13 \\
\hline Outlet & 10 & & & \\
\hline
\end{tabular}

Inlet ammonia $=30 \mathrm{ppm}$

Table 3

Changes in NO and ammonia concentrations Sampled June 6th , Location \#2

\begin{tabular}{|c|c|c|c|c|}
\hline Sample & \multicolumn{2}{|c|}{$270 \mathrm{C}$} & \multicolumn{2}{c|}{$320 \mathrm{C}$} \\
\hline Location & $\Delta \mathrm{NO}$ & $\Delta \mathrm{NH} 3$ & $\Delta \mathrm{NO}$ & $\Delta \mathrm{NH}$ \\
\hline & & & & 0 \\
\hline Inlet & 0 & 0 & 15 & 16 \\
\hline Middle & 5 & 7 & 36 & 21 \\
\hline Outlet & 16 & 19 & & 19 \\
\hline
\end{tabular}

Inlet ammonia $=30 \mathrm{ppm}$

The change in the NO concentration for the outlet sample at $320 \mathrm{C}$ is probably suspect and should not be given high significance. Note that the inlet ammonia was increased to $30 \mathrm{ppm}$ compared to $26 \mathrm{ppm}$ when the March samples were tested. It is difficult at low ammonia concentrations to exactly reproduce the same concentration.

For the samples taken in June, the inlet shows no SCR activity but in some cases, especially at the higher temperature, there is a loss of ammonia. The absence of SCR activity is expected since the catalyst has been completely removed from the supporting plate. At the middle and outlet regions, less than $50 \%$ of the ammonia is being utilized for the SCR reactor in regions where the catalyst has not been completely lost. In contrast, the March samples in the middle of the plate showed an ammonia utilization for the SCR reaction of 50 to $70 \%$. Therefore, the catalyst activity at locations 1 and 2 on June 6 shows a reduction compared to the March sample.

The extent of activity loss does not entirely account for the performance observed in the field. When the loss of activity is combined with the loss of catalyst due to erosion, the performance in the field more closely correlates with our laboratory results

We continue to observe ammonia removal during laboratory testing without a corresponding NO removal This continues to suggest a mechanism other than the SCR reaction is operating. The extent of reaction observed in the lab does not match the apparent activity in the field. We have taken pains to eliminate sampling and reactor variables but still do not have an explanation for the discrepancy. 
Chemical Analysis

Catalyst was scraped from plates sampled in March 25 and submitted for chemical analysis by XRF. The analysis techniques scans a sample for 48 elements and reports concentrations based on oxides. The analysis is semi quantitative, elements not reported were not found or were present at concentrations less than about 75 ppm. Elements particular to the catalyst are not reported here.

Table 4

Semi Quantitative analysis of catalyst removed from supporting plates.

Sampled March 25th

\begin{tabular}{|c|c|}
\hline $\begin{array}{c}\text { Element, as } \\
\text { Oxide }\end{array}$ & Weight \% \\
\hline & 0.34 \\
\hline $\mathrm{Na}_{2} \mathrm{O}$ & 6.1 \\
\hline $\mathrm{Al}_{2} \mathrm{O}_{3}$ & 8.1 \\
\hline $\mathrm{SiO} 2$ & 5.4 \\
\hline $\mathrm{As}_{2} \mathrm{O}_{5}$ & 5.0 \\
\hline $\mathrm{SO}_{3}$ & 1.2 \\
\hline $\mathrm{CaO}$ & 0.89 \\
\hline $\mathrm{TiO}_{2}$ & 1.8 \\
\hline $\mathrm{Fe}_{2} \mathrm{O}_{3}$ & \\
\hline
\end{tabular}

The presence of such a high arsenic concentrations was surprising. After the June sampling these analyses were repeated. In this these analysis a reference standard from the National Bureau of Standards (NBS) was used to calibrate the arsenic concentration. This analysis also include a quantitative determination of $\mathrm{Na}_{2} \mathrm{O}$ and $\mathrm{K}_{2} \mathrm{O}$ Results of these test are summarized in Table 5.

Table 5

Quantitative chemical analysis (weight \%) of catalyst sampled March 25 and June 6.

$\begin{array}{lcccc} & \text { LOI, } \% & \mathrm{As}_{2} \mathrm{O}_{3} \% & \mathrm{~K}_{2} \mathrm{O} \% & \mathrm{Na} 2 \mathrm{O} \% \\ \text { March 25 } & 15.3 & 3.84 & 0.0650 & 0.445 \\ \text { June 6, \#1 } & 33.8 & 2.05 & 0.0137 & 0.698 \\ \text { June 6, \#2 } & 26.2 & 2.76 & 0.0128 & 0.535\end{array}$

LOI --- Loss On Ignition (1000 C)

These analysis also show a high concentration of arsenic in the catalyst. The variation in concentration between these samples, probably results statistical sample to sample variation. At these levels significant catalyst deactivation can be expected. The LOI (Loss On Ignition) represents contributions from hydrated salts, ammonium sulfates and residual carbonaceous material.

Table 6

Semi - quantitative XRF chemical analysis of fly ash from Seward station Sampled June 10th 


\begin{tabular}{|c|c|}
\hline $\begin{array}{c}\text { Element, as } \\
\text { Oxide }\end{array}$ & Weight \% \\
\hline & \\
\hline $\mathrm{Na}_{2} \mathrm{O}$ & 0.25 \\
\hline $\mathrm{MgO}$ & 0.92 \\
\hline $\mathrm{Al}_{2} \mathrm{O}_{3}$ & 23.8 \\
\hline $\mathrm{SiO}_{2}$ & 50.5 \\
\hline $\mathrm{P}_{2} \mathrm{O}_{5}$ & 0.56 \\
\hline $\mathrm{SO}_{3}$ & 0.30 \\
\hline $\mathrm{K}_{2} \mathrm{O}$ & 2.40 \\
\hline $\mathrm{CaO}$ & 1.2 \\
\hline $\mathrm{TiO}_{2}$ & 0.89 \\
\hline $\mathrm{Fe}_{2} \mathrm{O}_{3}$ & 18.5 \\
\hline $\mathrm{ZrO}_{2}$ & 0.12 \\
\hline
\end{tabular}

Elements not reported were either not found or were present at concentrations less than about $75 \mathrm{ppm}$. Arsenic was reported as less than $75 \mathrm{ppm}$.

\section{$\underline{\text { Conclusions }}$}

At the design temperature $(315 \mathrm{C})$ and space velocity $\left(15,000 \mathrm{hr}^{-1}\right)$ the current catalyst will not meet design conditions ( $20 \mathrm{ppm}$ to $2 \mathrm{ppm} \mathrm{NH}_{3}$ at $150 \mathrm{ppm} \mathrm{NO}$ ). The chemical poisoning by arsenic is a major factor in the loss of performance for ammonia destruction. Catalyst loss by erosion was also greater than anticipated and contributed to the loss of performance. It is import to determine the velocity profile at the catalyst face to further understand the impact on the observed erosion.

A visual assessment of the June sample plates, showed 40 to $70 \%$ catalyst loss, exceeding our design expectations. The catalyst loss was primarily from the leading edge in the flow direction. The extent of catalyst loss was much greater than was observed in the March sample.

Activity data from the June samples shows a decrease compared to the March sample. Chemical analysis of the March and June samples showed over 2 weight $\%$ arsenic as $\mathrm{As}_{2} \mathrm{O}_{3}$. We continue to see ammonia removal via a reaction that does not involve $\mathrm{NO}_{\mathrm{x}}$. Whether this mechanism has a significant impact on the catalyst performance in the field is uncertain. 
APPENDIX B 


\title{
GPU/Genco Seward Station Unit 5 Duct B
}

\section{Summary of SCR Catalyst Pilot Performance Test Report}

\author{
Submitted by \\ CORMETECH, INC.
}

Environmental Technologies

5000 International Drive

Durham, NC 27712

(919) 620-3000

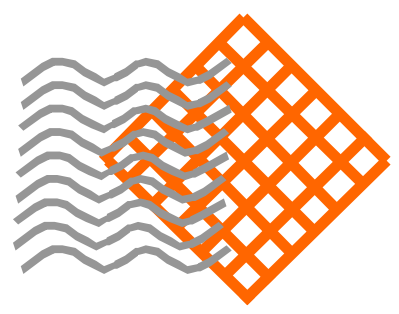

Robert von Alten

Deborah L. Sunick, Ph.D.

July 6, 1999 


\begin{tabular}{|c|}
\hline $\begin{array}{c}\text { CORMETECH, INC. } \\
\text { Laboratory Services }\end{array}$ \\
GPU/Genco Seward Station Unit 5 Duct B \\
SCR Catalyst Pilot Performance Test Report \\
July 6,1999
\end{tabular}

\section{INTRODUCTION}

Cormetech tested SCR samples from Seward Unit 5 Modules 4 and 9. These samples were removed from the catalyst bed in March 1998 after 3,250 hours of operation. Cormetech also tested SCR samples from Seward Unit 5 Modules 6 and 10. These samples were removed from the catalyst bed in October 1998 after 7,050 hours of operation. The catalytic activity loss was substantial; however, it was within expectations based on the arsenic concentration detected on the catalyst samples.

Decomposable / volatile catalyst poisons in the form of ammonium bisulfate were detected on the surface of the Module 4 catalyst sample. This poison had a minor impact on catalytic activity loss compared to arsenic poisoning.

This report summarizes the results of the catalyst performance test audit of these samples.

\section{PURPOSE}

Testing was conducted to measure and analyze the change in catalytic potential of SCR catalyst over time by measuring the performance of field catalyst samples that have been in operation for a known duration and flue gas condition. Catalytic potential was measured and results were compared to Cormetech's experience base. In addition, catalyst chemical composition, physical properties and coal and ash chemical profiles were also analyzed and discussed relative to the performance of the catalyst samples. 


\begin{tabular}{|c|}
\hline $\begin{array}{c}\text { CORMETECH, INC. } \\
\text { Laboratory Services }\end{array}$ \\
GPU/Genco Seward Station Unit 5 Duct B \\
SCR Catalyst Pilot Performance Test Report \\
July 6, 1999
\end{tabular}

\section{RESULTS}

The catalyst activity decreased substantially mainly due to arsenic deposition on the catalyst surface. Given the amount of arsenic detected on the catalyst sample, this loss in catalyst activity is within expectations. Arsenic in the coal is on the order of 5 to 7 times higher than the expected $2 \mathrm{ppm}$ value. Given this higher concentration of arsenic in the coal sample, the arsenic concentrations detected on the catalyst are reasonable.

The graph below shows the loss in catalyst relative activity, Kt/Ko over time. Each data point represents the average value of the two samples. Activity, $\mathrm{K}$, is a measure of the effective catalyst performance and $\mathrm{Kt} / \mathrm{Ko}$ is the ratio of aged activity versus fresh activity. For example, a Kt/Ko of 0.50 indicates that the aged catalyst has one-half of the performance potential of the fresh catalyst. The threshold value is the relative activity as measured in the pilot reactor at which the actual field performance at design conditions is expected to reach end-of-life.

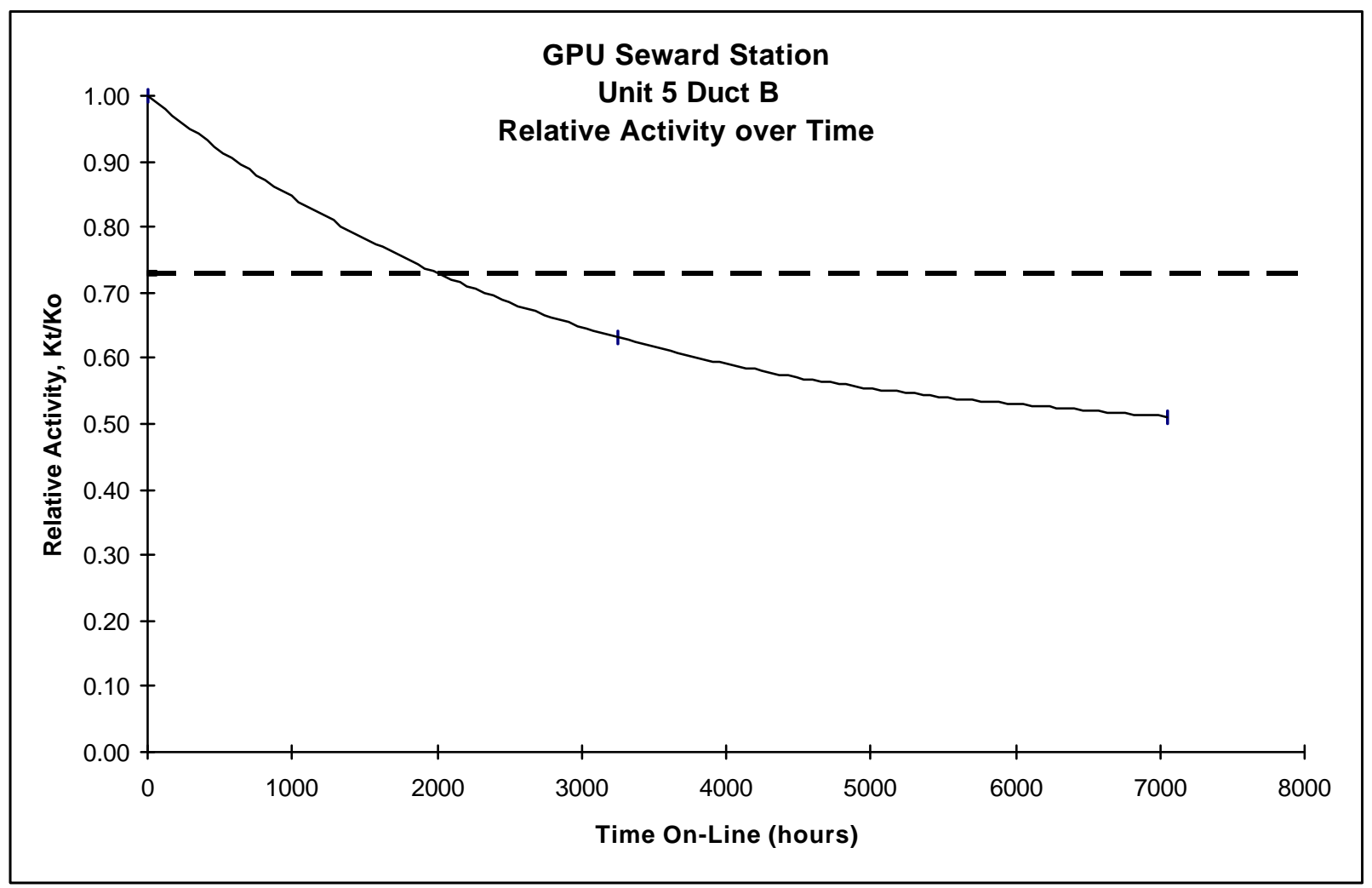




\begin{tabular}{c|}
\hline CORMETECH, INC. \\
Laboratory Services \\
GPU/Genco Seward Station Unit 5 Duct B \\
SCR Catalyst Pilot Performance Test Report \\
July 6, 1999
\end{tabular}

Arsenic, a known catalyst poison, is present in high concentrations over the catalyst length on both the surface and in the bulk material of the samples audited. The graph below shows the surface concentration distribution of arsenic over the length of the catalyst elements. As expected the arsenic concentration is highest at the inlet and decreases over the length of the element.

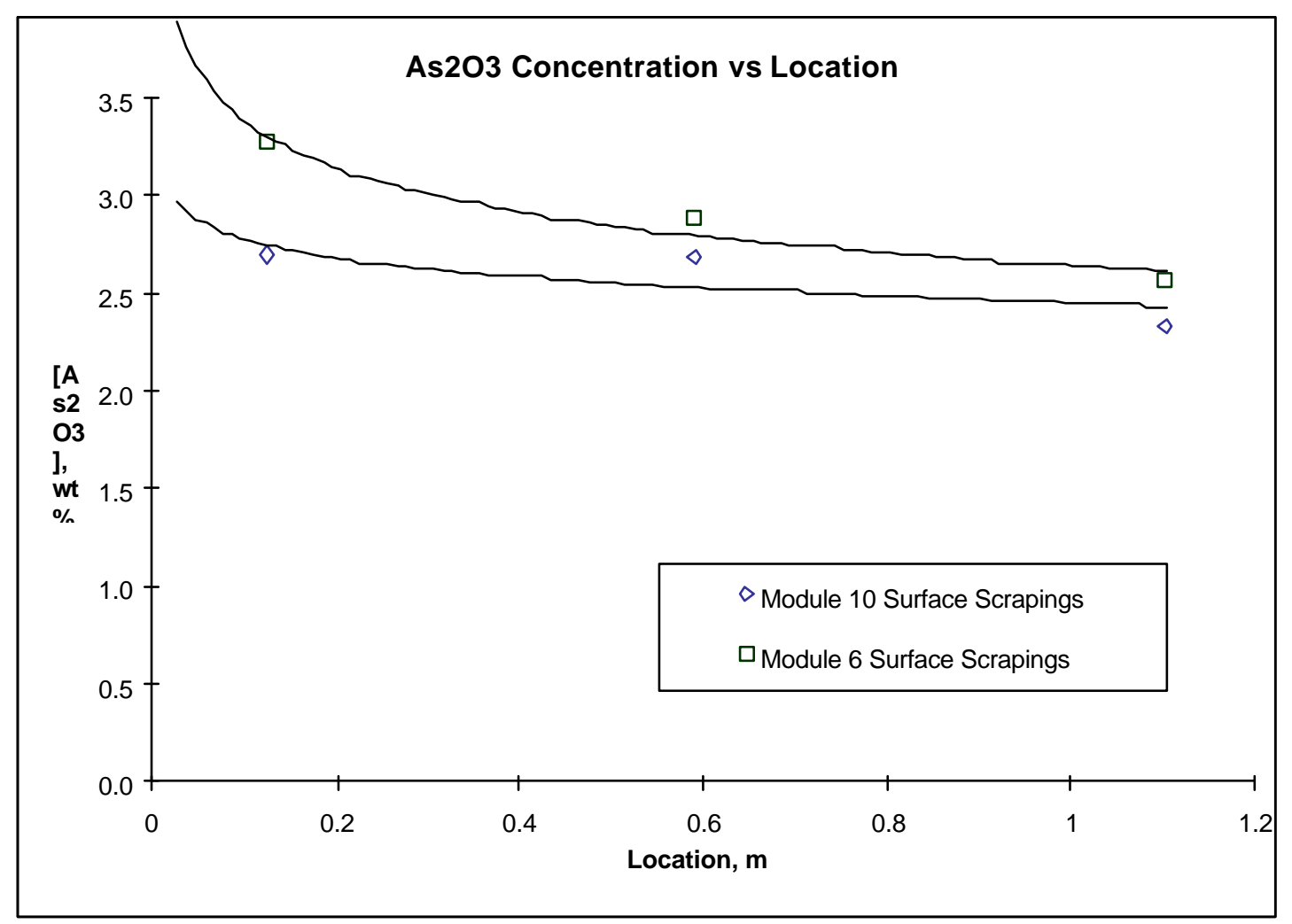

Based on prior studies performed on German units and accelerated poison tests, the surface arsenic concentrations can be used to estimate deactivation due to arsenic. For the arsenic surface concentrations of the March 1998 samples, the data estimates a $0.56 \mathrm{Kt} / \mathrm{Ko}$ ratio. This is consistent with the measured values. Therefore, nearly all of activity loss is due to arsenic poisoning.

The average arsenic concentration for the coal and ash samples taken in October 1998 (15.4 and $135 \mathrm{ppm}$ respectively) is consistent with the observed high arsenic concentrations in the catalyst. A review of the history of arsenic in fuel from January 14 to June 10, 1998 shows an average coal arsenic concentration of $9.7 \mathrm{ppm}$ as reported to GPU by Standard Laboratories, Inc. These values are consistently lower than the 


\begin{tabular}{|c|}
\hline CORMETECH, INC. \\
Laboratory Services \\
GPU/Genco Seward Station Unit 5 Duct B \\
SCR Catalyst Pilot Performance Test Report \\
July 6,1999
\end{tabular}

measured values determined by Cormetech (15.4 ppm average). Arsenic trioxide is a volatile component of the arsenic content of the ash. Depending upon the analysis method employed, the lower arsenic values may have resulted from the loss of arsenic trioxide upon sample preparation. The Cormetech value represents the average of three samples.

Activity loss is not due to physical property changes, specifically changes in surface area.

\section{RECOMMENDATIONS}

Provide increased amount of $\mathrm{CaO}$ to limit gaseous phase arsenic at catalyst to extend catalyst life.

Evaluate the economics of catalyst replacements versus limestone injection (including impacts to boiler operation) to optimize injection quantity. 
APPENDIX C 


\title{
$\mathrm{SO}_{3}$ ABSORBER EVALUATION
}

\section{FINAL REPORT}

\author{
Prepared By \\ CONSOL Inc. \\ Research and Development \\ 4000 Brownsville Road \\ Library, Pennsylvania, 15129-9566 \\ Principal Investigators \\ W. A. Rosenhoover \\ G. L. Cairns \\ Prepared for

\section{GPU Generation Corp.} \\ 1001 Broad Street \\ Johnstown, Pennsylvania 15907
}

March 1999

CONSOL Inc.

Research \& Development

4000 Brownsville Road

Library, Pennsylvania 15129-9566 


\section{DISCLAIMER OF WARRANTIES AND LIMITATION OF LIABILITIES}

This report was prepared by CONSOL Inc. as an account of work sponsored by GPU Generation Corp. Neither CONSOL nor GPU nor any person acting on behalf of any of them:

(A) Makes any warranty or representation whatsoever, express or implied, (1) with respect to the use of any information, apparatus, method, process or similar item disclosed in this report, including merchantability and fitness for a particular purpose; or (2) that such use does not infringe on or interfere with privately owned rights, including any party's intellectual property; or (3) that this report is suitable to any particular user's circumstance; or

(B) Assumes any responsibility for any damages or other liability whatsoever (including any consequential damages, even if CONSOL or GPU or any representative has been advised of the possibility of such damages) resulting from your selection of use of this report or any information, apparatus, method, process or similar item disclosed in this report.

(C) Reference herein to any specific commercial product, process, or service by trade name, trademark, manufacturer, or otherwise, does not necessarily constitute or imply its endorsement, recommendation, or favoring by the United States government, or any agency thereof. The views and opinions of authors expressed herein do not necessarily state or reflect those of the United States government or any agency thereof. 


\section{TABLE OF CONTENTS}

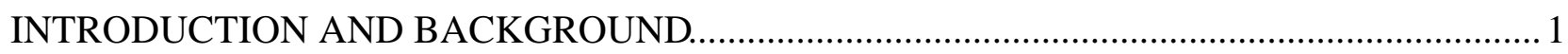

CONCLUSIONS

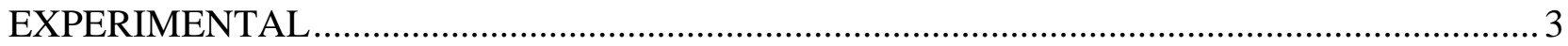

1. Combustor Test Facility......................................................................................... 3

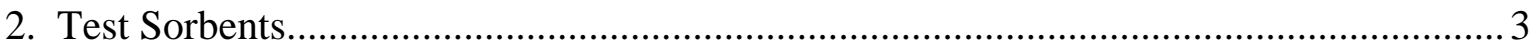

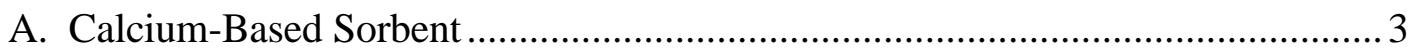

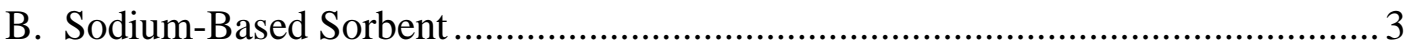

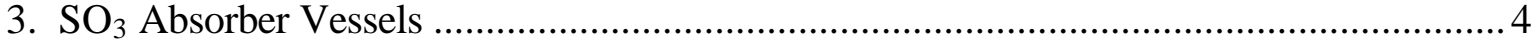

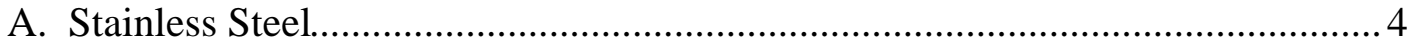

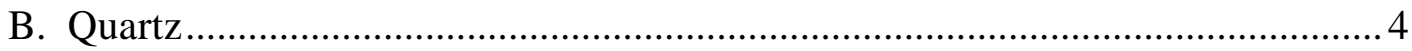

4. Ammonia Sampling Equipment and Procedure ...............................................................5

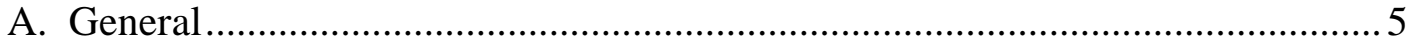

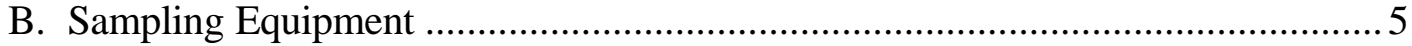

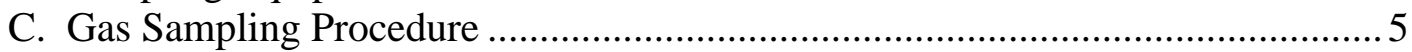

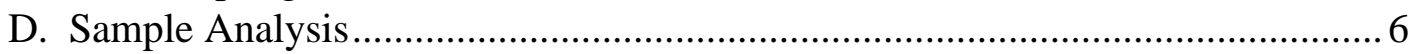

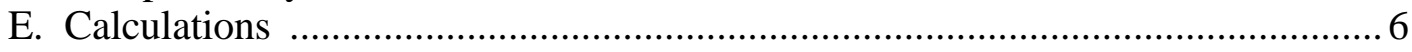

5. $\mathrm{SO}_{3}$ Sampling Equipment and Procedure................................................................

6. Analytical Procedures ....................................................................................... 8

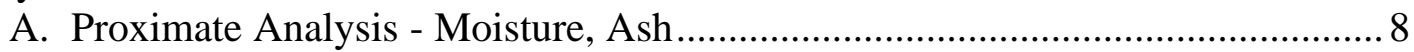

B. Ultimate Analysis - Carbon, Hydrogen, Nitrogen........................................... 8

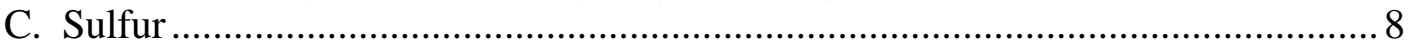

D. Major Ash Elements Including Phosphates.......................................................... 9

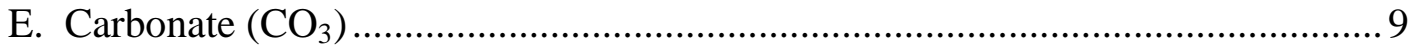

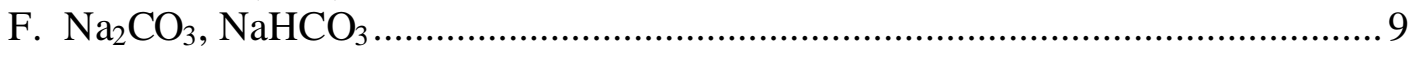

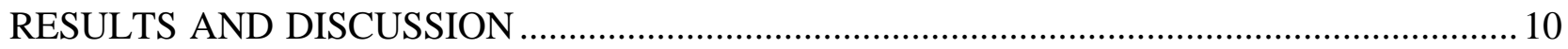

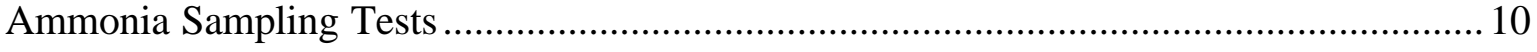

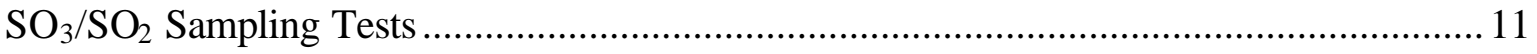

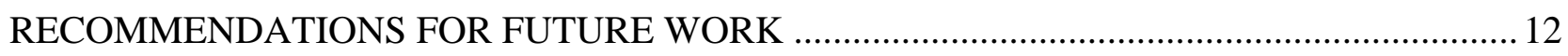

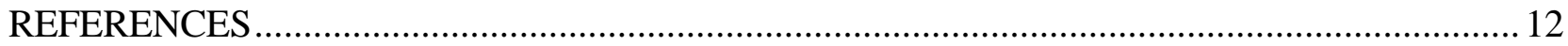




\section{LIST OF TABLES AND FIGURES}

Table

Page

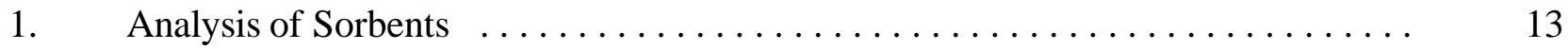

2. Ammonia Sampling Tests - R\&D Pilot Combustor $\ldots \ldots \ldots \ldots \ldots \ldots \ldots$

3. $\mathrm{SO}_{2}$ and $\mathrm{SO}_{3}$ Sampling Tests - R\&D Pilot Combustor - Quartz Absorber Vessel . . . 15

Figure

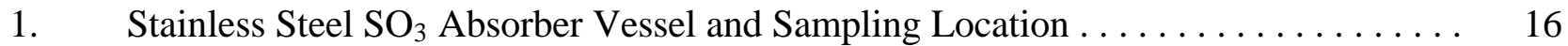

2. $\mathrm{NH}_{3}$ Injection Hardware $-\mathrm{SO}_{3}$ Absorber $\ldots \ldots \ldots \ldots \ldots \ldots \ldots \ldots \ldots \ldots$

3. Apparatus for Sodium Bicarbonate Production $\ldots \ldots \ldots \ldots \ldots \ldots \ldots \ldots \ldots \ldots$

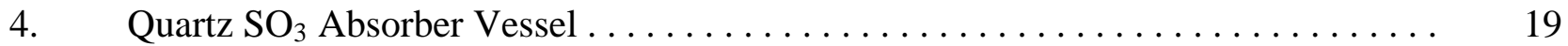

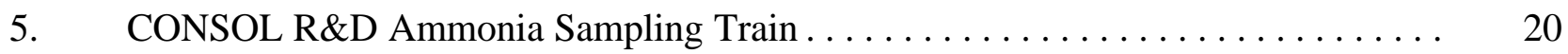

6. CONSOL R\&D Controlled Condensation $\mathrm{SO}_{3}$ Sampling Train. . . . . . . . . . 21

7. Photos of Quartz Vessel/Sample Tube......................... 22 


\section{INTRODUCTION AND BACKGROUND}

In the selective non-catalytic reduction (SNCR) process, urea $\left(\mathrm{NH}_{2} \mathrm{CONH}_{2}\right)$ or ammonia $\left(\mathrm{NH}_{3}\right)$ are injected into the post-combustion zone of a coal-fired boiler to convert flue gas $\mathrm{NO}_{\mathrm{x}}$ to nitrogen $\left(\mathrm{N}_{2}\right)$, carbon dioxide $\left(\mathrm{CO}_{2}\right)$, and water $\left(\mathrm{H}_{2} \mathrm{O}\right)$ by the following reactions:

$$
\begin{aligned}
& 4 \mathrm{NO}+2 \mathrm{NH}_{2} \mathrm{CONH}_{2}+\mathrm{O}_{2} \rightarrow 4 \mathrm{~N}_{2}+2 \mathrm{CO}_{2}+4 \mathrm{H}_{2} \mathrm{O} \\
& 2 \mathrm{NO}_{2}+2 \mathrm{NH}_{2} \mathrm{CONH}_{2}+\mathrm{O}_{2} \rightarrow 3 \mathrm{~N}_{2}+2 \mathrm{CO}_{2}+4 \mathrm{H}_{2} \mathrm{O} \\
& 4 \mathrm{NO}+4 \mathrm{NH}_{3}+\mathrm{O}_{2} \rightarrow 4 \mathrm{~N}_{2}+6 \mathrm{H}_{2} \mathrm{O} \\
& 6 \mathrm{NO}_{2}+8 \mathrm{NH}_{3} \rightarrow 7 \mathrm{~N}_{2}+12 \mathrm{H}_{2} \mathrm{O}
\end{aligned}
$$

In this process, $\mathrm{NH}_{3}$ can be found in the flue gas as a result of incomplete utilization of urea or $\mathrm{NH}_{3}$. This is referred to as $\mathrm{NH}_{3}$ slip. The $\mathrm{NH}_{3}$ slip can have several adverse effects. Ammonia reacts with flue gas sulfur trioxide $\left(\mathrm{SO}_{3}\right)$ forming ammonium bisulfate $\left(\mathrm{NH}_{4} \mathrm{HSO}_{4}\right)$ :

$$
\mathrm{NH}_{3}+\mathrm{H}_{2} \mathrm{O}+\mathrm{SO}_{3} \rightarrow \mathrm{NH}_{4} \mathrm{HSO}_{4}
$$

Ammonium bisulfate condenses in the air preheater and deposits on metal surfaces, resulting in reduced heat transfer capacity and increased pressure drop. The $\mathrm{NH}_{4} \mathrm{HSO}_{4}$ can also deposit on ESP fly ash resulting in a problem with ash sale, and/or present the costly process of landfilling an otherwise salable ash.

To reduce $\mathrm{NH}_{3}$ slip, a SCR/SNCR hybrid process can be employed. The catalyst bed used in this process, in addition to enhancing $\mathrm{NO}_{\mathrm{x}}$ removal, converts the $\mathrm{NH}_{3}$ to $\mathrm{N}_{2}$ by reactions 3 and 4 . If successful, the post catalyst $\mathrm{NH}_{3}$ slip would be $\leq 2 \mathrm{ppmv}$, which is desirable for eliminating operational and ash sale/disposal problems.

Another process for $\mathrm{NO}_{\mathrm{x}}$ reduction and $\mathrm{NH}_{3}$ slip control is selective catalytic reduction (SCR). This involves injection of vaporized $\mathrm{NH}_{3}$ into the flue gas stream upstream of a catalyst bed. When passing over the catalyst, the $\mathrm{NH}_{3}$ acts as a reducing agent, converting $\mathrm{NO}_{\mathrm{x}}$ to nitrogen and water (equations 3 and 4).

A reliable flue gas $\mathrm{NH}_{3}$ analyzer would be beneficial in the optimization of the performance of $\mathrm{SCR}, \mathrm{SNCR}$ or hybrid systems. The analyzer can be used to monitor the $\mathrm{NH}_{3}$ slip, and control the injection rate of $\mathrm{NH}_{3}$ or urea.

CONSOL has been active in evaluating $\mathrm{NH}_{3}$ analyzers since 1992. The work has involved three separate test programs. Two programs were conducted at northeast power plants: one full-scale operation employing an SNCR process, and the other involving a experimental hybrid process on an $\mathrm{NH}_{3}$-spiked slipstream of the flue gas. The third program used an in-house, bench-scale combustor with $\mathrm{NH}_{3}$ addition to the flue gas. The test programs involved $\mathrm{NH}_{3}$ analyzers with extractive sampling systems and in-situ analyzers. In each program, the performance of the analyzers was determined by manual sampling of the flue gas using standard $\mathrm{NH}_{3}$ sampling and analytical procedures. 
A few of the analyzers evaluated showed promise. There were positive responses to increases and decreases in flue gas $\mathrm{NH}_{3}$ concentration and, for short time periods, accurate measurement of flue gas $\mathrm{NH}_{3}$ concentration. However, any accuracy that was displayed was not maintained over a significant time period. Also, none of the analyzers could be maintained without significant maintenance. Consequently, the analyzers evaluated were not judged to be accurate and reliable tools for the continuous monitoring or controlling of $\mathrm{NH}_{3}$ slip in a SNCR, SCR, or hybrid process.

A number of design problems were identified in the analyzer evaluation programs. One of these was a deposit discovered in the extractive sampling system of one of the analyzers, and in the analyzer itself. Analysis of the deposit showed an ammonia compound(s), suggesting $\mathrm{NH}_{4} \mathrm{HSO}_{4}$ deposition in "cold" sections of the system. A deposit of this nature would, of course, contain a portion of the flue gas ammonia that did not reach the analysis section of the analyzer, thus giving an erroneously low analyzer reading. Based on manual sampling results, analyzer readings from CONSOL's evaluation programs were, in most cases, low. It is not known whether the deposition of $\mathrm{NH}_{4} \mathrm{HSO}_{4}$ was a problem with other evaluated analyzers since access to the internal components of these systems was not possible. It is believed, however, that $\mathrm{NH}_{4} \mathrm{HSO}_{4}$ deposition can be a potential problem with any analyzer with an extractive sampling system.

To address the possible problem of $\mathrm{NH}_{4} \mathrm{HSO}_{4}$ deposition in the sampling system of an $\mathrm{NH}_{3}$ analyzer, or in the analyzer itself, a program was conducted to design and test an absorber to remove $\mathrm{SO}_{3}$ and prevent $\mathrm{NH}_{4} \mathrm{HSO}_{4}$ formation (Reaction 5). The results of this program are reported here. Commercially, the absorber would be located at the front end of an extractive-type $\mathrm{NH}_{3}$ analyzer flue gas sampling line. Ideally, the absorber would contain a sorbent which would remove $100 \%$ of the $\mathrm{SO}_{3}$ in the flue gas sample, while being inert to $\mathrm{NH}_{3}$.

The testing was performed using CONSOL's 1.5 MM Btu/hr pilot scale coal combustor as the flue gas source. The flue gas was spiked with varying amounts of $\mathrm{NH}_{3}(15-40$ ppmv) to simulate slips that could be found in an SNCR, SCR, or hybrid process. Two absorber vessels were tested: one constructed of 316 stainless steel, and the other of quartz. Two sorbents were tested: one a commercially available calcitic quicklime $(\mathrm{CaO})$, and the other a mix of sodium carbonate $\left(\mathrm{Na}_{2} \mathrm{CO}_{3}\right)$ and sodium bicarbonate $\left(\mathrm{NaHCO}_{3}\right)$. The sorbents were chosen based on a literature analysis of promising sorbents for capture of flue gas $\mathrm{SO}_{\mathrm{x}}$ compounds. ${ }^{1}$ The absorber, containing sorbent, was heated in situ by placing it inside the combustor flue gas duct. Duct temperatures for these tests ranged from $540^{\circ} \mathrm{F}$ to $770^{\circ} \mathrm{F}$. Tests were conducted for $\mathrm{NH}_{3}$ and $\mathrm{SO}_{3}$ using standard manual flue gas sampling and analytical procedures. For each sampling test, two gas samples were collected and analyzed: one through the absorber to measure the amount of $\mathrm{NH}_{3}$ or $\mathrm{SO}_{3}$ captured by the sorbent bed, and the other through a line bypassing the absorber to measure the $\mathrm{NH}_{3}$ or $\mathrm{SO}_{3}$ concentration in the flue gas. The inlet to the sorbent bed and the inlet to the bypass line were at essentially the same location in the duct.

\section{CONCLUSIONS}

- $\quad$ Sampling tests showed that the calcitic quicklime $(\mathrm{CaO})$ used in this study is not suitable as a sorbent for an $\mathrm{SO}_{3}$ absorber. The $\mathrm{CaO}$ reacted with a substantial portion of the flue gas $\mathrm{NH}_{3}$. Four tests showed an average $\mathrm{NH}_{3}$ removal of $49 \%$. No $\mathrm{SO}_{\mathrm{x}}$ removal tests were conducted with the $\mathrm{CaO}$. 
- $\quad$ A mixture of $\mathrm{Na}_{2} \mathrm{CO}_{3}$ and $\mathrm{NaHCO}_{3}$ proved to be an excellent sorbent for an $\mathrm{SO}_{3}$ absorber. This sorbent showed no reaction with flue gas $\mathrm{NH}_{3}$, and captured $100 \%$ of the $\mathrm{SO}_{2}$ and $\mathrm{SO}_{3}$.

- $\quad$ Of the two materials tested as $\mathrm{SO}_{3}$ absorber vessels, quartz is preferable. There is evidence that the stainless steel reacted with a portion of the flue gas $\mathrm{NH}_{3}$, while the quartz was chemically inert.

\section{EXPERIMENTAL}

\section{Combustor Test Facility}

CONSOL's 1.5 MM Btu/hr (100 lb/hr coal feed) combustion research facility was used as the source of flue gas for this study. The combustor, which simulates the operation of a commercial utility or industrial boiler, consists of a pulverized coal feed system, bottom ash pit, firebox, radiant section, nose section, convection pass, duct work, and particulate collection systems (ESP or fabric filter). The firebox can be configured to simulate opposed-firing, tangential-firing, or cyclone-firing. The radiant section contains an air-cooled tube array to simulate boiler water walls. The convection pass utilizes a water-cooled jacket to reduce flue gas temperature prior to particulate (fly ash) collection. Flue gas cleanup utilizes a baghouse and ESP, either one of which can be used for fly ash collection. The flue gas port used for the $\mathrm{NH}_{3}$ and $\mathrm{SO}_{3}$ sampling tests in this study was located in the fourth pass of the nine pass convection section of the combustor (Figure 1).

The desired $\mathrm{NH}_{3}$ concentration of the flue gas for the $\mathrm{NH}_{3}$ sampling tests was obtained by spiking the flue gas. The $\mathrm{NH}_{3}$ was obtained from compressed gas cylinders containing $10 \% \mathrm{NH}_{3}$ (balance nitrogen); and the flow was controlled with a mass flow controller. The $\mathrm{NH}_{3}$ was injected into the combustor convection pass, prior to the sampling location, using an injection lance presented in Figure 2. The lance was a 1/4" OD stainless steel (s/s) tube, with eight - 1/32" diameter holes drilled around the circumference of the tubing near the end. The holes provided efficient dispersion of the $\mathrm{NH}_{3}$ in the flue gas. The 1/4" tube, excluding the perforated end, was enclosed in a $3 / 8$ " OD s/s tube for support.

\section{Test Sorbents}

\section{A. Calcium-Based Sorbent}

One of the two $\mathrm{SO}_{3}$ sorbents used in this study was a high calcium quicklime (CaO) supplied by Mississippi Lime Co. of Ste. Genevieve, MO. The $\mathrm{CaO}$ was received as $1 / 2$ " x 1" chunks, and was ground and screened to 5 x 9 mesh (approximately 1/8" x 1/16") prior to testing. Analyses of the ground and screened fraction are presented in Table 1.

\section{B. Sodium-Based Sorbent}

The second sorbent was sodium carbonate $\left(\mathrm{Na}_{2} \mathrm{CO}_{3}\right)$ supplied in briquette form by Chemply Inc. The $\mathrm{Na}_{2} \mathrm{CO}_{3}$ was treated with carbon dioxide $\left(\mathrm{CO}_{2}\right)$ gas under high humidity conditions using the apparatus presented in Figure 3. This treatment was conducted to convert a portion of the $\mathrm{Na}_{2} \mathrm{CO}_{3}$ to sodium bicarbonate $\left(\mathrm{NaHCO}_{3}\right)$ by reaction 6: 


$$
\mathrm{Na}_{2} \mathrm{CO}_{3}+\mathrm{CO}_{2}+\mathrm{H}_{2} \mathrm{O} \rightarrow 2 \mathrm{NaHCO}_{3}
$$

Sodium bicarbonate has been found, in flue gas desulfurization tests, to be a more efficient sorbent than $\mathrm{Na}_{2} \mathrm{CO}_{3}$ for $\mathrm{SO}_{\mathrm{x}}$ removal. The theory ${ }^{1}$ is that $\mathrm{NaHCO}_{3}$, when exposed to heat, decomposes to the carbonate. This decomposition (Reaction 7) exposes more reactive sites for $\mathrm{SO}_{\mathrm{x}}$ capture.

$$
2 \mathrm{NaHCO}_{3}+\text { Heat } \rightarrow \mathrm{Na}_{2} \mathrm{CO}_{3}+\mathrm{H}_{2} \mathrm{O}+\mathrm{CO}_{2}
$$

The $\mathrm{Na}_{2} \mathrm{CO}_{3}$ then reacts with sulfur trioxide $\left(\mathrm{SO}_{3}\right)$, removing it from the flue gas (reaction 8 ).

$$
\mathrm{Na}_{2} \mathrm{CO}_{3}+\mathrm{SO}_{3} \rightarrow \mathrm{Na}_{2} \mathrm{SO}_{4}+\mathrm{CO}_{2}
$$

The treatment with $\mathrm{CO}_{2}$ converted approximately $38 \%$ of the $\mathrm{Na}_{2} \mathrm{CO}_{3}$ to $\mathrm{NaHCO}_{3}$. The sorbent was ground and screened to $5 \times 9$ mesh before use. Analyses of the $\mathrm{Na}_{2} \mathrm{CO}_{3}$ as received, and the $\mathrm{CO}_{2}$-treated $\mathrm{Na}_{2} \mathrm{CO}_{3}$ are presented in Table 1 .

\section{3. $\mathrm{SO}_{3}$ Absorber Vessels}

\section{A. Stainless Steel}

A diagram of the s/s absorber vessel, along with the combustor sampling port, is presented in Figure 1. The vessel was constructed of 1-1/2" schedule $40 \mathrm{~s} / \mathrm{s}$ pipe. The vessel was 36 " in length, with the front 24 " $(800 \mathrm{cc})$ used to contain the sorbent. The sorbent was charged to the vessel by adding a small portion, followed by tapping the outside of the vessel to pack the material. This procedure was repeated until the $800 \mathrm{cc}$ of sorbent was charged. Following this procedure ensured a dense bed of sorbent, and prevented gas channeling during sampling. The sorbent bed was backed up by a s/s screen, which was firmly held in place by a spring located between the screen and a pipe cap screwed on the back end of the vessel. A sintered s/s filter was attached to the front (in duct) end of the vessel to remove fly ash from the "absorber exit" flue gas sample. Ports were located at the back end of the vessel for withdrawal of the flue gas sample exiting the sorbent bed. The port being used held, with the use of a compression fitting, a short piece of quartz tubing which was connected to the $\mathrm{NH}_{3}$ sampling train.

Attached to the outside of the 1-1/2" pipe was a 48" length of 1/2" OD s/s tubing, equipped at the front end with a sintered s/s filter for removing fly ash from the "absorber inlet" flue gas sample (Figure 1). An $8 \mathrm{~mm}(0.315 ")$ OD quartz tube, open on both ends, was inserted into the 1/2" OD tubing. The quartz tube extended approximately 2 " out of the back end of the $1 / 2$ " s/s tube, and was connected to the $\mathrm{NH}_{3}$ sampling train.

As shown in Figure 1, a thermocouple (TC) was attached to the outside of the vessel. The tip of the TC was located by the sintered metal filters so the flue gas temperature at the inlet to the absorber could be monitored.

\section{B. Quartz}

A diagram of the quartz vessel is presented in Figure 4. The vessel, supplied by Ace Glass Inc., was fabricated from 1-1/4" OD, medium wall quartz glass. The vessel, which was 46" in length, 
contained a 24" long chamber for containment of the sorbent $(350 \mathrm{cc})$. The sorbent was charged to the quartz vessel using the same procedure described for the s/s vessel. The sorbent bed was sandwiched between two perforated discs, each of which covered the inside cross section of the vessel (Figure 4). This created sufficient pressure to keep the sorbent bed tightly packed, and prevent gas channeling during sampling. The inlet of the vessel (inside the duct) was open, and packed with quartz wool to remove fly ash during flue gas sampling. The exit of the vessel was tapered to a ball joint, which was connected to the $\mathrm{NH}_{3}$ sampling train ("absorber exit"). To protect the fragile quartz, the vessel was cradled inside the s/s vessel during flue gas sampling tests. A small piece of both the front and back ends of the 1-1/2" s/s pipe (Figure 1) was removed, and the quartz laid inside.

The 1/2" OD s/s tubing attached to the outside of the s/s vessel was left intact, and used for flue gas sampling ("absorber inlet"). The 1/2" tubing contained the $8 \mathrm{~mm}$ quartz tubing, as described for the s/s absorber. The only exception was that the sintered metal filter at the end of the $1 / 2$ " tube (Figure 1) was removed for the quartz absorber tests. A plug of quartz wool was inserted into the end of the tube to remove fly ash from the "absorber inlet" flue gas sample.

\section{Ammonia Sampling Equipment and Procedure}

\section{A. General}

The $\mathrm{NH}_{3}$ concentration in the gas is determined by pulling a known volume of flue gas through the $\mathrm{SO}_{3}$ absorber into an acidic solution. Ammonia is captured in the acidic solution, which is quantitatively recovered and analyzed for $\mathrm{NH}_{3}$ using an ion specific electrode. The concentration of $\mathrm{NH}_{3}$ in the gas is calculated from the concentration of $\mathrm{NH}_{3}$ in the acidic solution, the volume of the recovered solution, and the volume of flue gas sampled.

\section{B. Sampling Equipment}

A diagram of the sampling train is presented in Figure 5. The sampling equipment includes: a length of Teflon tubing containing a Teflon ball valve; a set of three mini-impingers connected in series and chilled with an ice water bath; Tygon tubing; a silica gel drying tube; a gas flow meter (rotameter); and a meter box which contains a dry test meter, a sampling valve and a vacuum pump. The outlet of the $\mathrm{SO}_{3}$ absorber is connected via the Teflon tubing to the inlet of the first mini-impinger. The first two mini-impingers are each filled with $20 \mathrm{~mL}$ of $0.01 \mathrm{~N}$ nitric acid $\left(\mathrm{HNO}_{3}\right)$ solution. The third impinger is left empty to collect water droplets from the first two impingers. The exit of the third mini-impinger is connected to the silica gel trap and the rotameter via Tygon tubing. The silica gel trap protects the rotameter and downstream equipment from moisture. The exit of the rotameter is connected directly to the meter box inlet (dry test meter inlet). The gas pump (connected to the dry test meter exit) pulls the gas sample through the system.

\section{Gas Sampling Procedure}

After each sampling train (Figure 5) is assembled, the following leak check procedure is performed prior to sampling. With the sampling train disconnected from the $\mathrm{SO}_{3}$ absorber, the pump is started and an ambient air flow of $0.1 \mathrm{ft}^{3} / \mathrm{min}$ established. A rubber stopper is inserted into the inlet of the Teflon tubing and the rotameter activity noted. If there is no leaks, the 
rotameter ball drops to zero. If a leak is detected, the sampling train components are systematically checked until the leak is found and corrected. Following a successful leak check, the rubber stopper is removed, the sampling valve on the meter box closed, the Teflon valve closed, the sampling train (Figure 5) connected to the $\mathrm{SO}_{3}$ absorber, and the starting volume of the dry test meter recorded. The purpose of closing the Teflon valve is to prevent the acidic solutions from being sucked out of the impingers by the negative duct pressure.

Sampling begins by first opening the sampling valve on the meter box, then the Teflon valve. The sampling rate is set to approximately $0.1 \mathrm{ft}^{3} / \mathrm{min}$ using the rotameter. The rotameter setting, dry test meter volume, dry test meter temperatures, system vacuum and flue gas temperature are recorded every six minutes. To spot check for leaks in the sampling train, the $\mathrm{O}_{2}$ content of the flue gas is measured periodically at the meter box exhaust using a portable $\mathrm{O}_{2}$ meter. A sudden increase in the $\mathrm{O}_{2}$ reading would be indicative of a leak. No leaks were observed in the tests reported here. Gas sampling time is 48 minutes. A copy of the field (raw) data sheets for the $\mathrm{NH}_{3}$ sampling tests are presented in Appendix A.

At the completion of the test, the Teflon valve is shut and the rotameter observed to confirm a leak-free system at the end of the test. The sampling valve on the meter box is then shut and the final volume of the dry test meter recorded. The $\mathrm{SO}_{3}$ absorber is removed from the duct; and the Teflon tubing and impingers disassembled for sample recovery. The $\mathrm{SO}_{3}$ absorber inlet and exit quartz wool filters are discarded. The contents of the impingers are transferred to a volumetric flask. The impingers, the Teflon tubing, the $8 \mathrm{~mm}$ OD quartz tube (absorber inlet sample), and the sorbent-free section of the quartz $\mathrm{SO}_{3}$ absorber vessel (absorber exit sample) are rinsed with high purity deionized (DI) water; and the rinsing transferred to the flask containing the impinger solutions. The flask is diluted with DI water to a known volume, capped, and the solution stored for analysis.

\section{Sample Analysis}

The samples are analyzed using an $\mathrm{NH}_{3}$ ion specific electrode connected to a millivolt $(\mathrm{mV})$ meter. A $50-\mathrm{mL}$ aliquot of the diluted impinger solution is transferred to a $250-\mathrm{mL}$ beaker containing a magnetic stirring bar and placed on the stirrer. The electrode is inserted into the stirred solution and $1 \mathrm{~mL}$ of $1.0 \mathrm{~N}$ aqueous $\mathrm{NaOH}$ added. After allowing three to four minutes to line out, the $\mathrm{mV}$ reading on the meter is recorded. The $\mathrm{NH}_{3}$ concentration in the solution is determined from this reading using a calibration curve of $\log (\mathrm{mV})$ vs. $\mathrm{NH}_{3}$ concentration in parts per million by weight (ppmw). The calibration curve is prepared using standard aqueous solutions of $0.5,1.0,5.0,10.0$, and $20.0 \mathrm{ppmw} \mathrm{NH}_{3}$. The electrode response, $\log (\mathrm{mV})$ vs ppmw, is linear over this calibration range. A new calibration curve is made daily. The analysis are performed within 24 hours of the sampling tests. A table with the diluted impinger solution volumes and $\mathrm{NH}_{3}$ analyses for each $\mathrm{NH}_{3}$ sampling test is presented in Appendix A.

\section{E. Calculations}

The volume of gas measured by the dry test meter is corrected to standard conditions using the following equation:

$$
\left(\mathrm{V}_{\mathrm{m}}\right)_{\mathrm{std}}=\mathrm{V}_{\mathrm{m}} \mathrm{Y}\left(\mathrm{T}_{\mathrm{std}} / \mathrm{T}_{\mathrm{m}}\right)\left(\left(\mathrm{P}_{\mathrm{bar}}+{ }_{-} \mathrm{H} / 13.6\right) / \mathrm{P}_{\mathrm{std}}\right)
$$


where:

$$
\begin{array}{ll}
\mathrm{V}_{\mathrm{m}} & =\text { the volume of gas sample as measured by the dry gas meter, } \mathrm{ft}^{3} \\
\mathrm{Y} & =\text { dry gas meter calibration coefficient (dimensionless) } \\
\mathrm{Tstd} & =\text { standard absolute temperature }\left(528^{\circ} \mathrm{R}\right) \\
\mathrm{T}_{\mathrm{m}} & =\text { average dry gas meter temperature, }{ }^{\circ} \mathrm{R} \\
\mathrm{P}_{\mathrm{bar}} & =\text { barometric pressure, } \mathrm{Hg} \\
{ }_{-} \mathrm{H} & \left.=\text { average pressure differential across the orifice meter, (assumed to be } 0.02{ }^{\circ} \mathrm{H}_{2} \mathrm{O}\right) \\
\mathrm{P}_{\mathrm{std}} & =\text { standard absolute pressure }(29.92 " \mathrm{Hg})
\end{array}
$$

The dry gas meter calibration coefficient, $\mathrm{Y}$, is determined using a wet test meter before the sampling program. The Y-values are rechecked upon completion of the sampling program; the average change was less than $\pm 0.5 \%$.

The concentration of ammonia in the flue gas sample, $\mathrm{C}_{\mathrm{NH} 3}$, is calculated by:

$$
\mathrm{C}_{\mathrm{NH} 3}=\left(\mathrm{C}_{\mathrm{imp}} \mathrm{V}_{\mathrm{imp}}\right) /\left(20.064\left(\mathrm{~V}_{\mathrm{m}}\right)_{\mathrm{std}}\right)
$$

where:

$$
\begin{aligned}
& \mathrm{C}_{\mathrm{imp}}=\text { the concentration of ammonia in the diluted impinger solution, ppmw as } \mathrm{NH}_{3} \\
& \mathrm{~V}_{\mathrm{imp}}=\text { the volume of the diluted impinger solution, } \mathrm{mL} \\
& \left(\mathrm{V}_{\mathrm{m}}\right)_{\mathrm{std}}=\text { the volume of dry gas sampled corrected to } 29.92{ }^{\circ} \mathrm{Hg} \text { and } 68^{\circ} \mathrm{F} \text {, } \mathrm{std} \mathrm{ft}^{3}
\end{aligned}
$$

\section{5. $\mathrm{SO}_{3}$ Sampling Equipment and Procedure}

Sulfur trioxide (sulfuric acid mist) and sulfur dioxide $\left(\mathrm{SO}_{2}\right)$ emissions (if desired) are measured using a CONSOL R\&D modified EPA "Miniature Acid Condensation System" (MACS). A diagram of the sampling train is presented in Figure 6. Only the quartz absorber was used for the $\mathrm{SO}_{3}$ sampling tests. The flue gas is pulled through the quartz $\mathrm{SO}_{3}$ absorber (or $8 \mathrm{~mm}$ quartz tube) into a glass condenser packed with glass wool. The condenser is maintained at $140^{\circ} \mathrm{F}$ by a circulating water bath. At $140^{\circ} \mathrm{F}, \mathrm{SO}_{3}$ is selectively removed from the flue gas sample by condensation as sulfuric acid $\left(\mathrm{H}_{2} \mathrm{SO}_{4}\right)$. The gas exits the condenser and is conveyed to two impingers containing a $3 \%$ hydrogen peroxide $\left(\mathrm{H}_{2} \mathrm{O}_{2}\right)$ solution, which oxidizes the $\mathrm{SO}_{2}$ to sulfate $\left(\mathrm{SO}_{4}\right)$. A third impinger is empty, and used to collect any droplet carryover from the first two impingers. A fourth impinger contains silica gel to remove water vapor, and protect the downstream sample pump and gas meter. The $\mathrm{SO}_{3}$ absorber, $8 \mathrm{~mm}$ quartz tube, and condenser are rinsed with high purity deionized water; and $\mathrm{SO}_{3}$ determined by barium chloride titration of the rinsings to a thorin endpoint (EPA Method 6). The liquid from the first three impingers is quantitatively recovered with deionized water, and titrated with barium chloride to a thorin endpoint to determine $\mathrm{SO}_{2}$. The sampling procedure (leak testing, sampling, data recording, calculations, etc.) is essentially the same as that described for the $\mathrm{NH}_{3}$ sampling tests. 


\section{Analytical Procedures}

The analytical methods used for this project are recommended by the American Society for Testing and Materials (ASTM), Environmental Protection Agency (EPA), the American Public Health Association, and the Electric Power Research Institute (EPRI).

\section{A. Proximate Analysis - Moisture, Ash}

ASTM D5142-90 Proximate Analysis of the Analysis Sample of Coal and Coke by Instrumental Procedures. Moisture and ash are determined by establishing the loss in mass of a test specimen under rigidly controlled conditions of temperature, time, atmosphere, and specimen mass.

All samples are analyzed in duplicate. Duplicate results must meet ASTM criteria for repeatability. A quality control sample is analyzed along with each batch of test samples. Results for the control sample must be within established limits for the parameters being measured or the results for the entire set of test samples will be rejected and the test procedure is repeated. The R\&D laboratory participates in interlaboratory round-robin programs on a monthly basis to provide an external quality assessment of laboratory data and performance.

\section{B. Ultimate Analysis - Carbon, Hydrogen, Nitrogen}

ASTM D5373-93 Instrumental Determination of Carbon, Hydrogen, and Nitrogen in Laboratory Samples of Coal and Coke. Carbon, hydrogen, and nitrogen are determined concurrently in an instrumental procedure. The procedure provides for the combustion and conversion of the subject elements in an oxygen stream in their entirety to carbon dioxide, water vapor, and nitrogen oxides. Carbon dioxide and water vapor are determined by infrared detection. Nitrogen oxides are reduced to nitrogen and determined by thermal conductivity.

The instrument is calibrated daily by analyzing National Institute for Standards and Technology (NIST) Standard Reference Material 1632b. All samples are analyzed in duplicate. Duplicate results must meet ASTM criteria for repeatability. A quality control sample is analyzed at least once for every ten samples. The results for the control sample must be within established limits for the parameters being measured or the test results obtained up to the last acceptable analyses of the control sample are rejected. The laboratory participates in interlaboratory round-robin programs on a monthly basis to provide an external quality assessment of data and performance.

\section{Sulfur}

\section{ASTM D4239-94 Method C Sulfur in the Analysis Sample of Coal and Coke Using High Temperature Tube Furnace Combustion with Infrared Absorption Detection. A known mass of the test specimen is burned at high temperature in a stream of oxygen. Sulfur in the test specimen is completely converted to sulfur dioxide. The sulfur dioxide is measured by an infrared absorption detector. \\ The equipment is calibrated and verification of the calibration daily by analyzing NIST Certified Coal Standard Reference Materials 2682, 2683a, 2684a, 2685, or 2692. All test specimens are analyzed in duplicate, and duplicate results must meet ASTM criteria for repeatability. A quality control sample is analyzed at least once during each hour the equipment is in operation. The}


result for the control sample must be within established limits or the results for the test specimens analyzed up to the last acceptable analysis of the control sample are rejected. External quality assessment of sulfur data and laboratory performance is provided by monthly participation in interlaboratory round robin programs.

\section{Major Ash Elements Including Phosphates}

(Major Ash Elements analysis includes $\mathrm{Na}_{2} \mathrm{O}, \mathrm{K} 2 \mathrm{O}, \mathrm{MgO}, \mathrm{CaO}, \mathrm{Fe}_{2} \mathrm{O}_{3}, \mathrm{TiO}_{2}, \mathrm{P}_{2} \mathrm{O}_{5}, \mathrm{SiO}_{2}, \mathrm{Al}_{2} \mathrm{O}_{3}$, and $\mathrm{SO}_{3}$ ).

A sample of 60 mesh coal is ashed according to the method outlined in ASTM D3682-78. The resulting ash is pressure-digested using hydrochloric, hydrofluoric and nitric acids.

The concentrations of ten major ash elements are determined by inductively coupled plasmaatomic emission spectroscopy (ICP-AES). All samples are digested and analyzed in duplicate. Duplicate analyses must meet the repeatability limits listed in ASTM D3682-78. A mass balance of 97.5-101.5 weight percent must be obtained for the ten elemental oxides. Samples not meeting this requirement are redigested and reanalyzed.

NIST fly ash 1633a is used to calibrate the ICP-AES. The calibration is checked with a secondary coal ash standard. The calibration is reassessed every eight samples by analyzing a quality control standard. The instrument is recalibrated as required.

\section{E. Carbonate $\left(\mathrm{CO}_{3}\right)$}

A sample is analyzed for carbonate using the Coulometrics, Inc. Carbon Dioxide Coulometer. The sample is acidified to release $\mathrm{CO}_{2}$. The $\mathrm{CO}_{2}$ is carried by an inert gas stream to a coulometer cell filled with a partially aqueous, proprietary solution containing monoethanolamine and a colorimetric indicator. A platinum cathode and a silver anode are positioned in the cell and the assembly is positioned between a light source and a photodetector in the coulometer. As the gas stream passes through the solution, $\mathrm{CO}_{2}$ is quantitatively absorbed, reacting with the monoethanolamine to form a titratable, organic acid. The acid causes the color indicator to fade. Photodetection monitors the change in the solutions's color as percent transmittance $(\% \mathrm{~T})$. As the $\% \mathrm{~T}$ increases, the titration current is automatically activated to stoichiometrically generate a base at a rate proportional to the $\% \mathrm{~T}$. When the solution returns to its original color (original $\% \mathrm{~T}$ ), the current stops. The titration current is continuously measured and integrated to units of $\mathrm{CO}_{3}$.

\section{F. $\mathrm{Na}_{2} \mathrm{CO}_{3}, \mathrm{NaHCO}_{3}$}

The amount of sodium carbonate and sodium bicarbonate in the sorbents are calculated from the ratio of carbonate $\left(\mathrm{CO}_{3}\right)$ to sodium $(\mathrm{Na})$ in the samples. For example, pure $\mathrm{Na}_{2} \mathrm{CO}_{3}$ and pure $\mathrm{NaHCO}_{3}$ have stoichiometric $\mathrm{CO}_{3} / \mathrm{Na}$ ratios of 1.305 and 2.611 , respectively. The ratio varies between these two values as the concentration of $\mathrm{Na}_{2} \mathrm{CO}_{3}$ and $\mathrm{NaHCO}_{3}$ changes. Knowing the analytically-determined $\mathrm{CO}_{3}$ and $\mathrm{Na}$ concentrations in the sample, the concentration of the carbonate and bicarbonate compounds can be determined from a plot of the ratio of $\mathrm{Na}_{2} \mathrm{CO}_{3}$ to $\mathrm{NaHCO}_{3}$ as a function of the $\mathrm{CO}_{3} / \mathrm{Na}$ ratio. 


\section{RESULTS AND DISCUSSION}

\section{Ammonia Sampling Tests}

The conditions and results of the $\mathrm{NH}_{3}$ sampling tests are presented in Table 2. The tests were conducted to determine if the sorbent chosen for an $\mathrm{SO}_{3}$ absorber would have any effect on the $\mathrm{NH}_{3}$ concentration in the flue gas sample. The purpose of the absorber is to remove $100 \%$ of the $\mathrm{SO}_{3}$ from the flue gas sample being sent to an extractive-type continuous $\mathrm{NH}_{3}$ analyzer. Sulfur trioxide $\left(\mathrm{SO}_{3}\right)$ reacts with $\mathrm{NH}_{3}$ in the flue gas to form ammonium bisulfate $\left(\mathrm{NH}_{4} \mathrm{HSO}_{4}\right)$. ${ }^{2}$ The ammonium bisulfate can condense in the sampling line of an analyzer, or in the analyzer itself, resulting in erroneous low analyzer $\mathrm{NH}_{3}$ readings. The sorbent used for capturing $\mathrm{SO}_{3}$ must not react with the $\mathrm{NH}_{3}$ in the gas sample, which would also result in erroneously low analyzer readings.

The initial four tests were conducted with the stainless steel absorber vessel (Figure 1). In Tests 1 and 2 , the sorbent was a mixture of Ca-based $(\mathrm{CaO})$ and $\mathrm{Na}$-based $\left(\mathrm{Na}_{2} \mathrm{CO}_{3} / \mathrm{NaHCO}_{3}\right)$ compounds; 18 " of $\mathrm{CaO}$ followed by 6" of $\mathrm{Na}_{2} \mathrm{CO}_{3} / \mathrm{NaHCO}_{3}$. The results showed an undesirable $\mathrm{NH}_{3}$ capture of 13 to $47 \%$. Test $3 \mathrm{~A}$, conducted with just $\mathrm{CaO}$, produced a $93 \% \mathrm{NH}_{3}$ capture. Based on these results, it appears that quicklime (at least the Mississippi quicklime used in this study) is not suitable as an $\mathrm{SO}_{3}$ sorbent. It is surprising that a compound such as quicklime, that is known for acid gas $\left(\mathrm{SO}_{2}, \mathrm{CO}_{2}, \mathrm{HCl}\right.$, etc.) removal, would react so extensively with a basic compound such as $\mathrm{NH}_{3}$. However, $\mathrm{NH}_{3}$ is a very reactive gas. For example, studies ${ }^{3}$ have shown that compounds of certain metals (magnesium, iron, aluminum) can react with $\mathrm{NH}_{3}$ to form nitrate $\left(\mathrm{NO}_{3}{ }^{-1}\right)$ and/or nitride $\left(\mathrm{N}^{-3}\right)$ compounds. These metals are present in the quicklime (Table 1). The potential nitrates or nitrides could be retained, partially at least, in the sorbent bed. It would not require a large amount of impurities to account for the $\mathrm{NH}_{3}$ removal shown in these tests. For example, in Test $3 \mathrm{~A}$, the $27 \mathrm{ppmv}$ of $\mathrm{NH}_{3}$ captured by the sorbent is only $14 \times 10^{-5}$ mols $(0.0024$ grams) of $\mathrm{NH}_{3}$. An $800 \mathrm{cc}$ bed of quicklime sorbent, the volume used in the stainless absorber, is approximately 840 grams of quicklime. This amount of quicklime contains $0.031,0.015$, and 0.156 mols of $\mathrm{Al}, \mathrm{Fe}$, and $\mathrm{Mg}$, respectively, more than enough of these impurities to react with the $27 \mathrm{ppm}$ of $\mathrm{NH}_{3}$ removed in test $3 \mathrm{~A}$.

Test 4 was conducted with an empty stainless steel absorber vessel (no sorbent). The results showed a small removal of the $\mathrm{NH}_{3}(11 \%)$. Even though the difference between the vessel inlet $\mathrm{NH}_{3}$ (28 ppmv) and vessel exit $\mathrm{NH}_{3}(25 \mathrm{ppmv})$ can be attributed, in part at least, to experimental error, it could also indicate some reaction taking place between the metal and $\mathrm{NH}_{3}$. Test 6 , conducted with an empty quartz vessel, showed no removal of $\mathrm{NH}_{3}$. This is expected based on the chemically inert properties of quartz, and indicates that this material would be preferred over stainless as an $\mathrm{SO}_{3}$ absorber material.

Test 5 was conducted with the quartz absorber vessel packed with quicklime. The test resulted in a $43 \%$ capture of $\mathrm{NH}_{3}$, again showing Mississippi quicklime $(\mathrm{CaO})$ as a poor sorbent for an $\mathrm{SO}_{3}$ absorber.

Tests 7, 8, and 9 were conducted with the quartz absorber and $\mathrm{Na}_{2} \mathrm{CO}_{3} / \mathrm{NaHCO}_{3}$ mix as the sorbent. None of the three tests showed any $\mathrm{NH}_{3}$ capture by the Na-based sorbent. This may be due to the presence of substantially less metal $(\mathrm{Mg}, \mathrm{Al}, \mathrm{Fe})$ impurities in the Na-based sorbent 
than in the Ca-based sorbent (Table 1). The results from tests 7, 8, and 9 do, however, show slightly higher $\mathrm{NH}_{3}$ concentrations at the absorber exit than at the absorber inlet. Possible explanations for this could be $\mathrm{NH}_{3}$ stratification in the flue gas duct; or a loss of $\mathrm{NH}_{3}$ from ammonium compounds that formed in the flue gas, and condensed in the cold sections of the inlet gas sampling train. Stratification would not seem likely since the gas inlet to the absorber and inlet to the absorber bypass (Figure 1) are in such close proximity. A condensation of and partial loss of ammonium compounds in the absorber inlet sampling lines would appear to be more likely. There was clearly a deposit formation in the $8 \mathrm{~mm}$ quartz tube and Teflon tubing of the absorber inlet sampling train (Figures 1 and 5). This may have been ammonium bisulfate $\left(\mathrm{NH}_{4} \mathrm{HSO}_{4}\right)$ formed by a reaction of the flue gas $\mathrm{NH}_{3}$ and $\mathrm{SO}_{3}$, and condensing in the cold sections of the sampling train. Since ammonium salts can decompose, even at room temperature, $\mathrm{NH}_{3}$ could have been lost during the time period between the sampling test and the deionized water rinsing of these lines. In some cases, as long as a half hour elapsed between the sampling test and the rinsing procedure. The quartz absorber vessel (Figure 4) and associated absorber exit sample lines (Figure 5) showed no evidence of a deposit, indicating that the $\mathrm{SO}_{3}$ was being removed by the sorbent, and consequently, not forming $\mathrm{NH}_{4} \mathrm{HSO}_{4}$.

Tests 10, 11, and 12 were made with the quartz absorber vessel and a mix of $\mathrm{Na}_{2} \mathrm{CO}_{3}$ and $\mathrm{NaHCO}_{3}$ as the sorbent. The difference between tests 7, 8, and 9 and tests 10 through 12 was that in the last three tests, the $8 \mathrm{~mm}$ quartz tube and Teflon tubing of the absorber inlet sampling train were immediately rinsed after sampling. This was done to prevent any possible volatilization of condensed ammonia compounds. Also, the rinsing medium was the dilute $(0.01 \mathrm{~N})$ nitric acid solution used in the impingers. The somewhat stronger acidic solution was used instead of the normal deionized water rinse in the event that the condensed $\mathrm{NH}_{3}$ compounds were adhering to the quartz and/or Teflon tubing. Tests 10,11 , and 12 showed essentially the same $\mathrm{NH}_{3}$ concentration at the absorber inlet and exit. In test 10 , the inlet and exit $\mathrm{NH}_{3}$ concentrations were 38 and 39 ppmv, respectively. In test 11, the inlet and exit $\mathrm{NH}_{3}$ concentrations were 36 and 37 ppmv, respectively. In test 12, the inlet and exit $\mathrm{NH}_{3}$ concentrations were 26 and 28 ppmv, respectively. These small differences between the inlet and exit are well within experimental error. They could also indicate that there was still a small decomposition of $\mathrm{NH}_{3}$ compounds in the absorber inlet sample train prior to recovery. Regardless, the results strongly indicate that the Na-based sorbent does not react with flue gas $\mathrm{NH}_{3}$; and from an $\mathrm{NH}_{3}$ capture standpoint, is preferred over the quicklime as $\mathrm{SO}_{3}$ absorber sorbent.

\section{$\mathrm{SO}_{3} / \mathrm{SO}_{2}$ Sampling}

The summarized conditions and results of the $\mathrm{SO}_{3} / \mathrm{SO}_{2}$ sampling tests are presented in Table 3 . Detailed sampling data, flue gas conditions, and results are presented in Appendix A. The results show that the $\mathrm{Na}_{2} \mathrm{CO}_{3} / \mathrm{NaHCO}_{3}$ mix is a very promising sorbent for an $\mathrm{SO}_{3}$ absorber. Two sampling tests, each conducted at the absorber inlet and exit showed $92 \%$ to $98 \% \mathrm{SO}_{3}$ removal. The flue gas (absorber inlet) $\mathrm{SO}_{3}$ content ranged from 4.6 to $9.0 \mathrm{ppm}$. The absorber exit $\mathrm{SO}_{3}$ content ranged from 0.2 to $0.3 \mathrm{ppm}$. This small concentration of $\mathrm{SO}_{3}$ at the absorber exit is insignificant, and may be due to experimental error. Regardless, it would have essentially no effect on any $\mathrm{NH}_{3}$ present in an $\mathrm{NH}_{3}$ analyzer sampling system (Reaction 5). 
Sampling tests 1 and 2 (Table 3) were conducted without and with flue gas $\mathrm{NH}_{3}$ spiking, respectively. The flue gas $\mathrm{SO}_{3}$ contents without and with $\mathrm{NH}_{3}$ present were 9.0 and 4.6, respectively. The lower $\mathrm{SO}_{3}$ content with $\mathrm{NH}_{3}$ present may be due to a reaction of the two gas components to form ammonium bisulfate $\left(\mathrm{NH}_{4} \mathrm{HSO}_{4}\right.$-Reaction 5), which could condense on the fly ash and/or the cooler (water-jacketed) walls of the combustor convection pass.

The results show that the sodium-based sorbent was not only efficient in capturing essentially all of the $\mathrm{SO}_{3}$, but also captured $100 \%$ of the $\mathrm{SO}_{2}$. This is a positive feature with regard to the use of this type of absorber in an $\mathrm{NH}_{3}$ analyzer sample conditioning train. Some analyzers encounter an interference problem when the $\mathrm{SO}_{2}$ content in the sample becomes too high. This complete $\mathrm{SO}_{2}$ capture also ensures complete $\mathrm{SO}_{3}$ capture: in desulfurization tests, $\mathrm{SO}_{3}$ has been found to be several times more reactive than $\mathrm{SO}_{2} .{ }^{4}$

The $\mathrm{SO}_{3} / \mathrm{SO}_{2}$ sampling tests were conducted with the quartz absorber vessel. No sulfur removal tests were conducted with the quicklime sorbent, because of its reactivity with $\mathrm{NH}_{3}$.

\section{RECOMMENDATIONS FOR FUTURE WORK}

- The quartz absorber, containing $\mathrm{Na}_{2} \mathrm{CO}_{3} / \mathrm{NaHCO}_{3}$ sorbent, should be tested in the sampling train of an $\mathrm{NH}_{3}$ analyzer(s) to determine if the $\mathrm{SO}_{3}$ capture has a beneficial effect on analyzer performance.

- A life study should be conducted with the $\mathrm{SO}_{3}$ absorber to determine the volume of flue gas it can treat before $\mathrm{SO}_{\mathrm{x}}$ break through occurs. In a commercial application, this information would aid the operator in knowing when to repack or change the absorber.

\section{REFERENCES}

1. Rosenhoover, W. A., "Literature Analysis: Sorbents for Sulfur Trioxide $\left(\mathrm{SO}_{3}\right)$ Capture," Supplied to GPU Generation Corp. by CONSOL, Inc. R\&D, Cover letter from W. A. Rosen- hoover to J. Urbas, Jan. 26, 1998.

2. Shale, C. C.; Simpson, D. G.; and Lewis, P. S., "Removal of Sulfur and Nitrogen Oxides from Stack Gases by Ammonia," Chemical Engineering Progress Symposium Series, 115(67).

3. Mellor, J. W., "A Comprehensive Treatise on Inorganic and Theoretical Chemistry," Vol. VIII, 205-225.

4. Leppard, W. R., "Sulfate Control Technology Assessment, Phase I: Literature Search and Analysis," Prepared for the Environmental Protection Agency by Exxon Research and Engineering Co., Contract No. 68-03-0497, November 1974. 
TABLE 1

ANALYSES OF SORBENTS

\begin{tabular}{|c|c|c|c|}
\hline & $\begin{array}{c}\text { Mississippi } \\
\text { Quicklime }\end{array}$ & $\begin{array}{c}\text { Sodium } \\
\text { Carbonate }\end{array}$ & $\begin{array}{c}\text { Treated } \\
\text { Sodium } \\
\text { Carbonate (a) }\end{array}$ \\
\hline $\begin{array}{l}\text { Moisture,wt\% } \\
\mathrm{CO}_{3}, \text { wt\% (dry) } \\
\mathrm{Na}_{2} \mathrm{CO}_{3} \text { (dry) } \\
\mathrm{NaHCO}_{3} \text { (dry) }\end{array}$ & $\begin{array}{c}0.01 \\
0.21 \\
- \\
- \\
\end{array}$ & $\begin{array}{c}0.48 \\
56.40 \\
96.1 \\
2.8 \\
\end{array}$ & $\begin{array}{l}13.94 \\
62.1 \\
59.8 \\
39.3 \\
\end{array}$ \\
\hline $\begin{array}{c}\text { Proximate wt\% (dry) } \\
\text { Ash } \\
\text { Total Sulfur }\end{array}$ & $\begin{array}{c}98.80 \\
0.02\end{array}$ & $\begin{array}{c}58.84 \\
0.01\end{array}$ & - \\
\hline $\begin{array}{c}\text { Ultimate wt\% (dry) } \\
\text { Carbon } \\
\text { Hydrogen } \\
\text { Nitrogen } \\
\text { Ash }\end{array}$ & $\begin{array}{c}0.12 \\
0.15 \\
0.01 \\
98.80\end{array}$ & $\begin{array}{l}10.40 \\
0.11 \\
0.01 \\
58.84\end{array}$ & $\begin{array}{l}- \\
- \\
-\end{array}$ \\
\hline $\begin{array}{l}\text { Ash Elements, wt\% of Ash } \\
\mathrm{SiO}_{2} \\
\mathrm{Al}_{2} \mathrm{O}_{3} \\
\mathrm{TiO}_{2} \\
\mathrm{Fe}_{2} \mathrm{O}_{3} \\
\mathrm{CaO} \\
\mathrm{MgO} \\
\mathrm{Na}_{2} \mathrm{O} \\
\mathrm{K}_{2} \mathrm{O} \\
\mathrm{P}_{2} \mathrm{O}_{5} \\
\mathrm{SO}_{3} \\
\mathrm{UND}\end{array}$ & $\begin{array}{l}1.32 \\
0.19 \\
0.02 \\
0.14 \\
97.4 \\
0.76 \\
0.02 \\
0.01 \\
0.02 \\
0.04 \\
0.08\end{array}$ & $\begin{array}{c}0.03 \\
0.02 \\
0.01 \\
0.02 \\
0.05 \\
0.01 \\
57.21 \\
0.01 \\
0.01 \\
0.02 \\
42.65\end{array}$ & $\begin{array}{l}- \\
- \\
- \\
- \\
- \\
- \\
- \\
- \\
-\end{array}$ \\
\hline
\end{tabular}

(a) Treated with $\mathrm{CO}_{2}$ under high humidity conditions. 
Table 2

AMMONIA SAMPLING TESTS

R\&D PILOT COMBUSTOR

\begin{tabular}{|c|c|c|c|c|c|c|}
\hline \multirow[b]{2}{*}{$\begin{array}{c}\text { TEST } \\
\text { NO. }\end{array}$} & \multirow{2}{*}{$\begin{array}{c}\text { FLUE } \\
\text { GAS } \\
\text { TEMP, }^{\circ} \mathbf{F}\end{array}$} & \multirow[b]{2}{*}{$\begin{array}{l}\text { ABSORBER } \\
\text { VESSEL }\end{array}$} & \multirow[b]{2}{*}{ SORBENT (a) } & \multicolumn{2}{|c|}{$\mathrm{NH}_{3}$ CONCENTRATION, ppmv } & \multirow{2}{*}{$\begin{array}{c}\% \\
\mathrm{NH}_{3} \\
\text { REMOVED }\end{array}$} \\
\hline & & & & $\begin{array}{c}\text { ABSORBER } \\
\text { INLET } \\
\end{array}$ & $\begin{array}{c}\text { ABSORBER } \\
\text { EXIT }\end{array}$ & \\
\hline 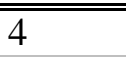 & 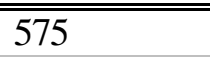 & STAINLESS & NONE & 28 & 25 & 11 \\
\hline 1 & 665 & STAINLESS & QL/Na MIX & 15 & 13 & 13 \\
\hline 2 & 690 & STAINLESS & QL/Na MIX & 17 & 9 & 47 \\
\hline $3 \mathrm{~A}$ & 555 & STAINLESS & QUICKLIME & 29 & 2 & 93 \\
\hline 6 & 540 & QUARTZ & NONE & 23 & 23 & 0 \\
\hline 5 & 560 & QUARTZ & QUICKLIME & 23 & 13 & 43 \\
\hline 7 & 650 & QUARTZ & $\mathrm{Na}$ MIX & 24 & 30 & - \\
\hline 8 & 690 & QUARTZ & $\mathrm{Na} \mathrm{MIX}$ & 30 & 34 & - \\
\hline 9 & 765 & QUARTZ & Na MIX & 30 & 32 & - \\
\hline 10 & 740 & QUARTZ & $\mathrm{Na} \mathrm{MIX}$ & 38 & 39 & - \\
\hline 11 & 746 & QUARTZ & $\mathrm{Na}$ MIX & 36 & 37 & - \\
\hline 12 & 710 & QUARTZ & Na MIX & 26 & 28 & - \\
\hline
\end{tabular}

(a) QL/Na MIX = QUICKLIME + Na MIX

QUICKLIME $=$ calcitic quicklime $(\mathrm{CaO})$

$\mathrm{Na} \mathrm{MIX}=$ mix of sodium carbonate $\left(\mathrm{Na}_{2} \mathrm{CO}_{3}\right)$ and sodium bicarbonate $\left(\mathrm{NaHCO}_{3}\right)$

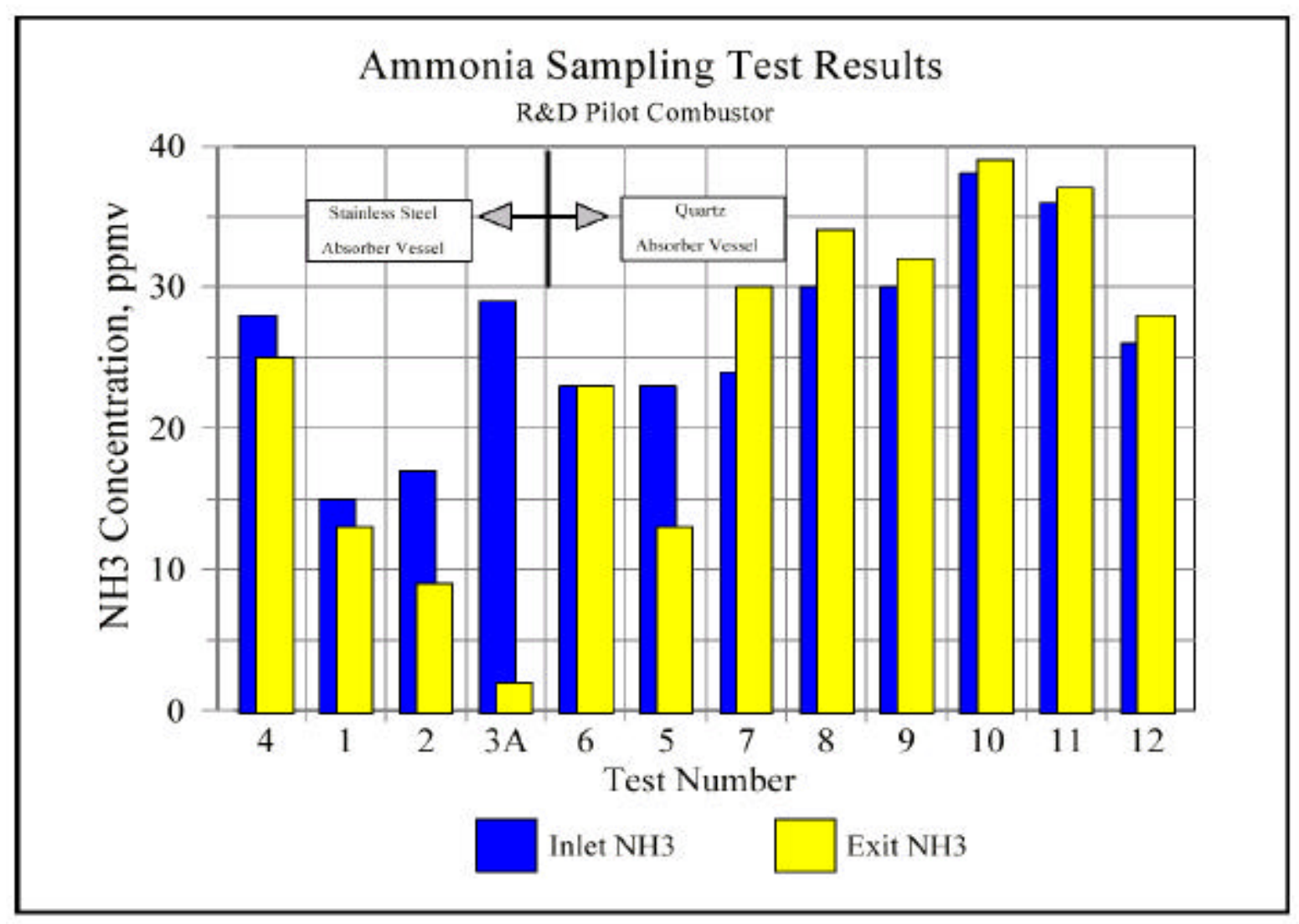


Table 3

\section{$\mathrm{SO}_{2} \mathrm{AND} \mathrm{SO}_{3} \mathrm{SAMPLING} \mathrm{TESTS}$ \\ R\&D PILOT COMBUSTOR \\ QUARTZ ABSORBER VESSEL \\ SORBENT: Na MIX (a)}

\begin{tabular}{|c|c|c|c|c|c|c|c||}
\hline \multirow{2}{*}{$\begin{array}{c}\text { TEST } \\
\text { NO. (b) }\end{array}$} & $\begin{array}{c}\text { FLUE } \\
\text { GAS } \\
\text { TEMP, }\end{array}{ }^{\circ}$ F & \multicolumn{3}{|c|}{ SO $_{2}$} & \multicolumn{3}{c||}{ ISO $_{3}$} \\
\hline 1 & 690 & 2,688 & 0 & 100 & 9.0 & 0.2 & 98 \\
\hline 2 & 711 & 2,625 & 0 & 100 & 4.6 & 0.3 & 94 \\
\hline
\end{tabular}

(a) $\mathrm{Na} \mathrm{MIX}=$ mix of sodium carbonate $\left(\mathrm{Na}_{2} \mathrm{CO}_{3}\right)$ and sodium bicarbonate $\left(\mathrm{NaHCO}_{3}\right)$

(b) Test 1 was made without $\mathrm{NH}_{3}$ spiking of the flue gas.

Test 2 was made with $\mathrm{NH}_{3}$ spiking. 

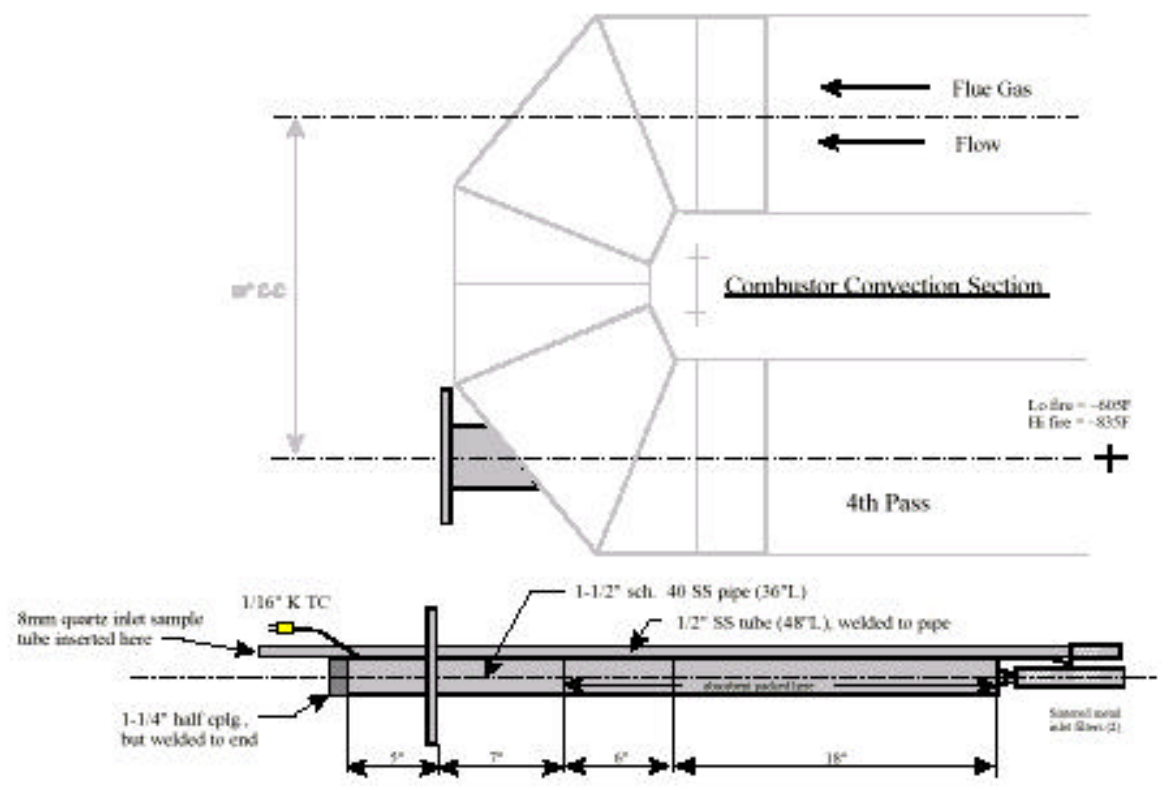

Figure 1

Stainless Steel SOs Absorber Vessel and Sampling Location 
Figure 2

NH3 Injection Hardware - SO3 Absorber
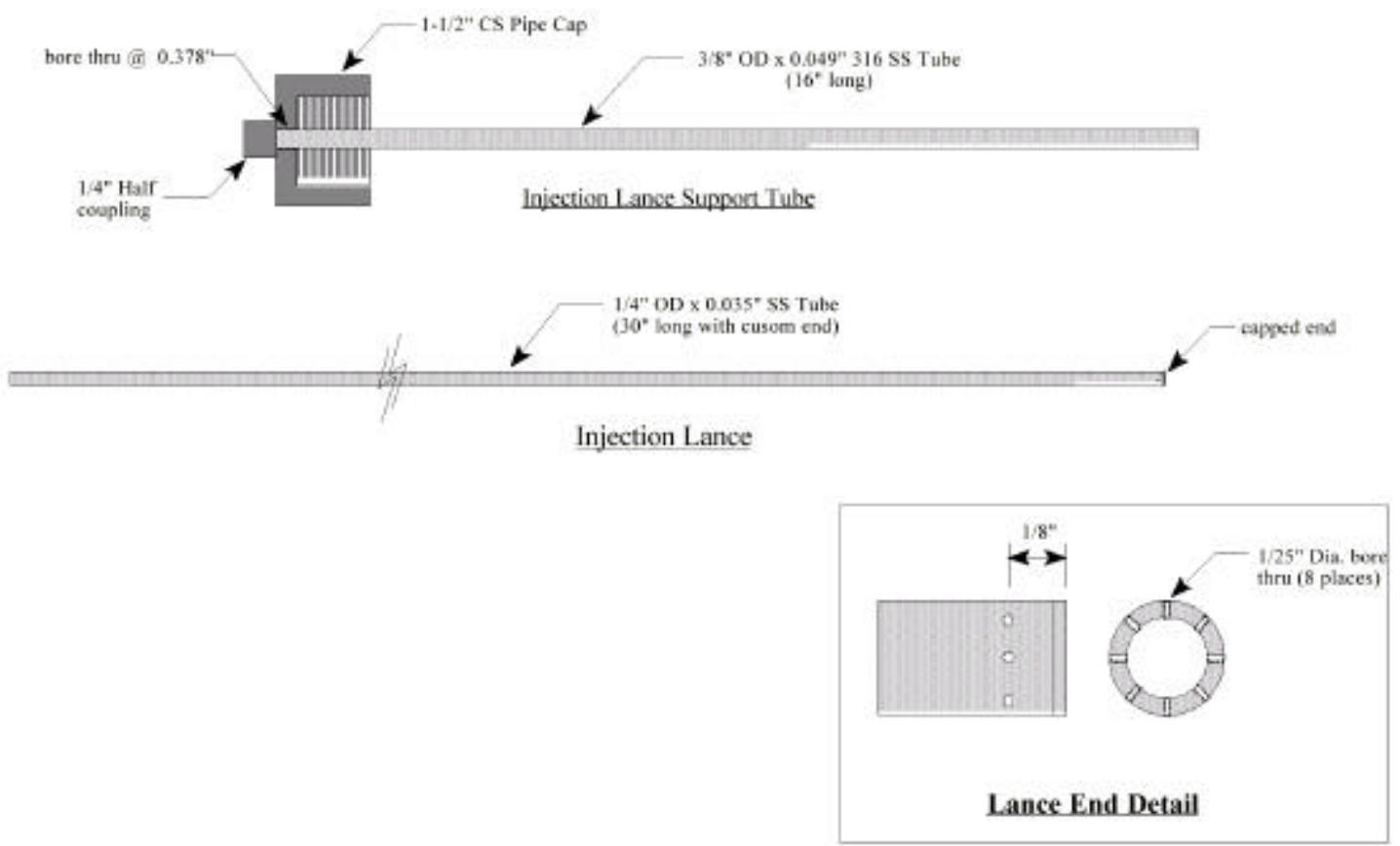


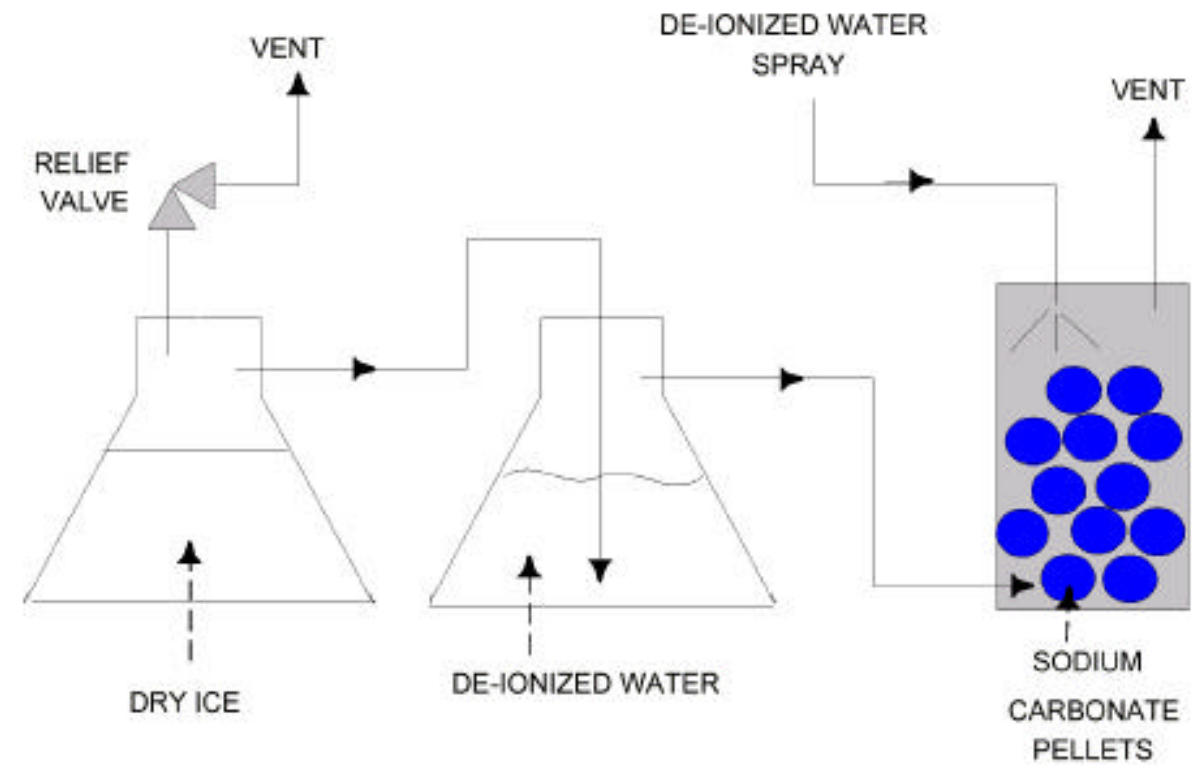

FIGURE 3

APPARATUS FOR SODIUM BICARBONATE PRODUCTION 

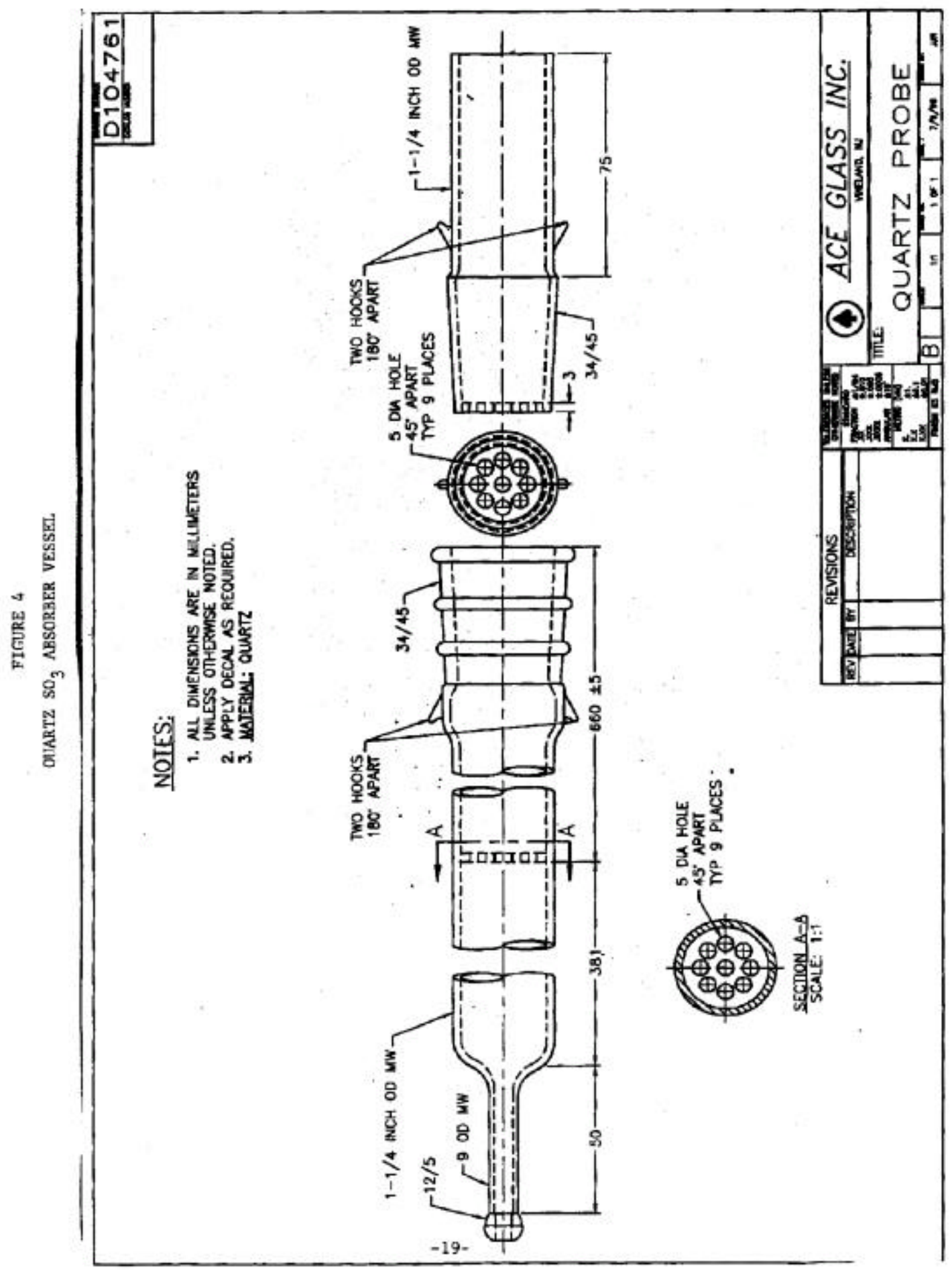
FIGURE 5

CONBOL RED AMMONIA SAMPLING TRAIN

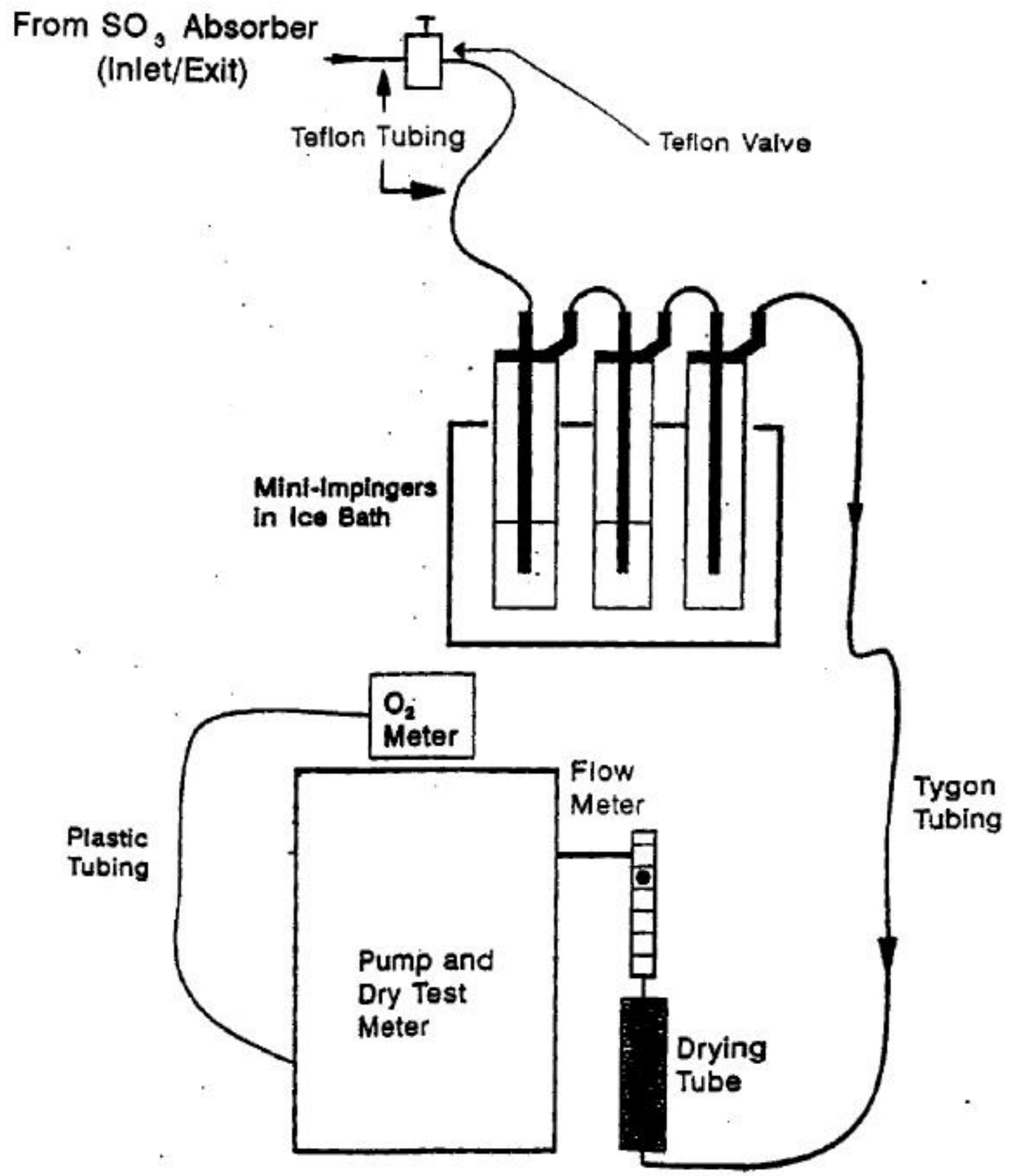




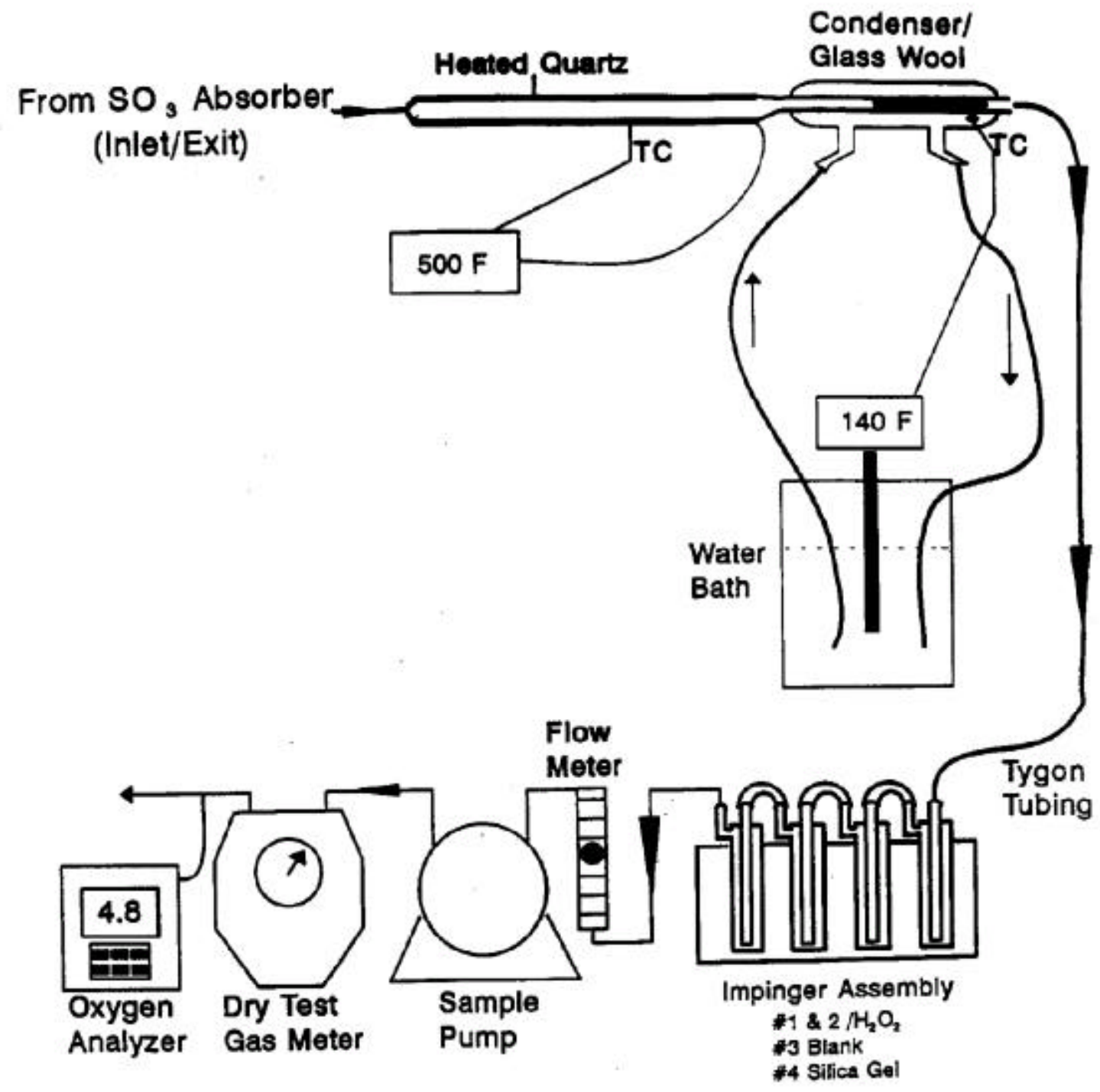

FIGURE 6

CONSOL R\&D Controlled Condenaation SO, Sampling Train 


\section{Figure 7}

Photos of quartz vessel/sample tube
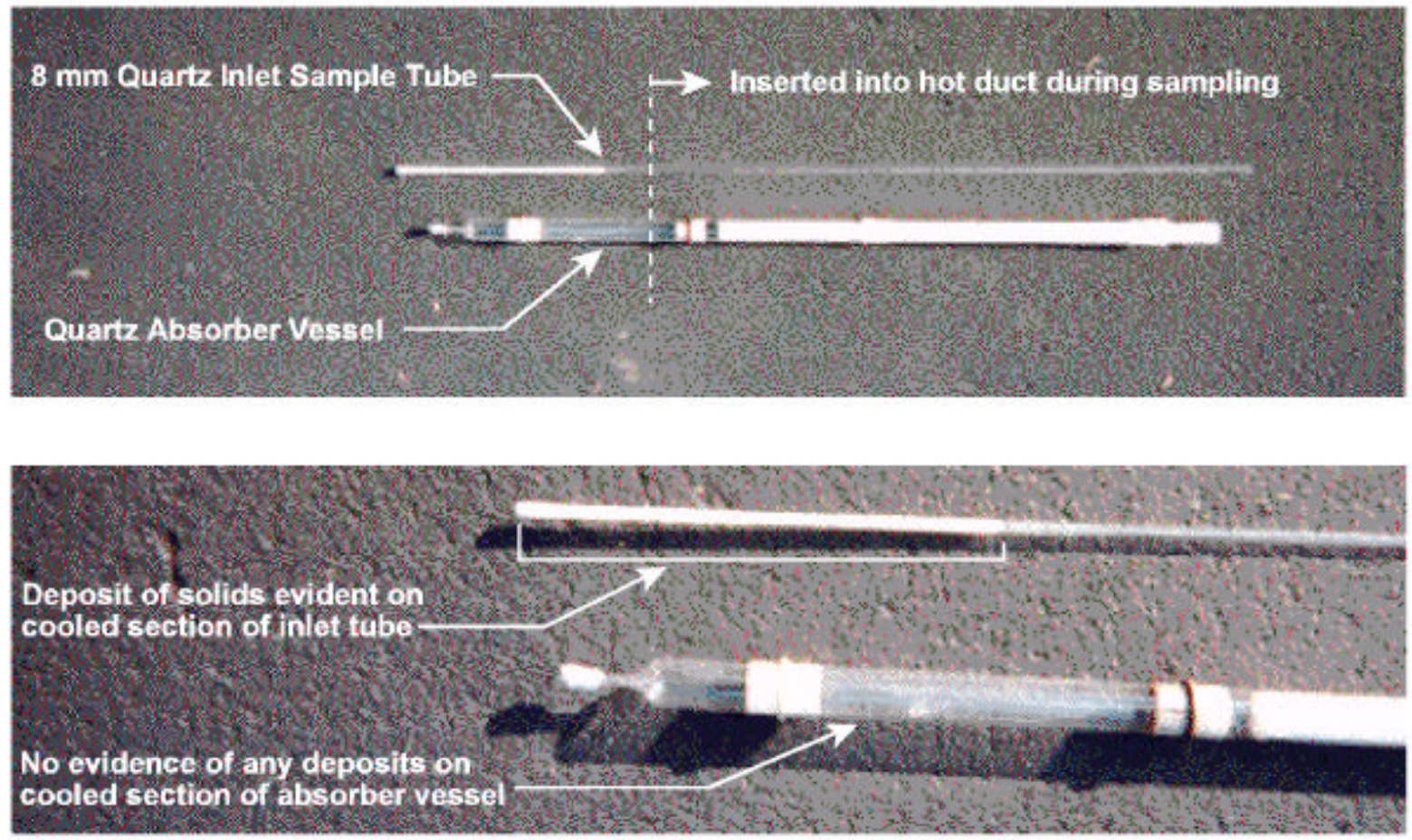


\section{APPENDIX A}

\section{FIELD DATA SHEETS AND ANALYTICAL RESULTS}

$\mathrm{NH}_{3}$ AND $\mathrm{SO}_{3} / \mathrm{SO}_{2}$ SAMPLING TESTS 


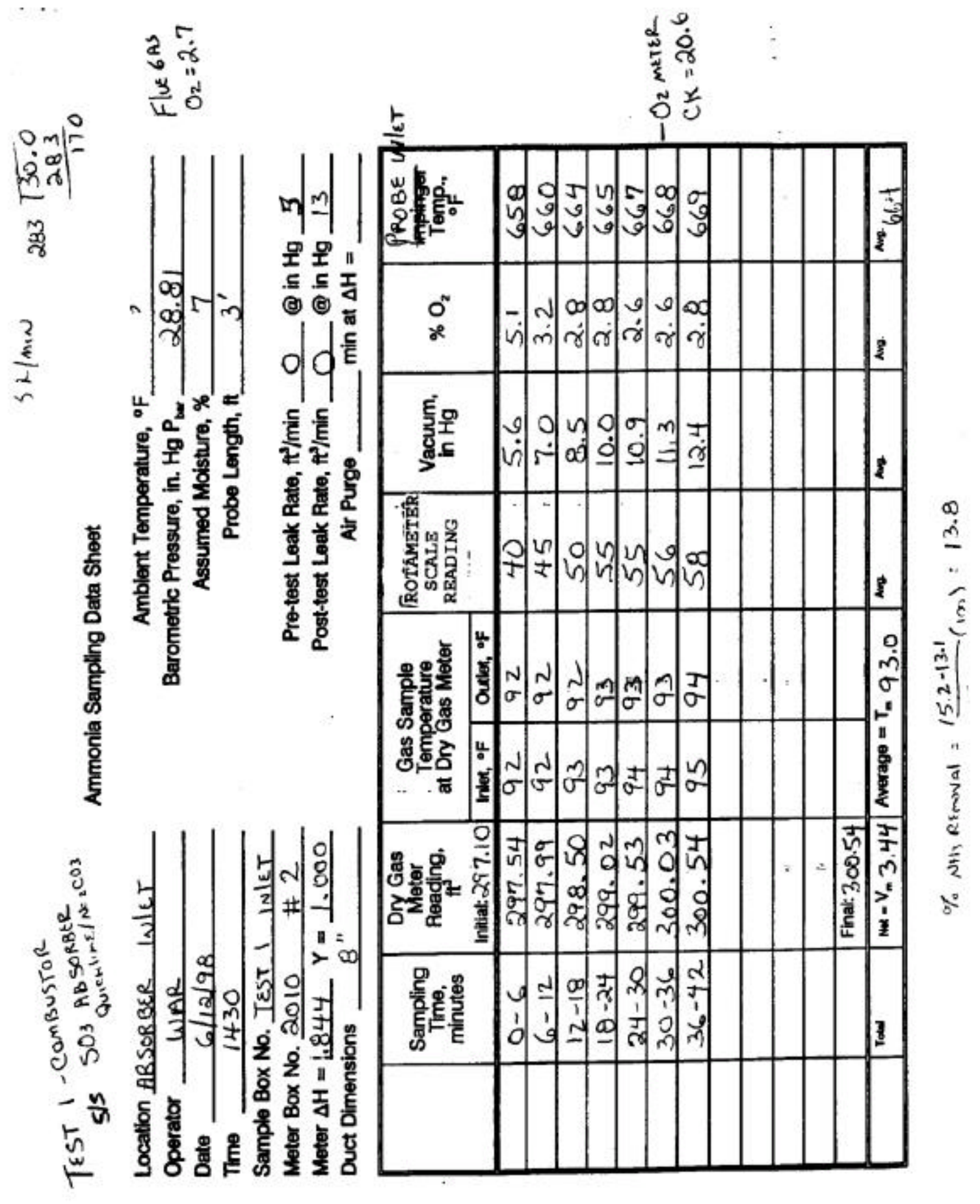




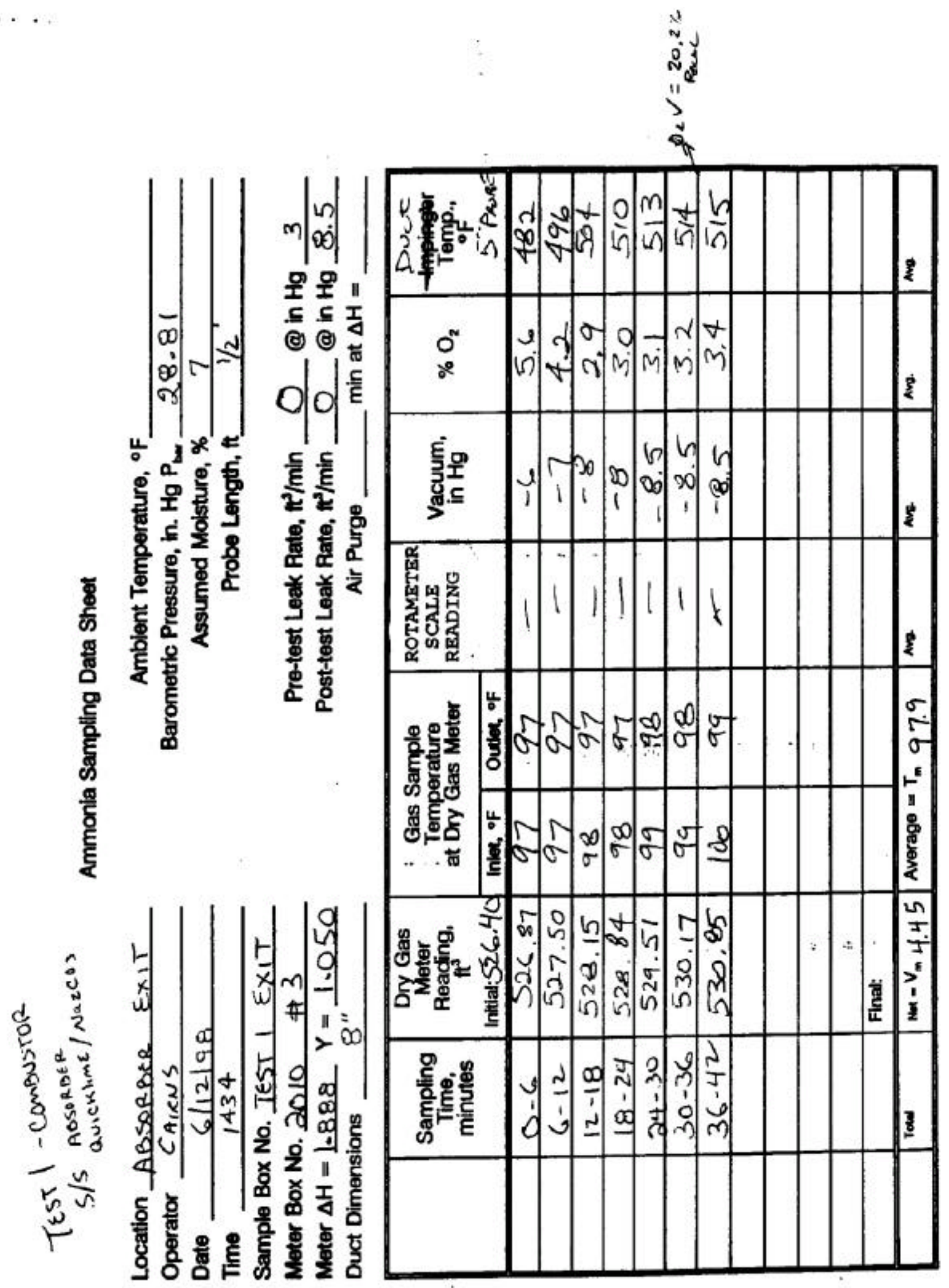




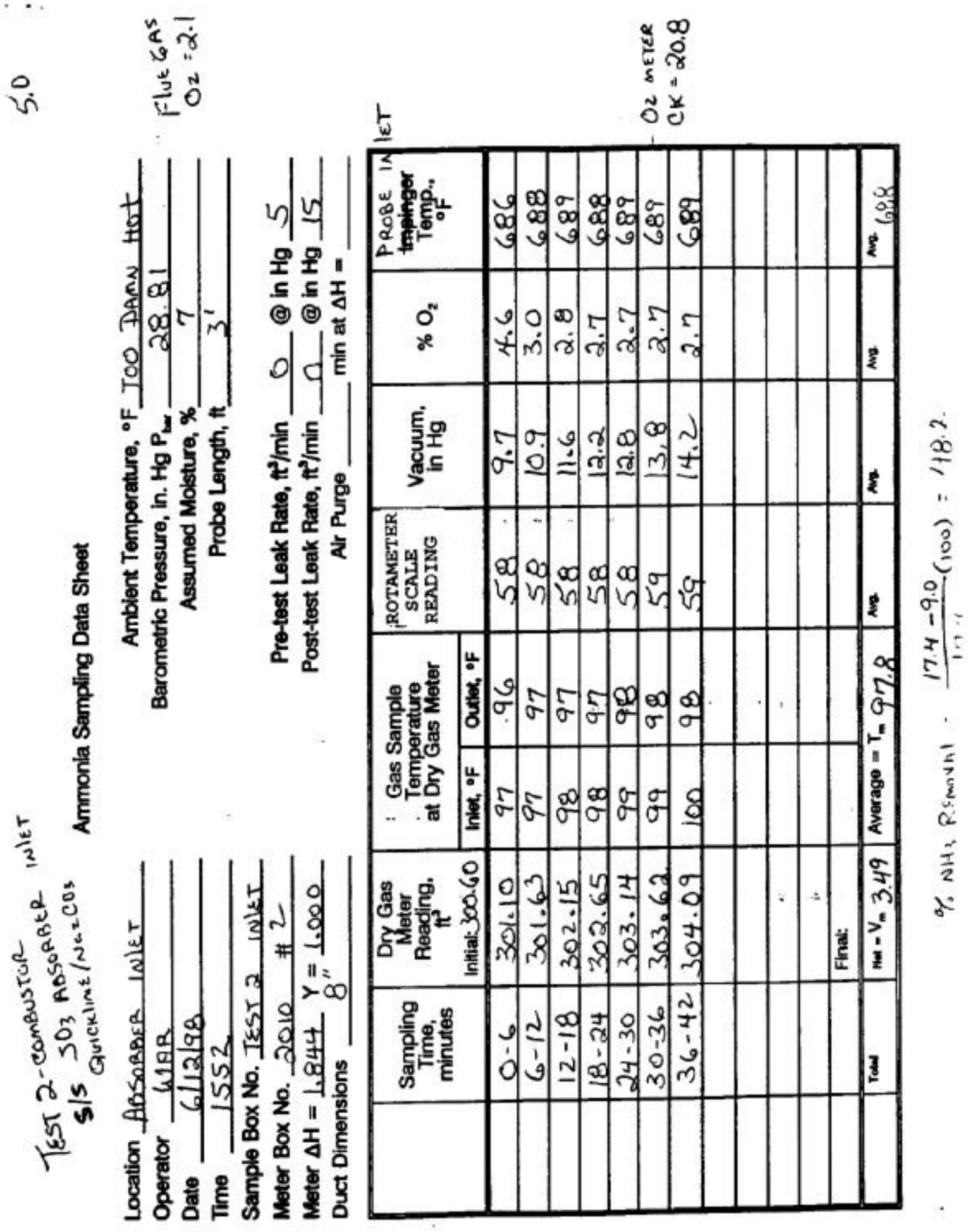




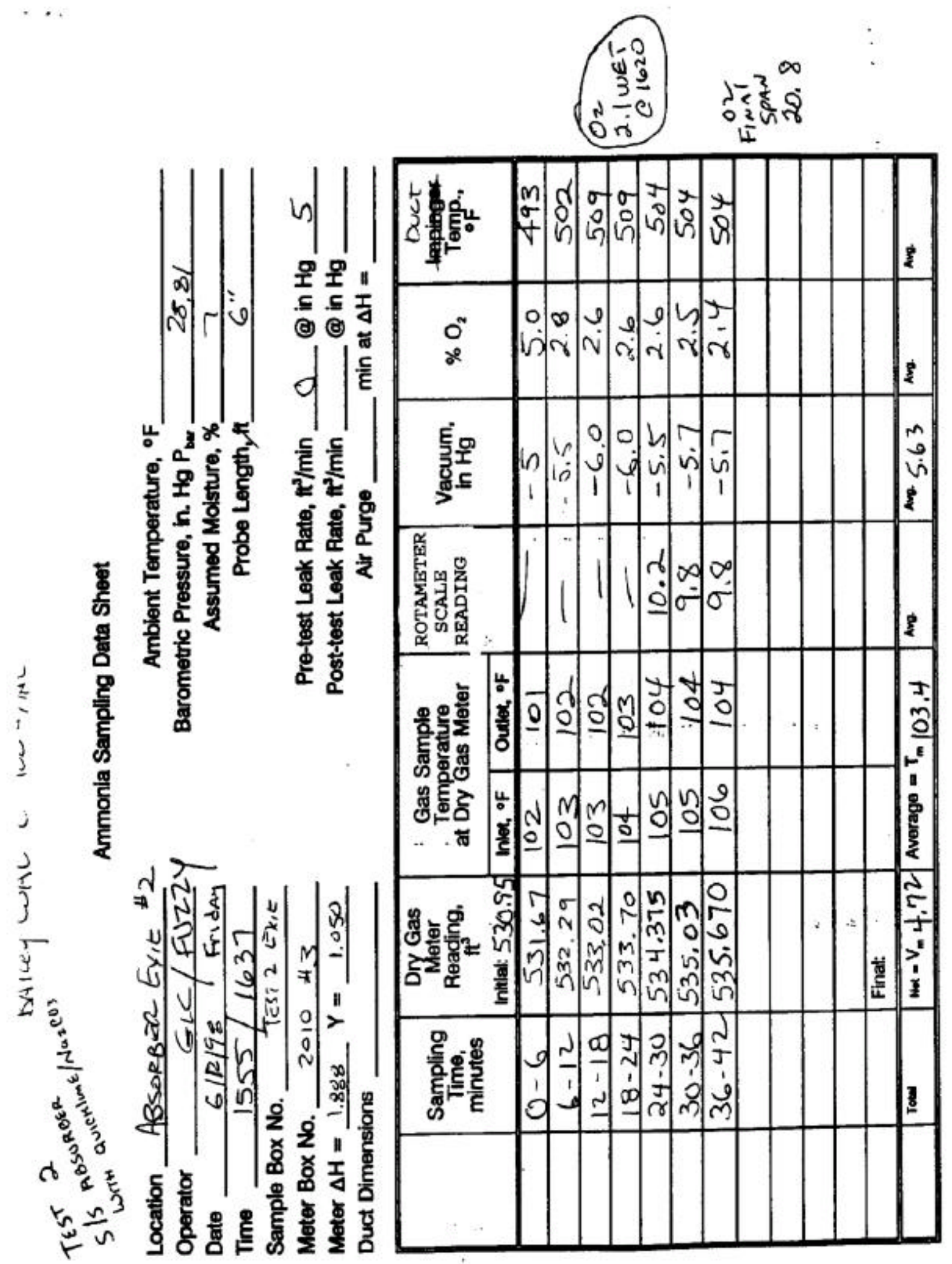




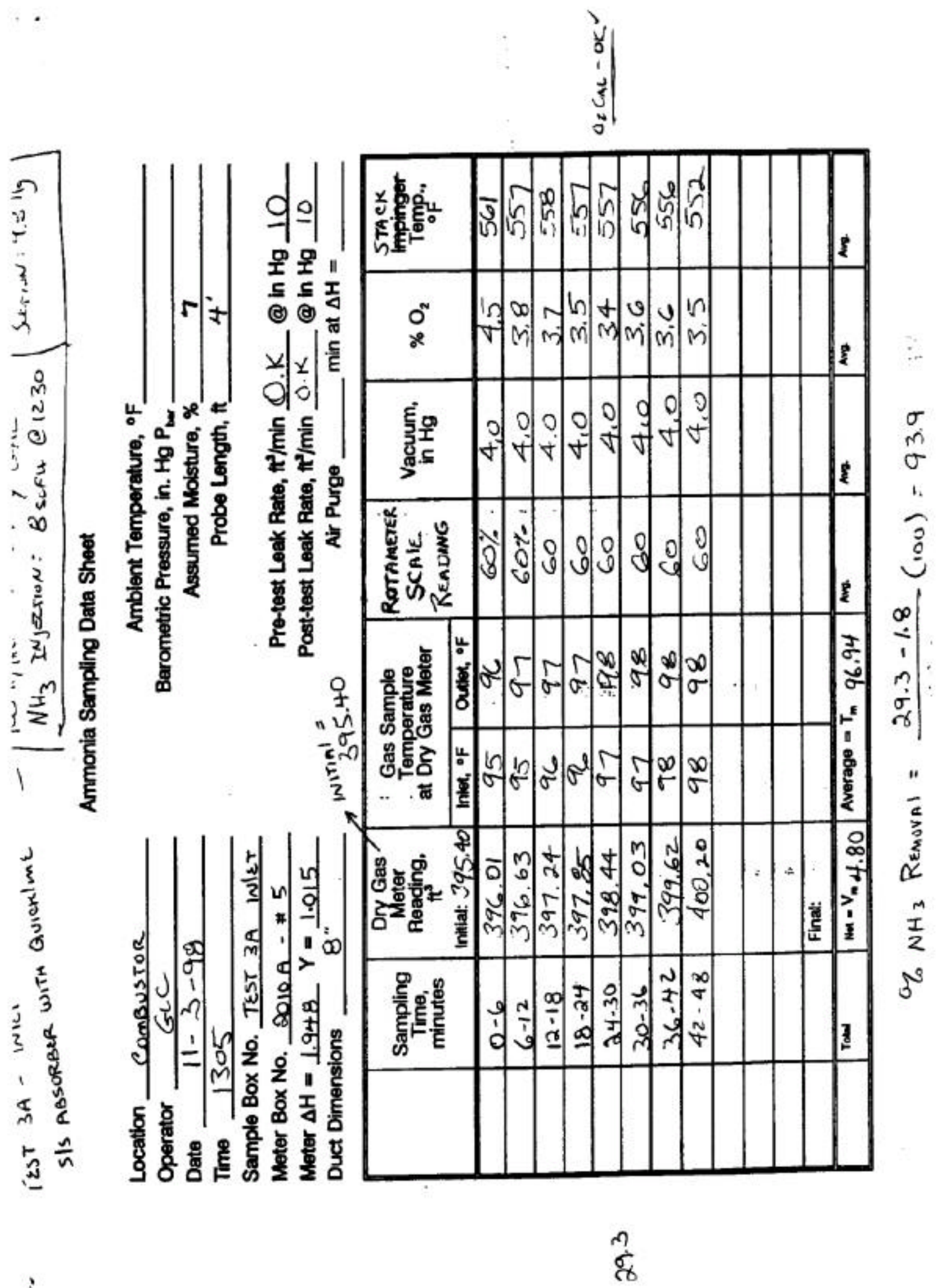




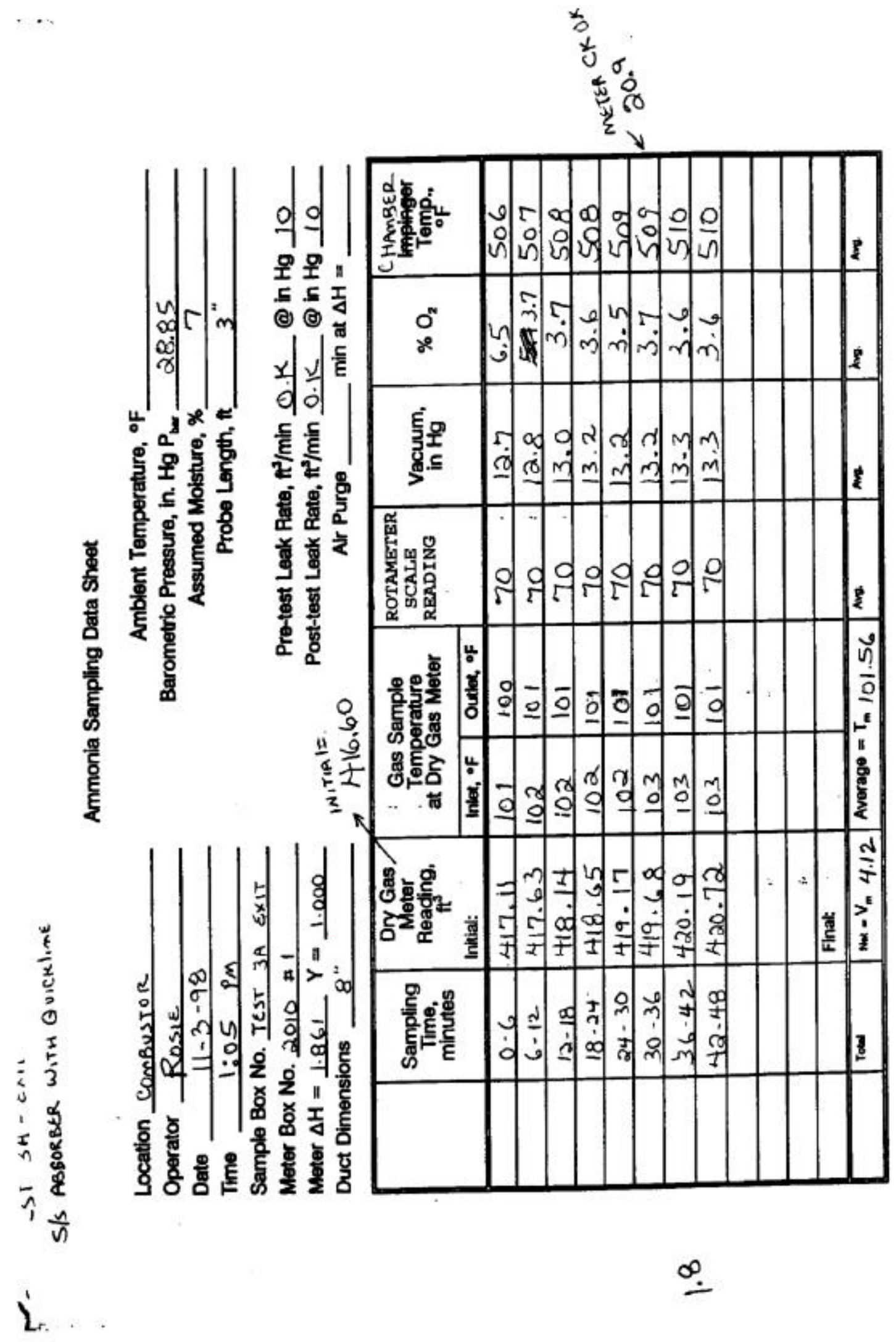




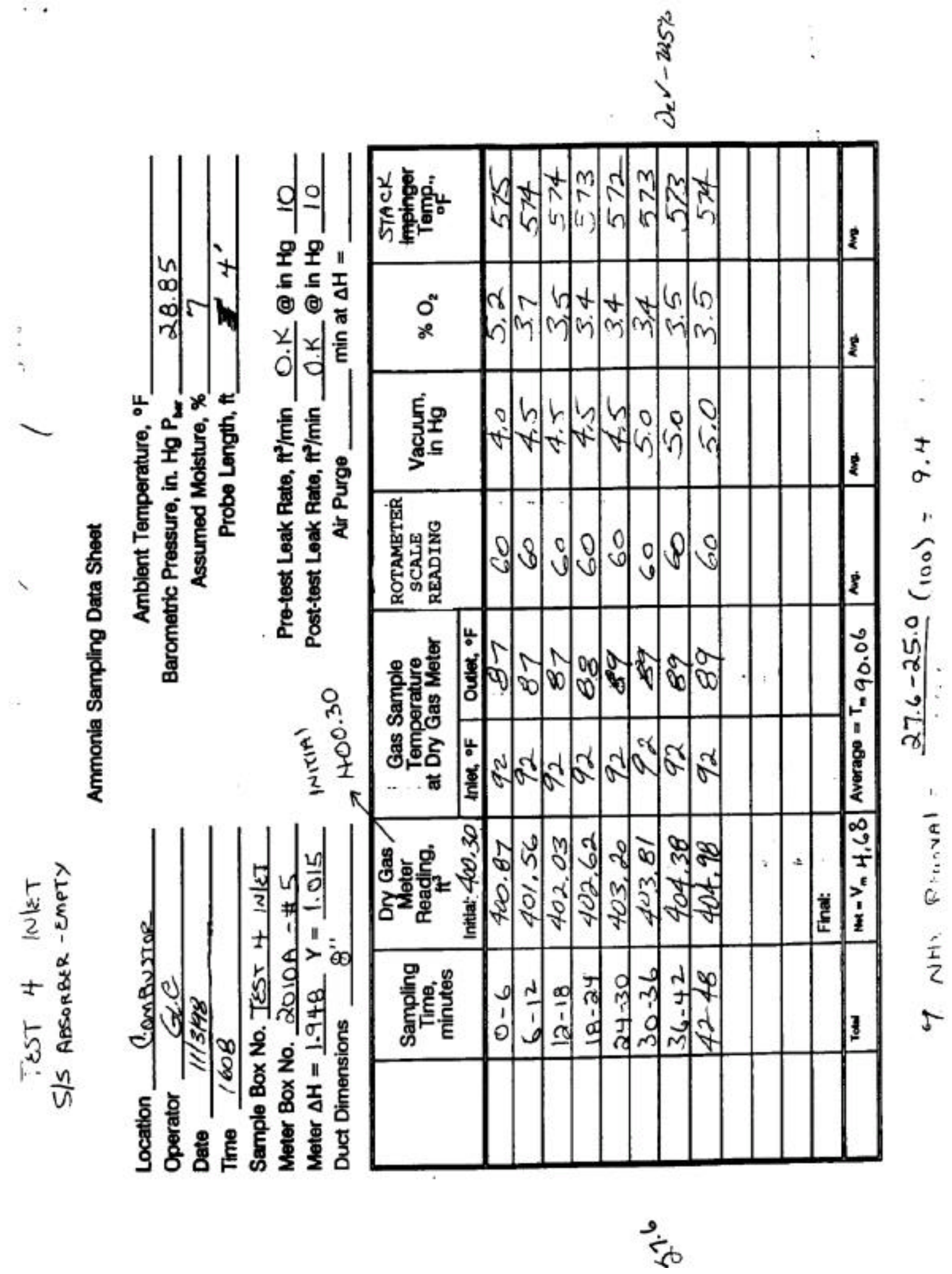




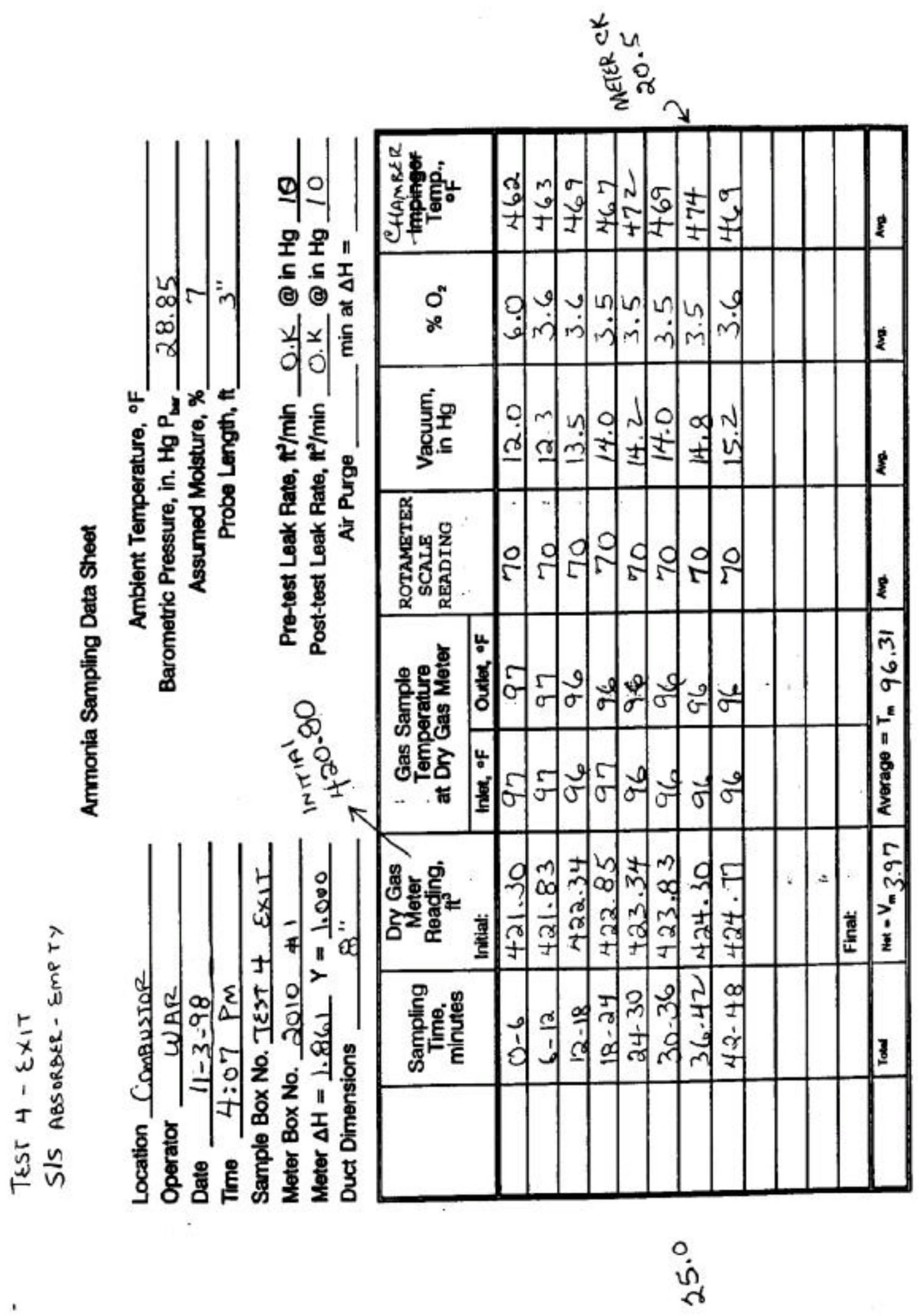




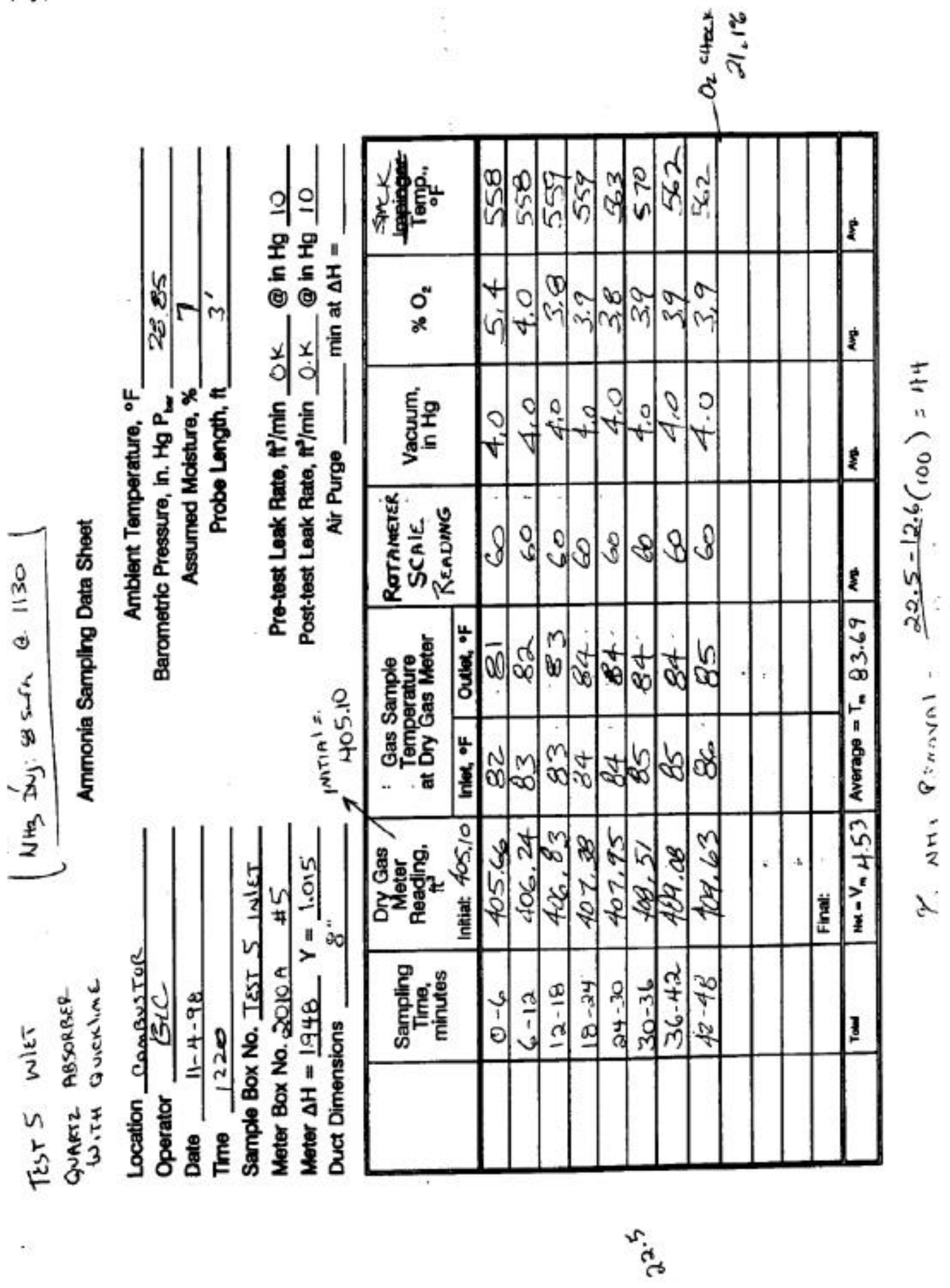




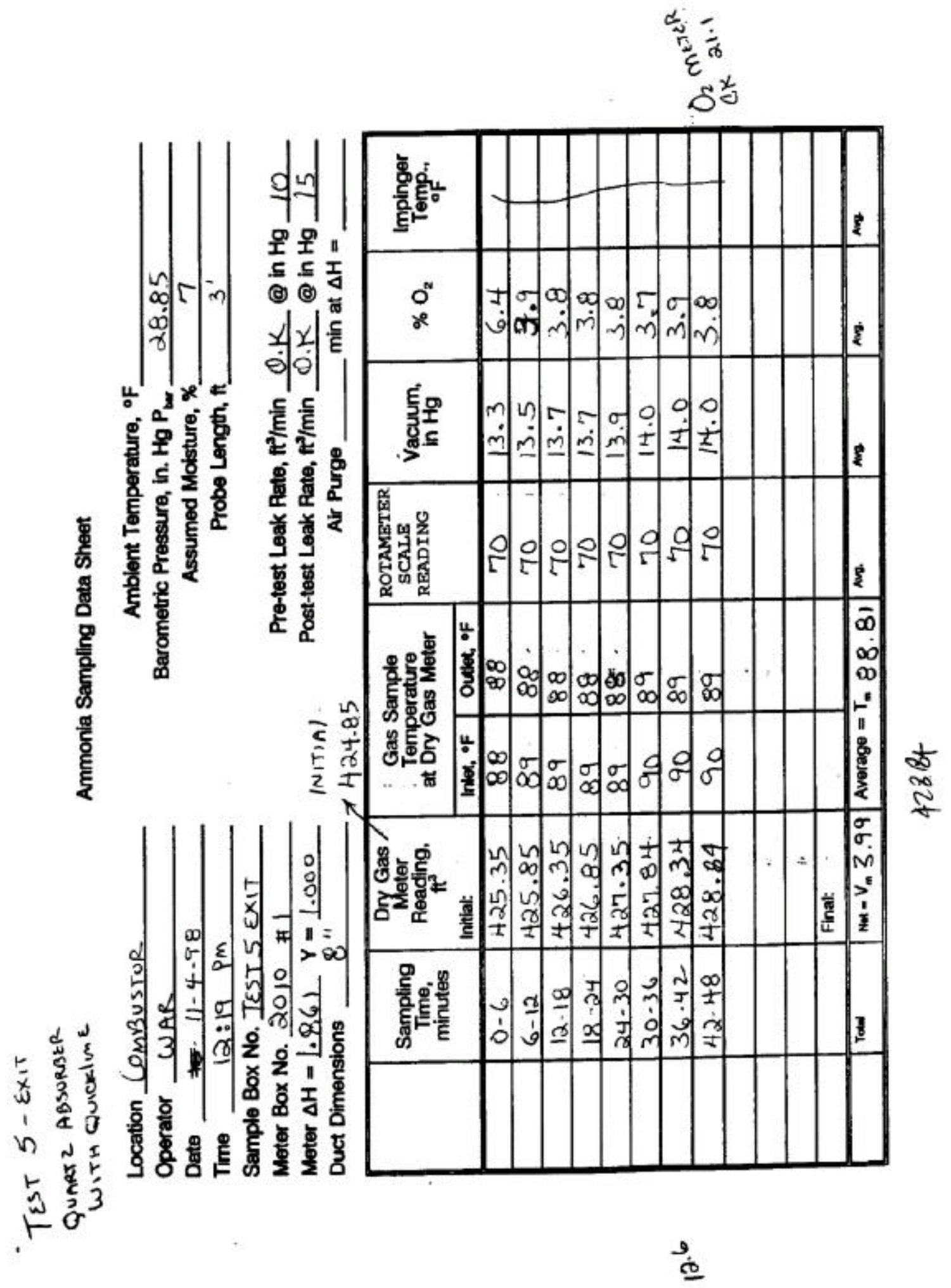




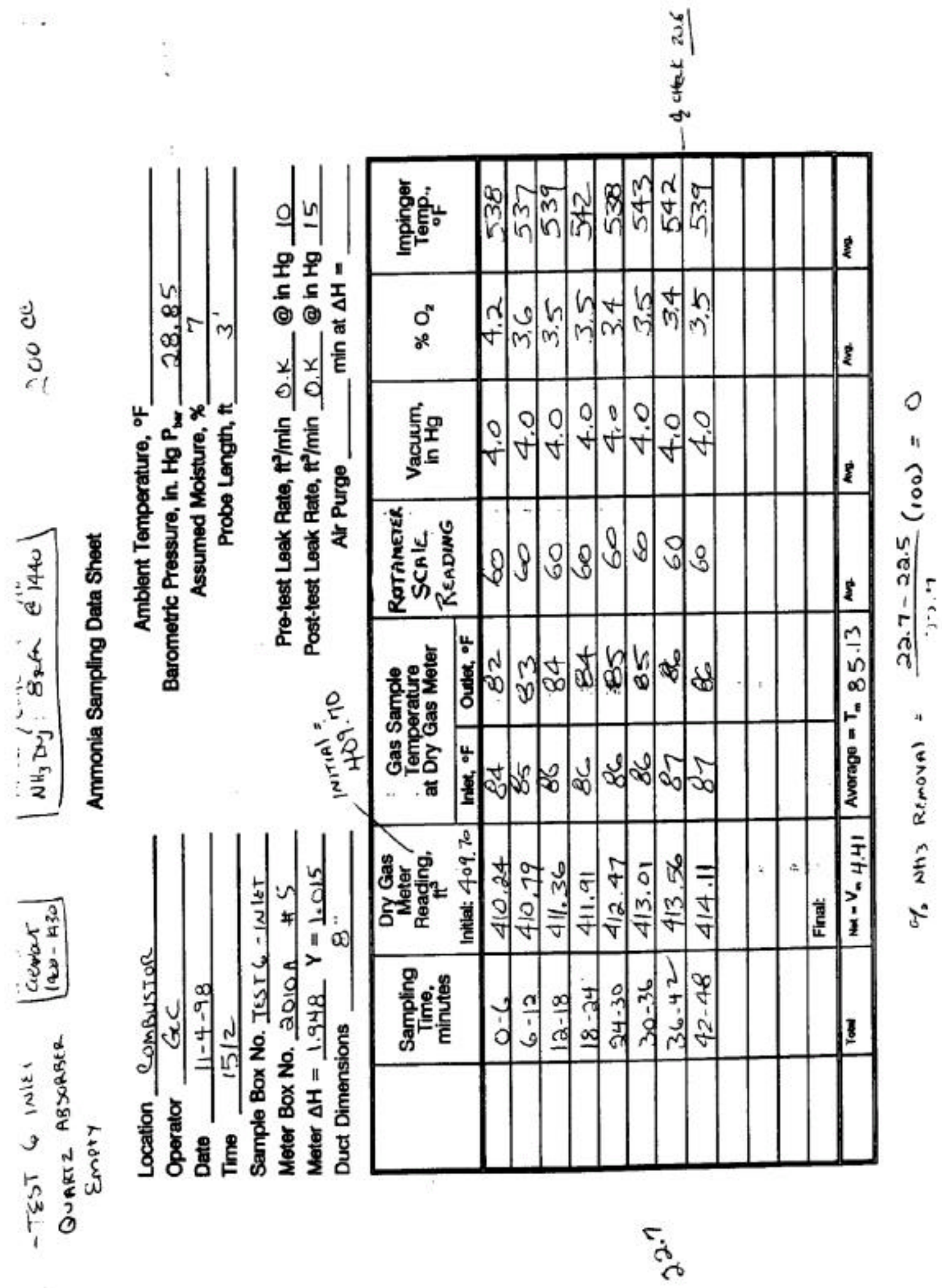




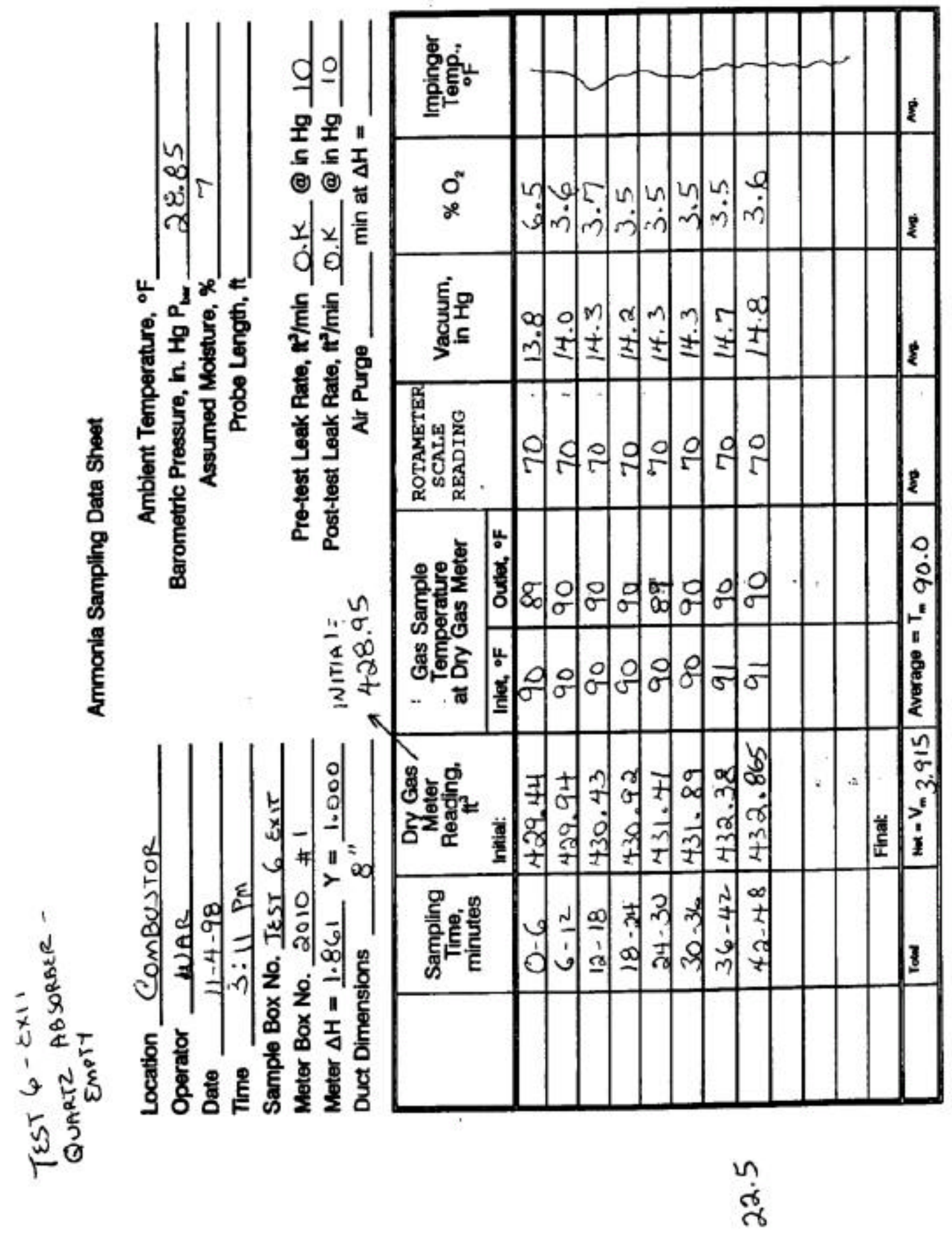




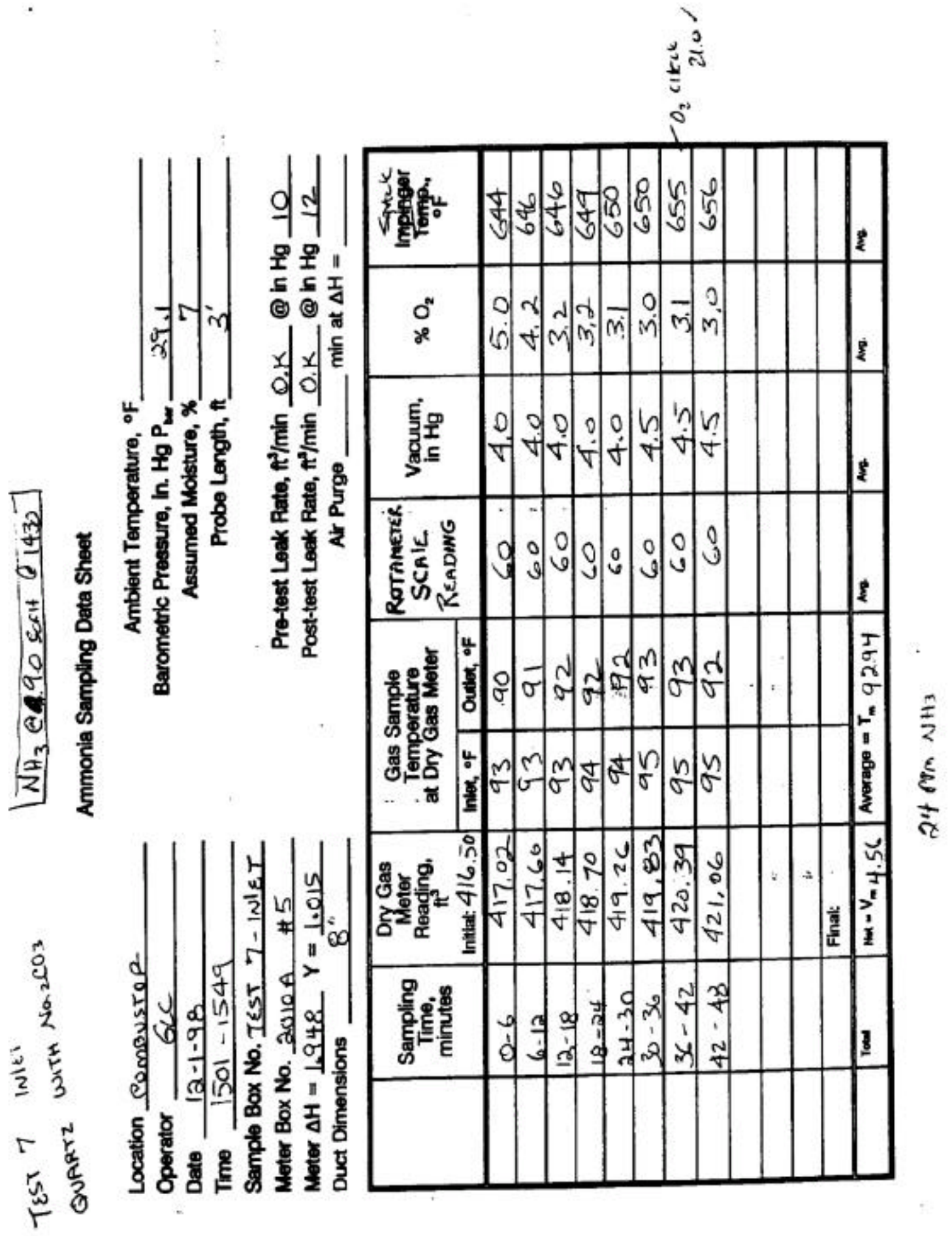




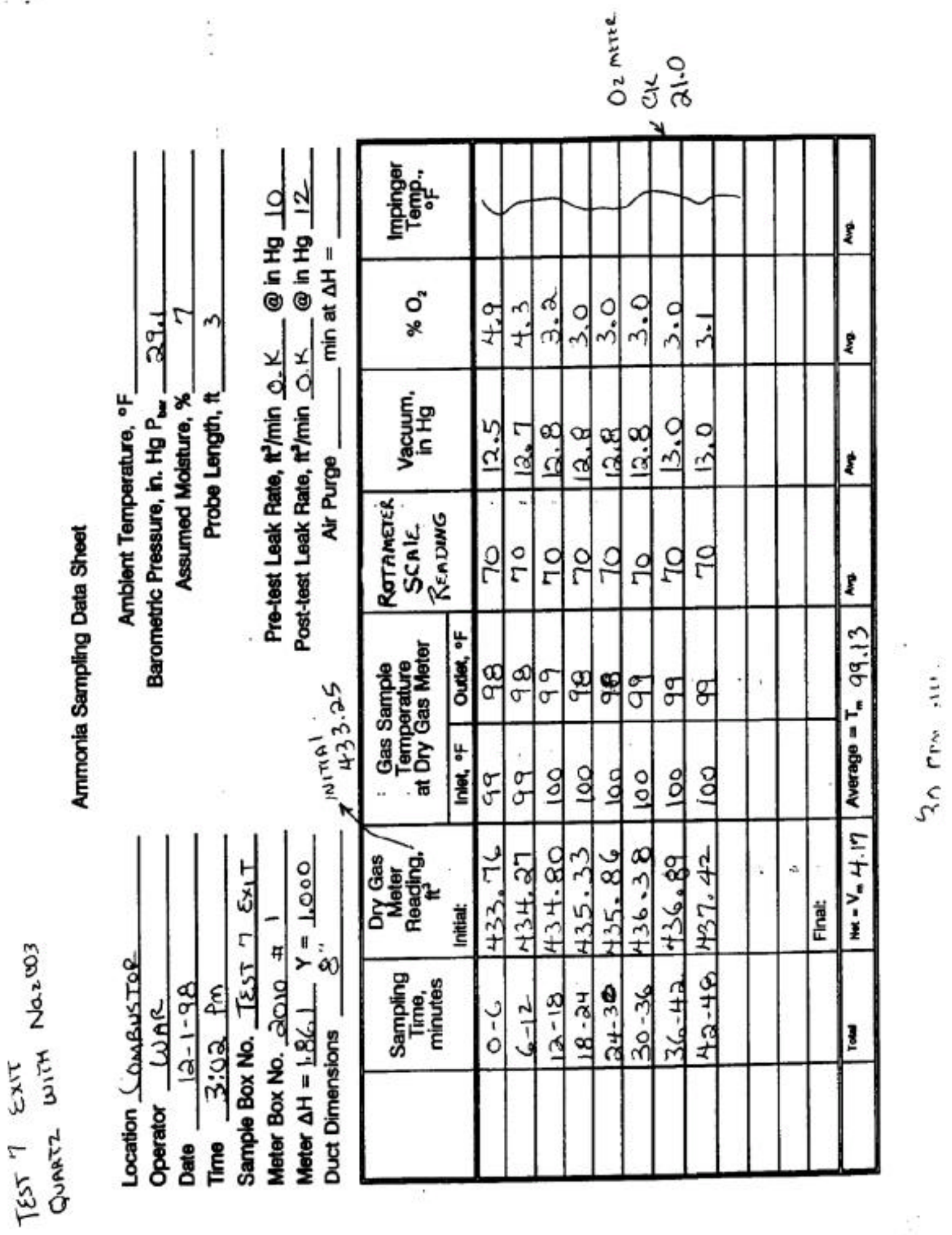




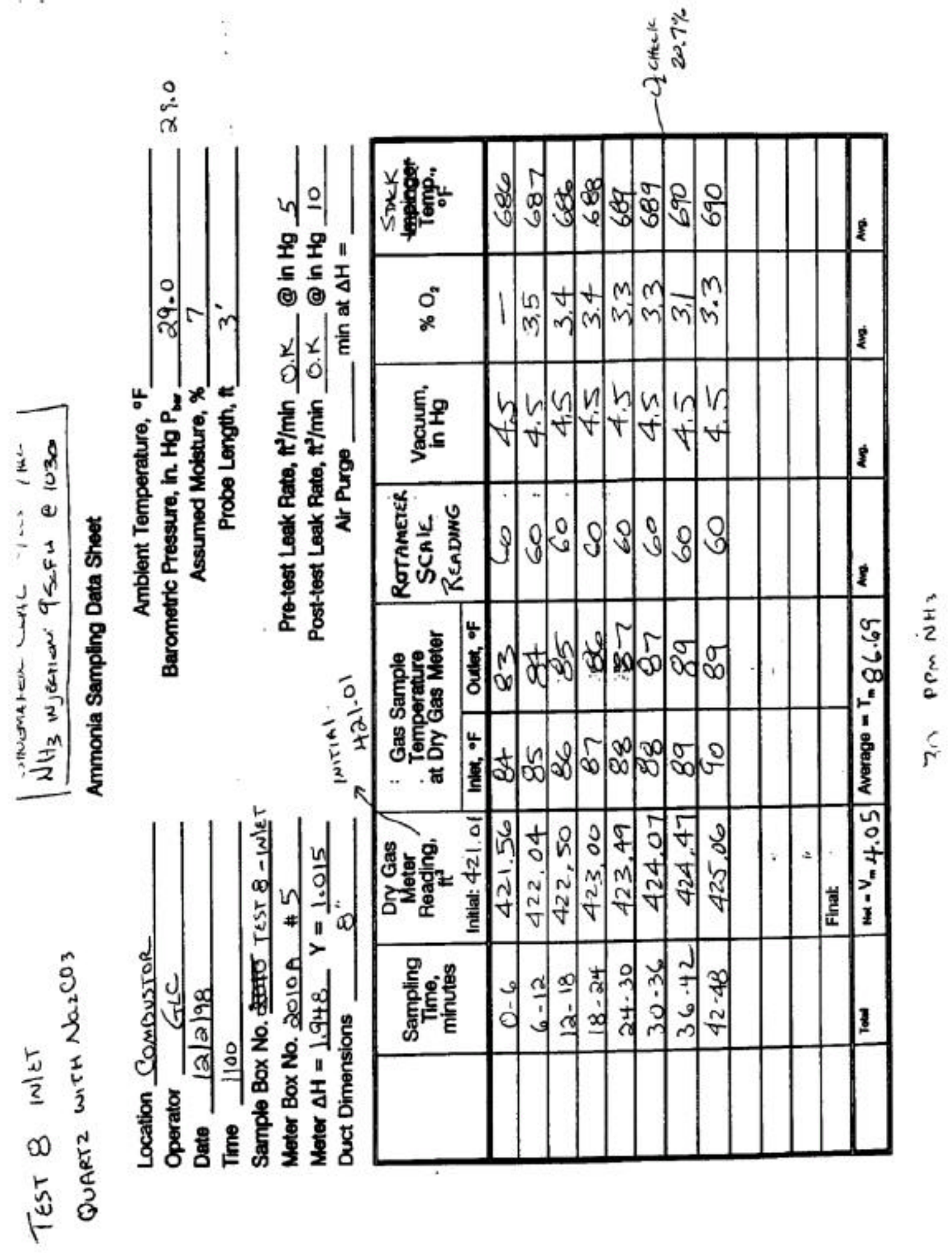




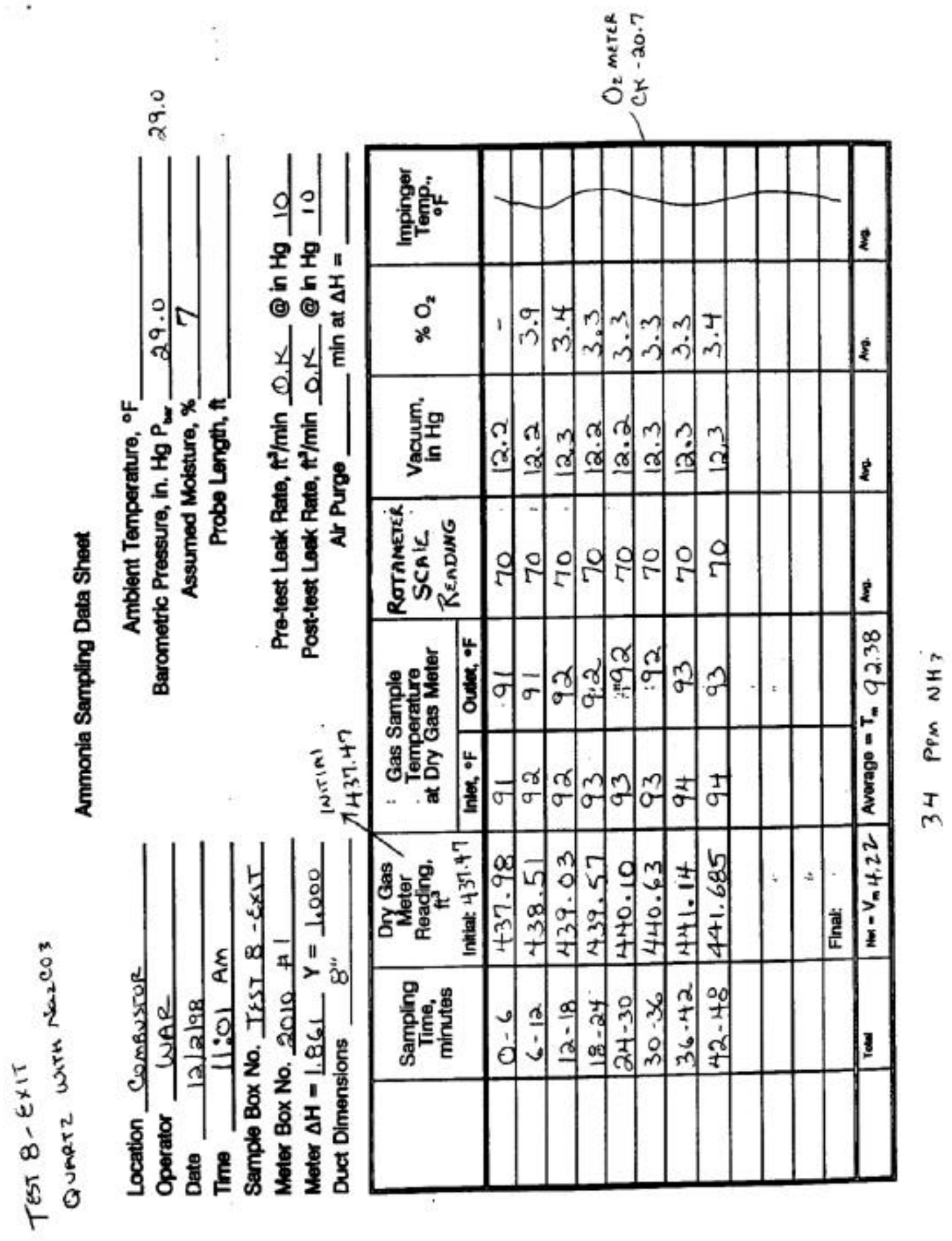




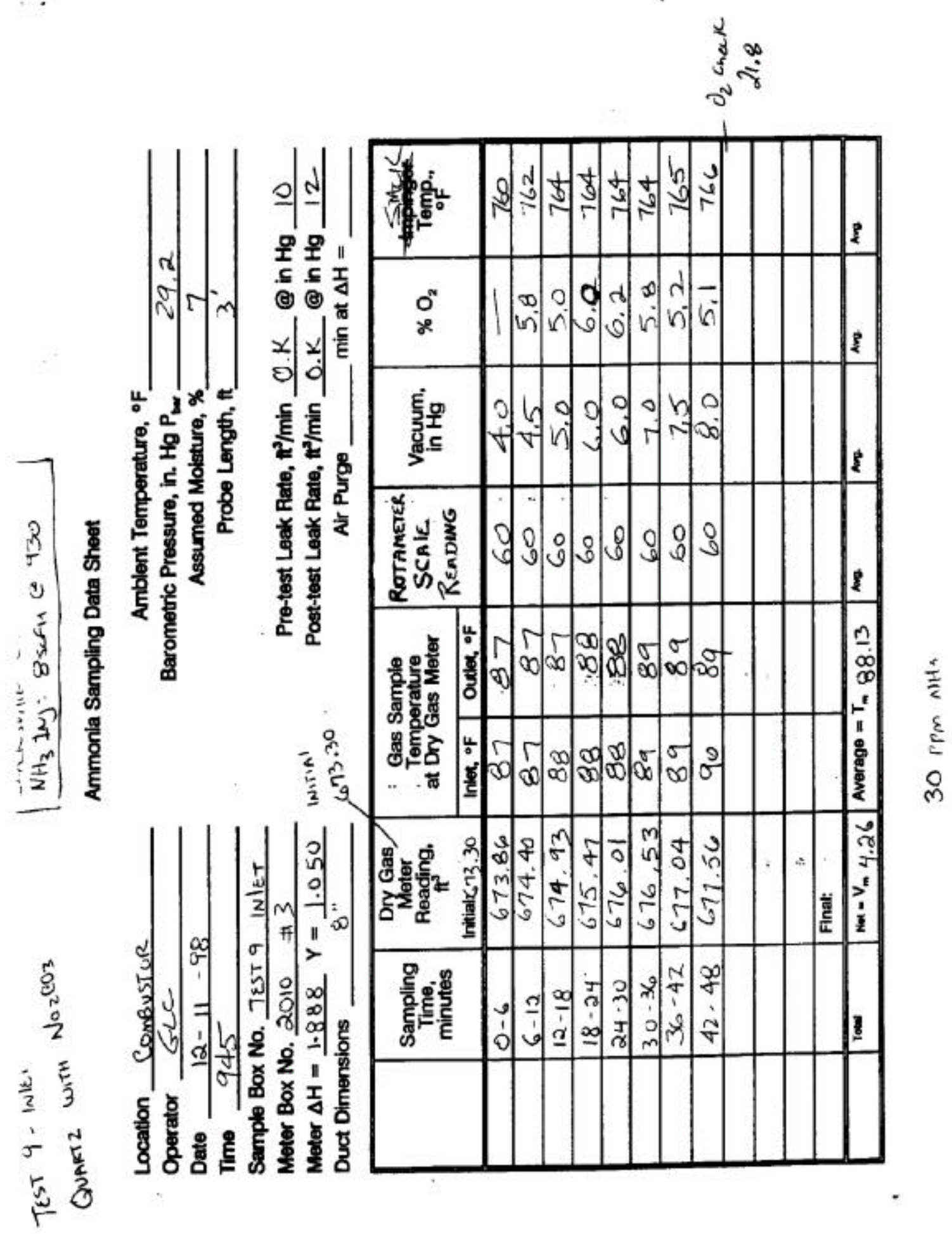




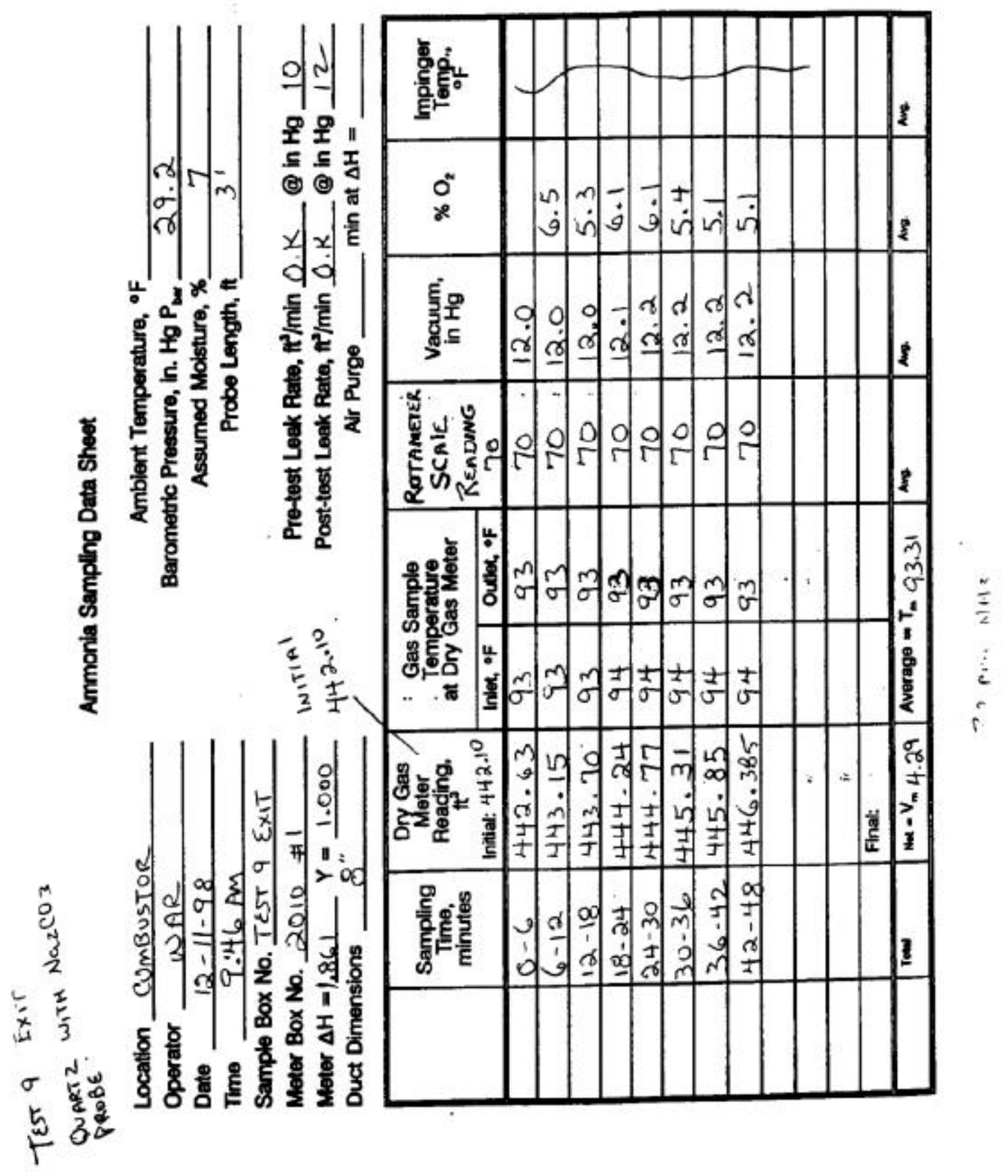


宽

कै है

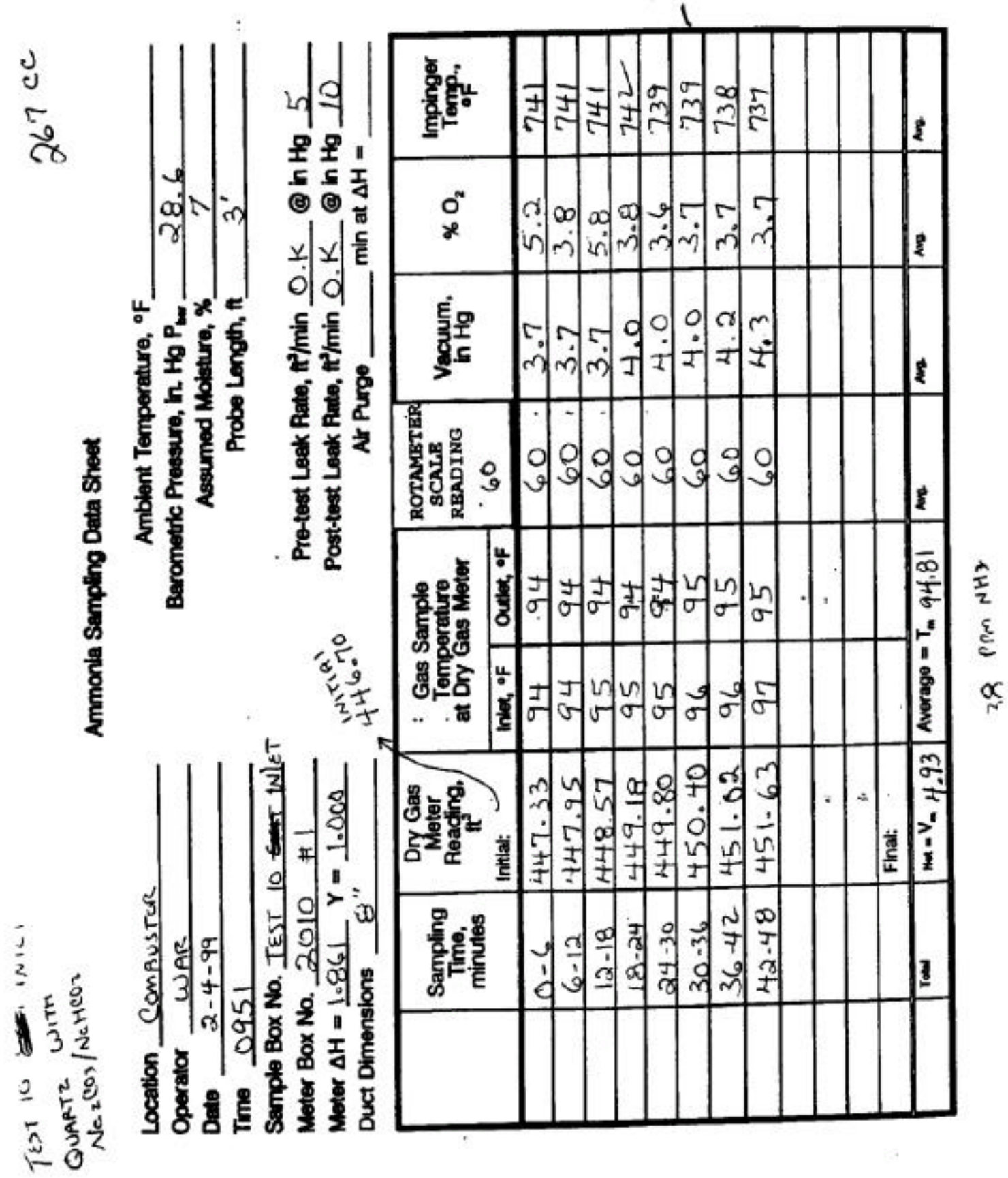




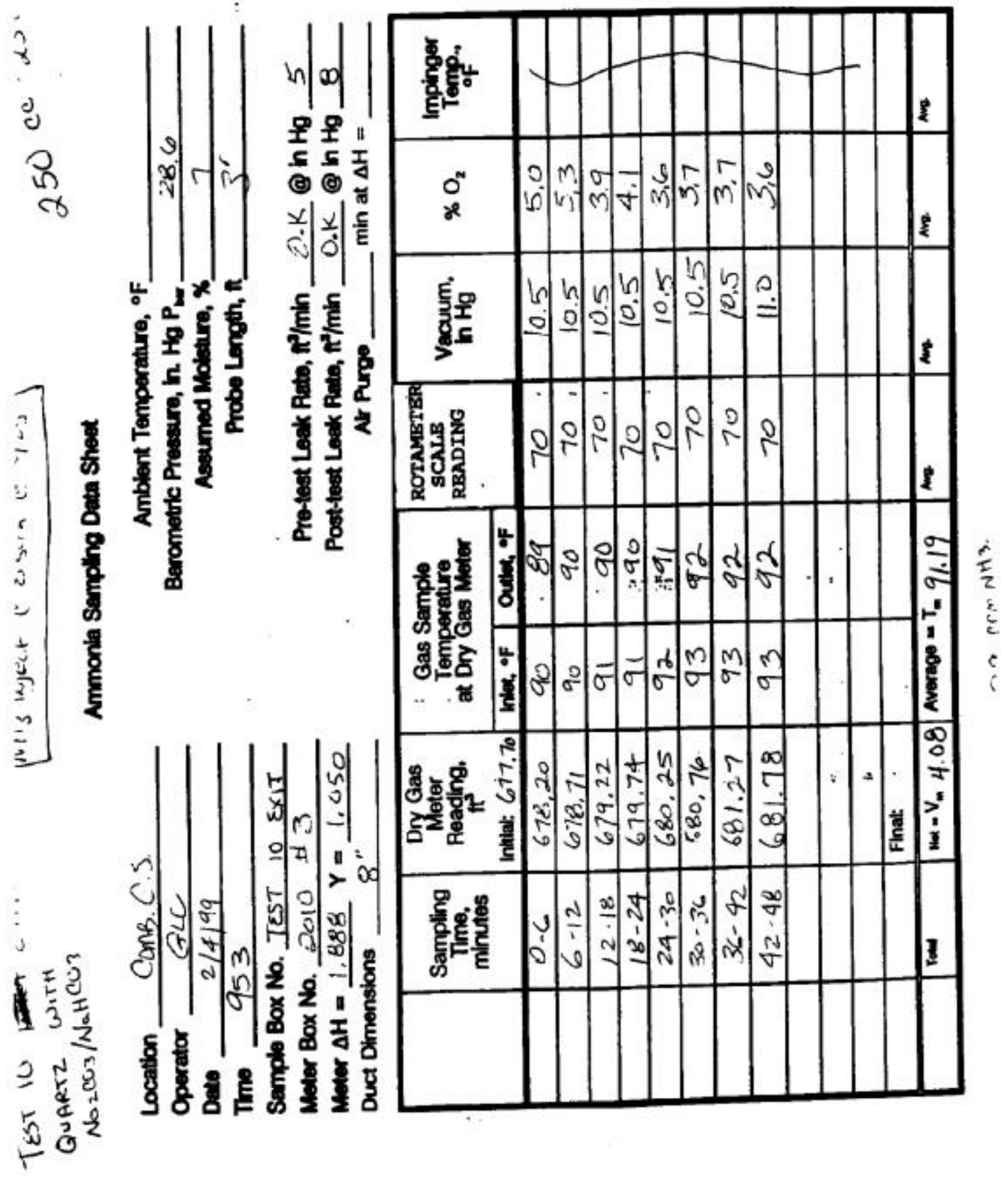




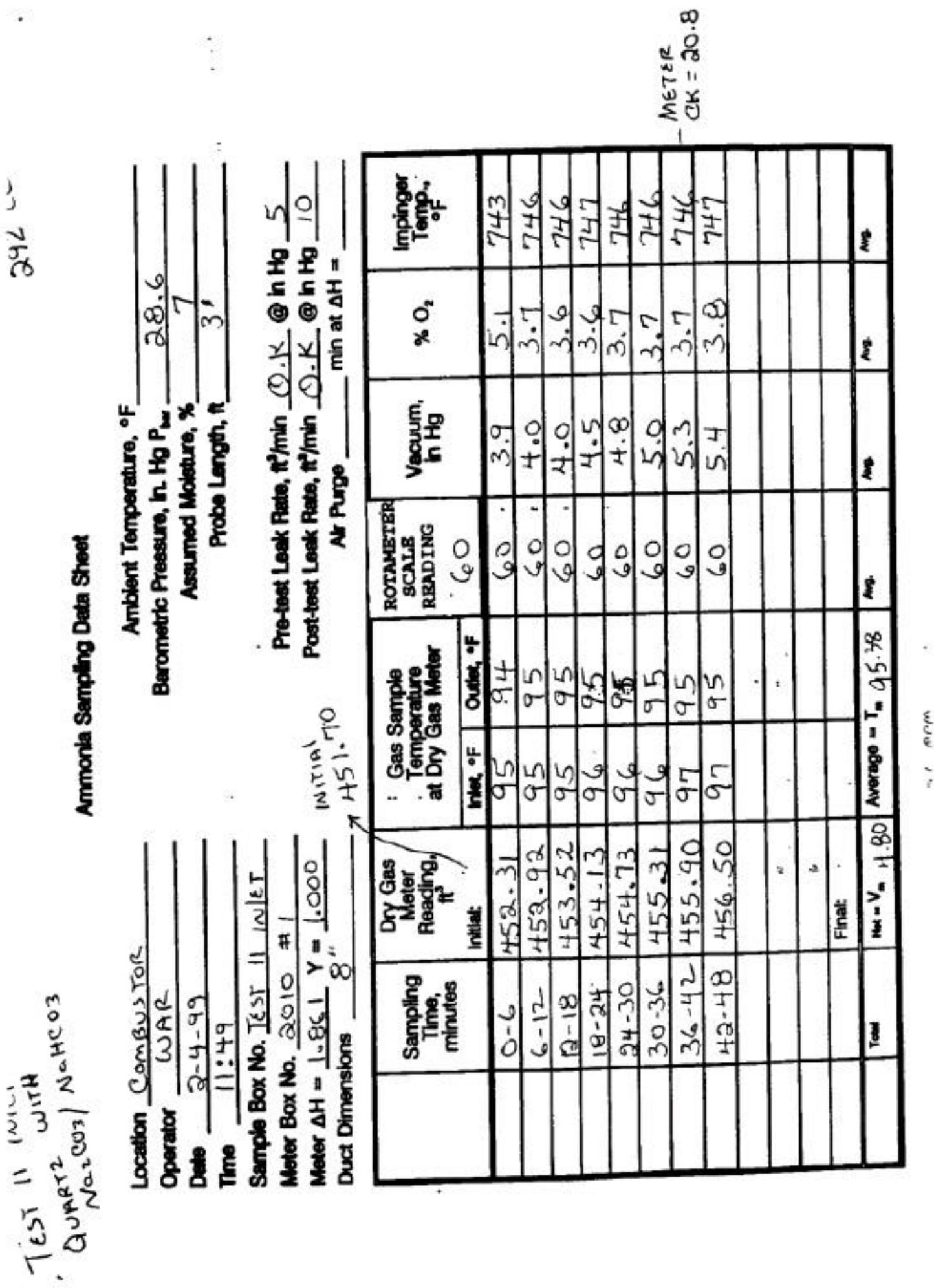




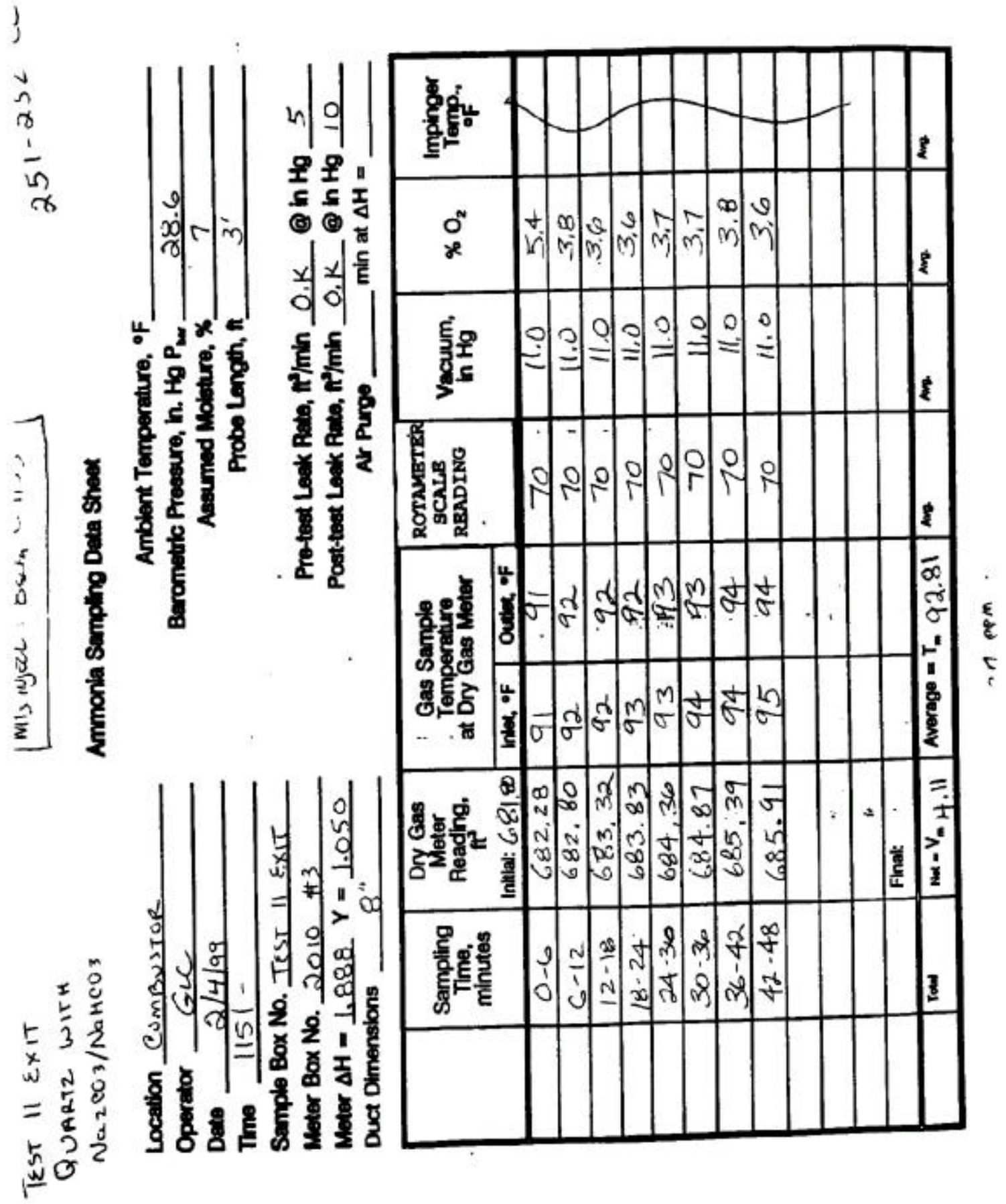




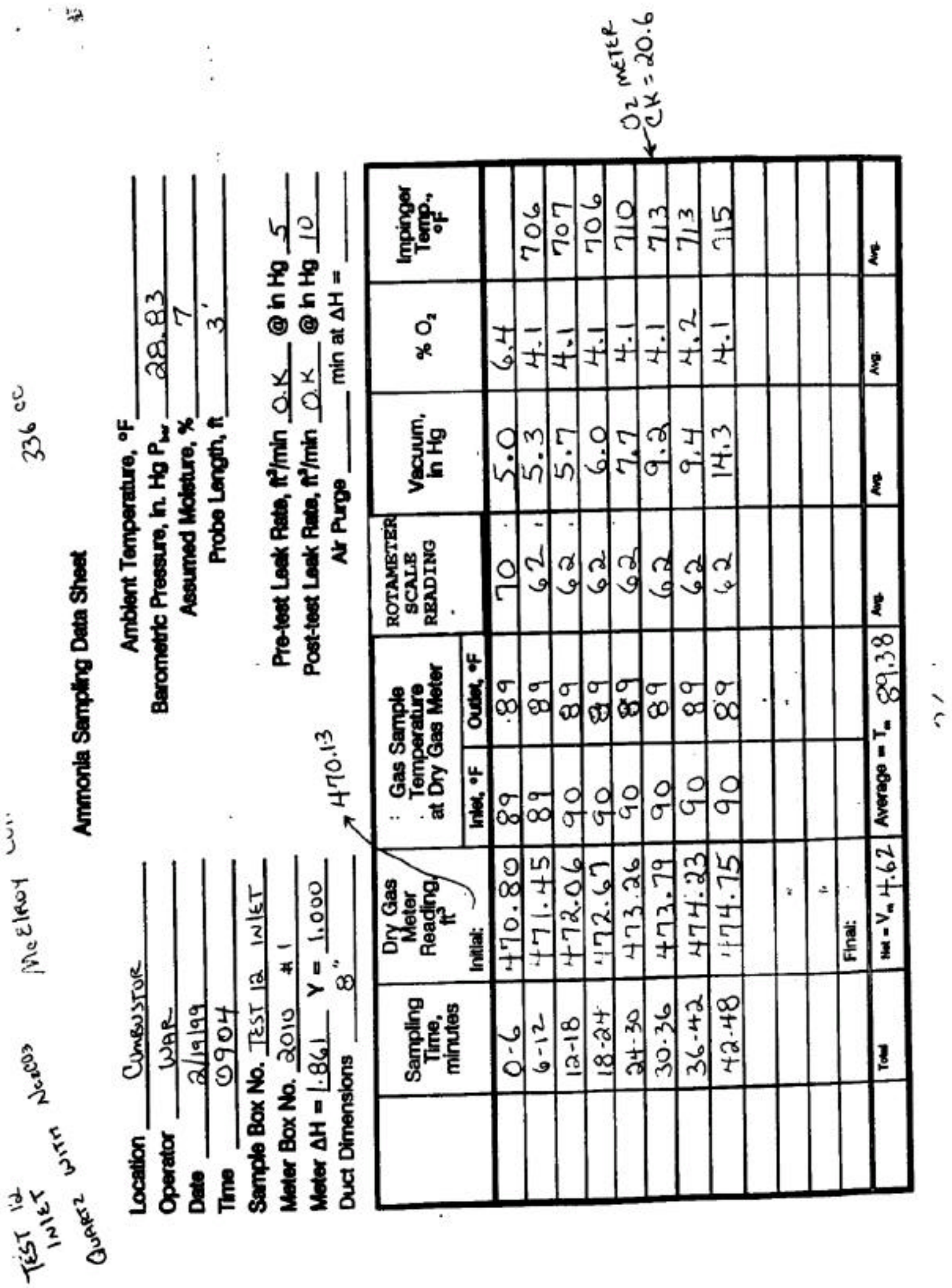




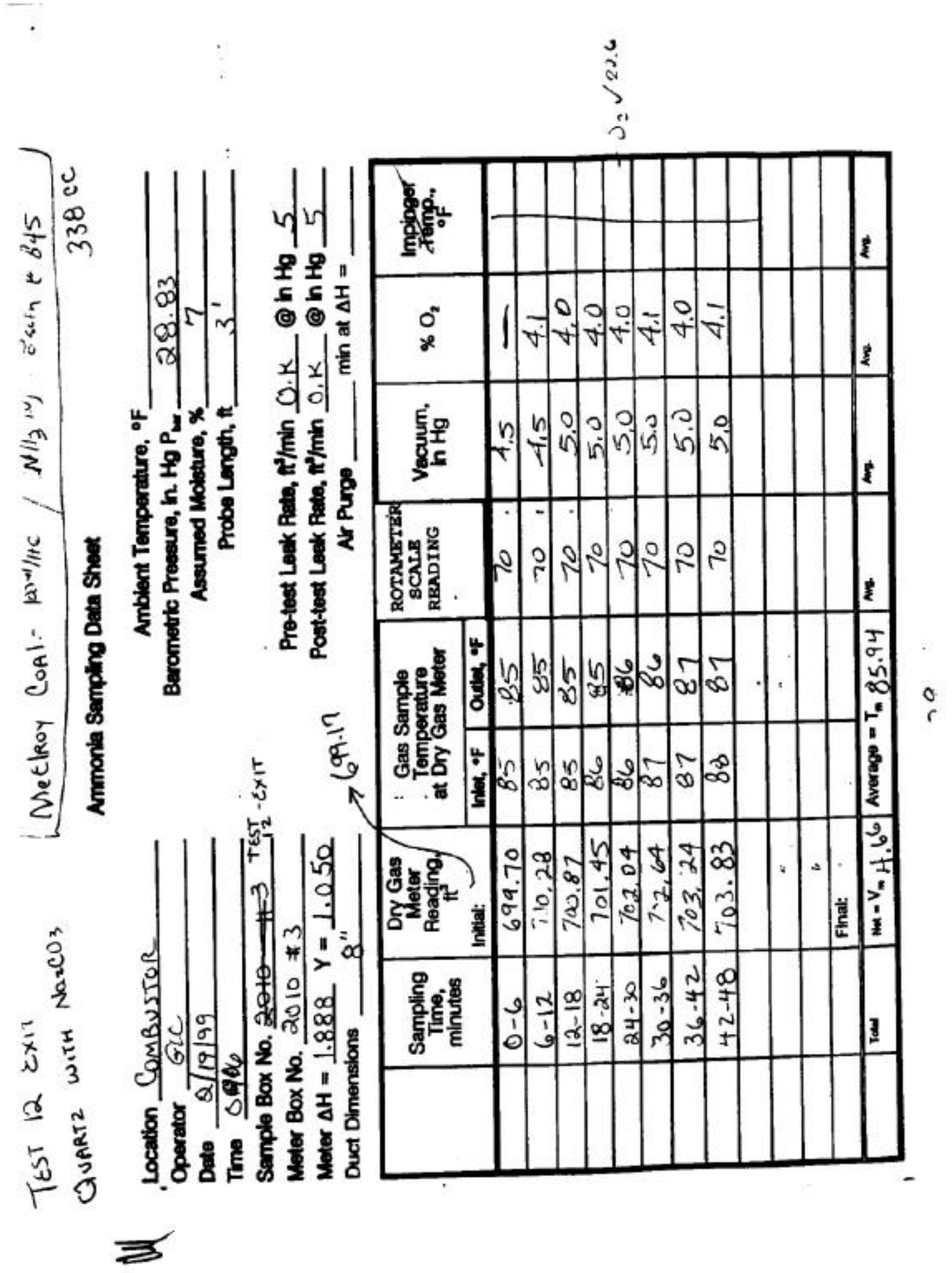


Solution Analyses $-\mathrm{NH}_{3}$ Sampling Tests

\begin{tabular}{|c|c|c|c|c|}
\hline \multirow{2}{*}{$\begin{array}{l}\text { Test } \\
\text { No. }\end{array}$} & \multicolumn{2}{|c|}{$\begin{array}{l}\text { Diluted } \\
\text { Solution } \\
\text { Volume, } \mathrm{mL}\end{array}$} & \multicolumn{2}{|c|}{$\begin{array}{c}\text { Solution } \\
\mathrm{NH}_{3} \\
\text { Concentration, } \\
\text { ppmw } \\
\end{array}$} \\
\hline & Inlet & Exit & Inle & Exit \\
\hline & & & & \\
\hline 1 & 224 & 224 & 4.3 & 5.0 \\
\hline 2 & 209 & 224 & 5.3 & 3.6 \\
\hline $3 \mathrm{~A}$ & 213 & 218 & 12.3 & 0.6 \\
\hline 4 & 212 & 217 & 11.5 & 8.4 \\
\hline 5 & 221 & 222 & 8.8 & 4.2 \\
\hline 6 & 200 & 244 & 9.5 & 6.7 \\
\hline 7 & 213 & 234 & 9.6 & 10.0 \\
\hline 8 & 200 & 250 & 11.6 & 10.7 \\
\hline 9 & 250 & 250 & 10.0 & 10.4 \\
\hline 10 & 267 & 250 & 12.7 & 12.4 \\
\hline 11 & 292 & 251 & 10.7 & 11.8 \\
\hline 12 & 336 & 338 & 6.6 & 7.5 \\
\hline
\end{tabular}




\section{$\mathrm{SO}_{3}$ Sampling Results, R\&D Combustor $\mathrm{SO}_{3}$ Absorbtion \\ TEST \#1 - w/o $\mathrm{NH}_{3}$ injection}

\begin{tabular}{|c|c|c|c|}
\hline $\begin{array}{l}\text { DATE } \\
\text { START TIME } \\
\text { END TIME } \\
\text { LOCATION } \\
\end{array}$ & \begin{tabular}{|l|}
$2 / 18 / 99$ \\
0912 \\
1012 \\
INLET \\
\end{tabular} & $\begin{array}{l}\text { 2/18/99 } \\
0914 \\
1029 \\
\text { OUTLET }\end{array}$ & \\
\hline \multicolumn{4}{|l|}{ MEASURED METER VARIABLES } \\
\hline SAMPLE TIME [Minutes] & 60 & 75 & \\
\hline BAROMETRIC PRESSURE [" Hg] & 29.02 & 29.02 & \\
\hline SAMPLE VOLUME [ft ${ }^{3}$ ] & 6.15 & 6.01 & \\
\hline METER TEMPERATURE $\left[{ }^{\circ} \mathrm{F}\right]$ & 92.5 & 89.6 & \\
\hline ORIFICE PRESSURE [" $\left.\mathrm{H}_{2} \mathrm{O}\right]$ & 0.01 & 0.01 & \\
\hline Y FACTOR & 1.000 & 1.050 & \\
\hline DSCF SAMPLED & 5.699 & 5.879 & \\
\hline CONDENSER TEMP $\left[{ }^{\circ} \mathrm{F}\right]$ & 124 & 127 & \\
\hline WATER BATH TEMP [ $\left.{ }^{\circ} \mathrm{F}\right]$ & 144 & 145 & \\
\hline CC/MIN@ @ONDENSER & 2975 & 2467 & \\
\hline DUCT OXYGEN [\%] & 3.83 & 3.90 & \\
\hline DUCT TEMP DURING TEST [ ${ }^{\circ} \mathrm{F}$ ] & 690 & 690 & \\
\hline \multicolumn{4}{|l|}{$\mathrm{SO}_{2}$} \\
\hline $\begin{array}{l}\mathrm{SO}_{2} \text { in IMPINGERS } \\
\text { lb/DSCF }\end{array}$ & & & $\mathrm{SO}_{2}$ Removal \\
\hline $\begin{array}{l}\text { Ib/DSCF } \\
\text { PPMV, As Sampled }\end{array}$ & $\begin{array}{l}4.45 E-04 \\
2688\end{array}$ & $\begin{array}{r}5.88 \mathrm{E}-08 \\
0\end{array}$ & \\
\hline PPMV,@ 0\% Oxygen & 3291 & 0 & $100 \%$ \\
\hline PPMV,@Duct Conditions & 2688 & 0 & $100 \%$ \\
\hline \multicolumn{4}{|l|}{$\mathbf{S O}_{3}$} \\
\hline $\mathrm{SO}_{3}$ in FILTER PLUG & & & \\
\hline $\mathrm{lb} / \mathrm{DSCF}$ & 2.28E-07 & & \\
\hline PPMV, As Sampled & 1.1 & & \\
\hline PPMV, @ 0\% Oxygen & 1.3 & & \\
\hline PPMV, @ Duct Conditions & 1.1 & & \\
\hline \multicolumn{4}{|l|}{$\mathrm{SO}_{3}$ in $\mathrm{PROBE}$} \\
\hline $\mathrm{lb} / \mathrm{DSCF}$ & 1.10E-06 & $1,84 \mathrm{E}-08$ & \\
\hline PPMV, As Sampled & 5.3 & 0.1 & \\
\hline PPMV, @ 0\% Oxygen & 6.5 & 0.1 & \\
\hline PPMV, @ Duct Conditions & 5.3 & 0.1 & \\
\hline \multicolumn{4}{|l|}{$\mathrm{SO}_{3}$ in CONDENSER } \\
\hline $\mathrm{lb} / \mathrm{DSCF}$ & $5.31 \mathrm{E}-07$ & $1.84 \mathrm{E}-08$ & \\
\hline PPMV, As Sampled & 2.6 & 0.1 & \\
\hline PPMV,@0\% Oxygen & 3.1 & 0.1 & \\
\hline \multirow[t]{2}{*}{ PPMV,@ Duct Conditions } & 2.6 & 0.1 & \\
\hline & & & $\mathrm{SO}_{3}$ Removal \\
\hline GAS PHASE $\mathrm{SO}_{3}$ [lb/DSCF] & $1.63 \mathrm{E}-06$ & 3.68E-08 & \\
\hline & 7.9 & 0.2 & \\
\hline GAS PHASE SO ${ }_{3}, 0 \%$ OXYGEN & & 0.2 & $98 \%$ \\
\hline TOTAL PHASE SO ${ }_{3}[\mathrm{lb} / \mathrm{DSCF}]$ & 1.86E-06 & $3.68 \mathrm{E}-08$ & \\
\hline TOTAL PHASE SO [Duct PPM] $^{2}$ & 9.0 & 0.2 & $98 \%$ \\
\hline TOTAL SO, $0 \%$ OXYGEN & 11.0 & 0.2 & \\
\hline$\%$ SO, in SOLIDS [filter olug/total] & 12.2 & 0.0 & \\
\hline
\end{tabular}


$\mathrm{SO}_{3}$ Sampling Results, R\&D Combustor

$\mathrm{SO}_{3}$ Absorbtion

TEST \#2 - w/ $\mathrm{NH}_{3}$ injection

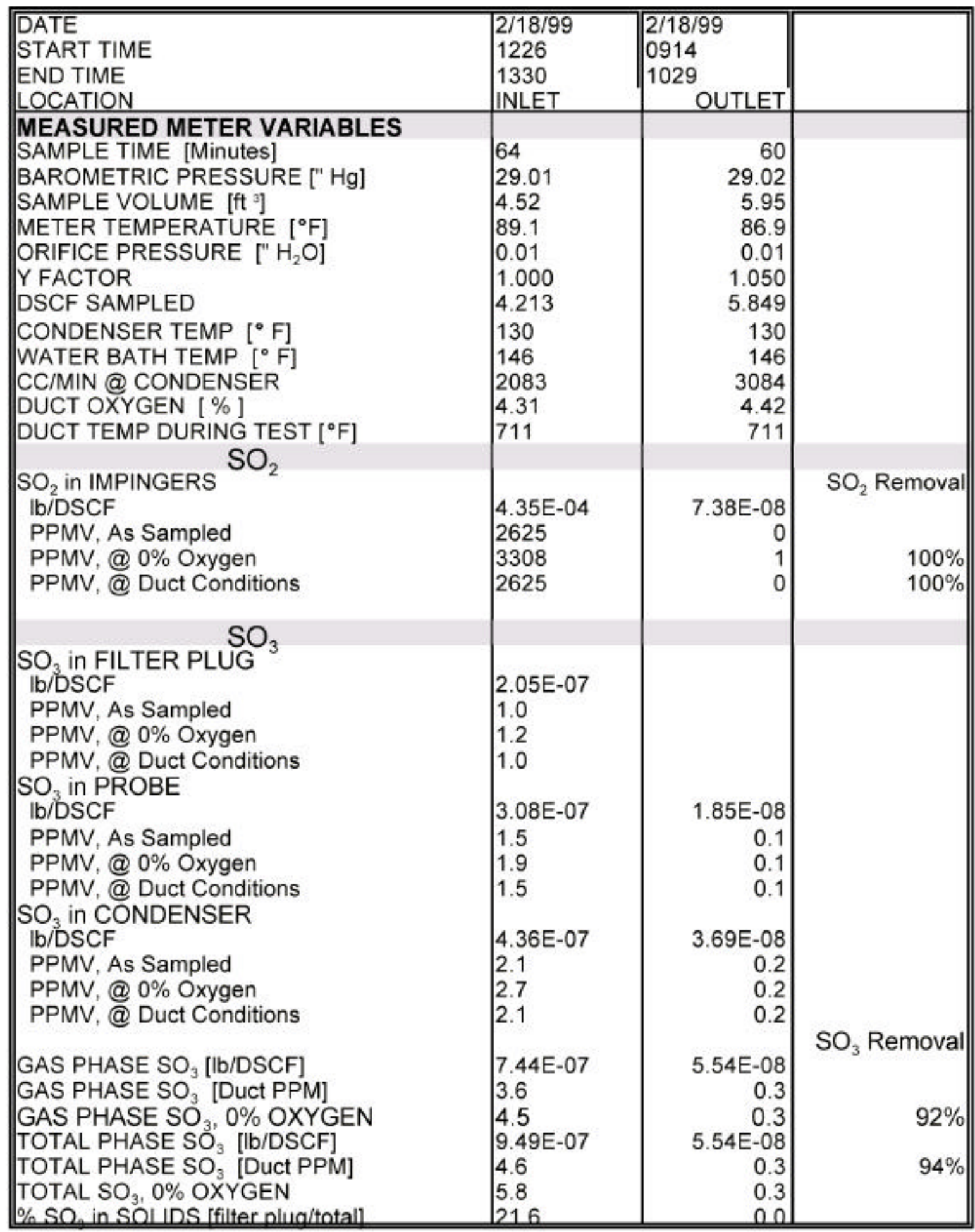


APPENDIX D 


\section{Agreement No. 0685672}

\section{ANALYSIS OF SEWARD STATION FLY ASH SAMPLES}

\section{FINAL REPORT}

CONSOL Inc.

\section{Prepared by:}

Research \& Development

4000 Brownsville Road

Library, PA 15129-9566

\section{Principal Investigator}

S. D. Brandes

\section{Prepared for:}

J. B. Urbas

GPU Generation, Inc. Genco Headquarters

1001 Broad Street

Johnstown, PA 15907

March 1999

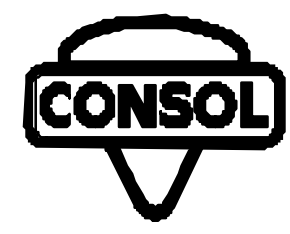

CONSOL Inc.

Research \& Development

4000 Brownsville Road

Library, PA 15129-9566 


\section{TABLE OF CONTENTS}

Page

SUMMARY AND CONCLUSIONS

INTRODUCTION

EXPERIMENTAL

Samples

Ammonia Analyses

Particle Size Distribution

Sulfur and LOI Analyses

RESULTS

RECOMMENDATIONS

1

1

1

1

2

2

2

3

\section{LIST OF TABLES}

$\underline{\text { Table }}$

Page

1 Plant Operating conditions for Days Sample Sets were Obtained 4

2 Analyses of Set 1 (October 1998)

3 Analyses of Set 2 (January 1999)

4 Analyses of Set 3 (February 1999)

5 Screen Analyses of Air Heater Samples from January 19, 1999 and February 25, 1999, Sample Sets

\section{LIST OF FIGURES}

Figure

Page

1 Seward Station Unit \#5 Location Plan for Fly Ash Samples 9

2 Ammonia Content vs. Sampling Location $\quad 10$

3 Ammonia Content vs. Loss on Ignition 10

4a Ammonia Content vs Diameter Below Which 50\% of Particles Lie 11

4b Ammonia Content vs Diameter Below Which 90\% of Particles Lie 11

5 Ammonia Content vs Sulfur Content 


\section{SUMMARY AND CONCLUSIONS}

Three sets of eight fly ash samples each were received by CONSOL R\&D from the GPU Seward Station Unit \#5. The samples were collected and analyzed to determine if the ammonia concentration in the samples could be correlated with physical or chemical characteristics (such as particle size or loss on ignition (LOI)).

The ammonia contents of the fly ash samples were low for the first set of samples obtained from Unit \#5 in October, 1998 (16-104 g/g). The ammonia contents of the sample sets collected in January and February 1999 were in the range of 49-616 g/g. The low ammonia contents of the first set are attributed to longer storage time and sample handling. Based on only two sets of fly ash samples (January and February), there is a strong correlation between ammonia content and sulfur content, and there is a correlation between fly ash ammonia content and the sample LOI. Based on the January and February set of samples, no apparent relationship exists between ammonia content and particle size of the fly ash.

\section{INTRODUCTION}

Three sets of eight fly ash samples each were received by CONSOL R\&D from the GPU Seward Station Unit \#5. The samples were collected and analyzed to determine if the ammonia concentration in the samples could be correlated with physical or chemical characteristics, such as the particle size or loss on ignition (LOI).

\section{EXPERIMENTAL}

\section{Samples}

The sample sets were collected by GPU on October 20, 1998, January 19, 1999, and February 25, 1999. The eight samples in each set were collected from the air heater hoppers, the Research Cottrell (RC) precipitator hoppers, and the Buell precipitator hopper. The eight samples were identified as follows: RC-A Front, RC-A Rear, RC-B Front, RC-B Rear, A Air Heater, B Air Heater, A Buell Front, and B Buell Front. The samples were collected in plastic bags. No other precautions were taken to prevent the loss of volatiles from the samples. Upon receipt by CONSOL, the samples were transferred to glass jars. The set of samples obtained on October 20 was received for analysis three weeks after sampling. The other two sets were received within one week. Analyses were completed within three weeks of receipt for all three sets.

Plant operating conditions associated with the samples are provided in Table 1. Sampling locations are shown in the schematic diagram (Figure 1). The fly ash samples were taken from the bottom of the hoppers via the fly ash transport system piping. Each set of samples was obtained at one time. Each sample was taken as a single aliquot and was considered by GPU to be representative of its sampling location.

\section{Ammonia Analyses}

The samples were analyzed for ammonia using an $\mathrm{NH}_{3}$ ion specific electrode connected to a millivolt $(\mathrm{mV})$ meter. The procedure used is the following. One gram of ash is weighed into a $150 \mathrm{~mL}$ beaker. $60 \mathrm{~mL}$ of deionized (DI) water is added. The solution is sonicated for 
$15 \mathrm{~min}$ and then filtered through Whatman No. 40 filter paper into a $100 \mathrm{~mL}$ volumetric flask. The filter paper containing the ash is washed several times with fresh DI water, and the washings are added to the filtrate in the flask. The solution is diluted with additional DI water to $100 \mathrm{~mL}$. A $50-\mathrm{mL}$ aliquot of the solution is transferred to a $250-\mathrm{mL}$ beaker containing a magnetic stirring bar and placed on the stirrer. The electrode is inserted into the stirred solution and $1 \mathrm{~mL}$ of $1.0 \mathrm{~N}$ aqueous $\mathrm{NaOH}$ is added. After allowing three to four minutes to line out, the $\mathrm{mV}$ reading on the meter is recorded. The $\mathrm{NH}_{3}$ concentration of the solution is determined from this reading using a calibration curve of $\mathrm{mV}$ versus the log of the $\mathrm{NH}_{3}$ concentration in parts per million by weight (ppmw). The calibration curve is prepared using standard aqueous solutions of $0.5,1.0,5.0,10.0$, and $20.0 \mathrm{ppmw} \mathrm{NH}_{3}$. The electrode response, $\mathrm{mV}$ versus log ppmw, is linear over this calibration range. A new calibration curve is made daily.

\section{Particle Size Distribution}

Particle size distributions were determined using a laser-scattering-based particle size analyzer, Malvern Instruments Model 2600. The particle size range which is effectively analyzed is $1.9 \mathrm{~m}$ to $181 \mathrm{~m}$. Samples are suspended in an acetone bath and scanned by a $633 \mathrm{~nm}$ wavelength laser at 1000 scans/15 s. In addition, samples with coarser particles were analyzed by screening through $28,48,100,200$, and 325 mesh screens.

\section{Sulfur and LOI Analyses}

Sulfur contents are determined by ASTM D-4239. LOI is determined as 1-ash content, where the ash content is determined by proximate analysis (ASTM D-5142).

\section{RESULTS}

The samples were analyzed by CONSOL R\&D for ammonia content, particle size distribution, and loss on ignition (LOI). The second and third sets of samples also were analyzed for total sulfur content. The results are provided in Tables 2-5.

The samples obtained from the air heater (A Air Heater and B Air Heater) in the sample set obtained in October were too coarse to be analyzed by the Malvern instrument. They were ground to $<147 \mathrm{~m}$ prior to analysis. These ground samples then were analyzed for ammonia, LOI, and particle size distribution. The corresponding samples from the January and February sets and the RC-B Rear sample from the February set also were too coarse for analysis by the size distribution instrument. Aliquots of these samples were reserved for ammonia, LOI, and sulfur analyses. The remainder of the samples were subjected to a screen analysis (Table 5). The $<147 \mathrm{~m}$ fractions were recombined in the same proportions that they were in the whole sample and analyzed by the Malvern instrument. The screen analyses show that $82 \%$ of the A Air Heater and $57.4 \%$ of the B Air Heater samples (January set), and $63 \%$ of the A Air Heater, $78 \%$ of the B Air Heater samples, and $60.2 \mathrm{wt} \%$ of the RC-B Rear sample (February set) are $<147 \mathrm{~m}$ (Table 5).

Figure 2 is a bar graph of ammonia content of each sample for all three sample sets. The samples obtained in October have much lower ammonia contents than the samples of the other two sets. It is believed that sample handling is responsible for the low ammonia contents of these samples. These samples were received three weeks after being taken from the electrostatic precipitators (ESPs) and air heater. The other two sets were received 
within six days of sampling. In addition, the air heater samples were ground prior to analysis (see above). This could contribute to the low ammonia contents of the A Air Heater and B Air Heater samples (Table 2). The high ammonia concentration for the B Air Heater sample obtained with the February sample set may, in part, be explained by the corresponding high LOI of that sample (10.54 wt \%). It is the largest LOI measured for any sample in the three sets. The sulfur content for this sample also is higher than any other measurement obtained (Figure 3; Tables 2-4). Without additional sampling at this location, this particular sample cannot be considered anomolous.

Figure 3 is a plot of ammonia content $(\mathrm{g} / \mathrm{g}$ ) of the ash samples plotted versus LOI (wt \%). The low ammonia content and the poor correlation between ammonia and LOI for the October sample set may be related to the longer storage times and prior grinding of two of the samples and are not representative of Seward Unit \#5 fly ashes. Because of these concerns, the remainder of the data analyses concentrated on the January and February samples.

Figure $4 \mathrm{a}$ is a plot of ammonia content versus the diameter below which $50 \%$ of the particles lie ( $\mathrm{m}$ ) for the January and February sample sets, and Figure $4 \mathrm{~b}$ is a plot of the ammonia content versus the diameter below which $90 \%$ of the particles lie for the January and February sample sets. The five samples that were screened prior to particle size analysis in the Malvern instrument are indicated on Figures $4 a$ and $4 b$. They all have larger particle size distributions than the other samples. Additionally, because the particle size analyses were performed only on the $<147 \mathrm{~m}$ particles, these five samples would be plotted at even higher values if the $>147 \mathrm{~m}$ portion of the sample were included. This, however, does not change the relative grouping exhibited on the plots. Both the very high ammonia content sample (B Air Heater, February set) and the lowest ammonia content samples (A Air Heater and B Air Heater from January set and RC-B Rear and A Air Heater samples from the February set) have relatively larger particle size distributions than all the other samples in both sets.

The sulfur content of the fly ash samples is strongly correlated with the ammonia content (Figure 5). Because of how the ammonia analyses were performed (see above), it is not known in what form the ammonia exists on the fly ash. It is possible that the ammonia exists on the fly ash in the form of ammonium sulfate salts. This would explain the strong correlation between the ammonia and sulfur.

\section{RECOMMENDATIONS}

The design and execution of an ammoniated ash sampling and analysis program is recommended. A statistically designed program to be carried out at varying SNCR performance conditions would provide significantly more information than was provided in the limited work described in this report. 
TABLE 1

\section{PLANT OPERATING CONDITIONS FOR DAYS SAMPLE SETS WERE OBTAINED}

\begin{tabular}{|l|c|c|c|}
\hline \multicolumn{1}{|c|}{ Condition } & Set 1 & Set 2 & Set 3 \\
\hline Date obtained & October 20, 1998 & January 19, 1999 & February 25, 1999 \\
\hline Coal Feed Rate, Ib/h & 120,000 & 108,000 & 114,000 \\
\hline Coal Gross Heating Value, Btu/lb & 12,080 & 12,133 & $12,200(\mathrm{a})$ \\
\hline Coal Sulfur Content, wt\% & 1.32 & 1.74 & $1.60(\mathrm{a})$ \\
\hline Coal Ash, wt\% & 14.42 & 13.86 & $14.23(\mathrm{a})$ \\
\hline SO ${ }_{2}$ Rate, lb/MMBtu & 2.54 & 2.85 & 2.62 \\
\hline $\begin{array}{l}\text { Flue gas SO }{ }_{3} \text { Concentration, } \\
\text { ppm (estimated) }\end{array}$ & $8-10$ & $8-10$ & $8-10$ \\
\hline Ammonia slip, ppm & $<2$ & $<2$ & $<2$ \\
\hline \begin{tabular}{l} 
Plant load, MW gross \\
\hline
\end{tabular}
\end{tabular}

(a) No analysis for February 25, monthly average used 
TABLE 2

\section{ANALYSES OF SET 1 (OCTOBER 1998)}

\begin{tabular}{|l|r|r|r|r|r|}
\hline & & & \multicolumn{3}{|c|}{ Particle Size, $\mathbf{m}(\mathbf{f})$} \\
\cline { 5 - 6 } Sample ID & $\begin{array}{r}\text { Ammonia, } \\
\mathbf{g} / \mathbf{g}\end{array}$ & $\begin{array}{r}\text { LOI (a) } \\
\mathbf{w t} \%\end{array}$ & $\mathbf{D}(\mathbf{v}, \mathbf{0 . 1}) \mathbf{( b )}$ & $\mathbf{D}(\mathbf{v}, \mathbf{0 . 5}) \mathbf{( c )}$ & $\mathbf{D}(\mathbf{v}, \mathbf{0 . 9}) \mathbf{( d )}$ \\
\hline A Air Heater (e) & 24 & 2.88 & 6.28 & 25.80 & 89.39 \\
\hline B Air Heater (e) & 16 & 4.47 & 8.02 & 98.30 & 169.31 \\
\hline RC-A Front & 59 & 2.67 & 4.96 & 13.24 & 34.10 \\
\hline RC-A Rear & 64 & 2.74 & 4.57 & 13.81 & 37.30 \\
\hline RC-B Front & 22 & 4.97 & 5.19 & 18.01 & 65.68 \\
\hline RC-B Rear & 28 & 4.26 & 4.66 & 16.24 & 64.12 \\
\hline A Buell Front & 104 & 3.81 & 3.20 & 11.26 & 36.97 \\
\hline B Buell Front & 37 & 6.19 & 4.28 & 18.55 & 78.22 \\
\hline
\end{tabular}
(a) $\mathrm{LOI}=$ loss on ignition
(b) $\mathrm{D}(\mathrm{v}, 0.1)=$ diameter below which $10 \%$ of the sample lies, $\mathrm{m}$
(c) $\mathrm{D}(\mathrm{v}, 0.5)=$ diameter below which $50 \%$ of the sample lies, $\mathrm{m}$
(d) $\mathrm{D}(\mathrm{v}, 0.9)=$ diameter below which $90 \%$ of the sample lies, $\mathrm{m}$
(e) samples ground prior to all analyses
(f) average of two determinations 
TABLE 3

ANALYSES OF SET 2 (JANUARY 1999)

\begin{tabular}{|l|r|r|r|r|r|r|}
\hline & & & \multicolumn{2}{|c|}{ particle size, $\mathbf{m}(\mathbf{f})$} \\
\cline { 5 - 7 } Sample ID & $\begin{array}{r}\text { Ammonia, } \\
\mathbf{g} / \mathbf{g}\end{array}$ & $\begin{array}{r}\text { LOI (a), } \\
\mathbf{w t} \%\end{array}$ & $\begin{array}{r}\mathbf{S}(\text { tot), } \\
\mathbf{w t} \%\end{array}$ & $\mathbf{D}(\mathbf{v}, \mathbf{0 . 1})(\mathbf{b})$ & $\mathbf{D}(\mathbf{v}, \mathbf{0 . 5})(\mathbf{c})$ & $\mathbf{D}(\mathbf{v}, \mathbf{0 . 9})(\mathbf{d})$ \\
\hline B Air Heater & 74.6 & 1.92 & 0.08 & $25.50(\mathrm{e})$ & $90.51(\mathrm{e})$ & $163.67(\mathrm{e})$ \\
\hline RC-A Front & 48.6 & 3.32 & 0.07 & $92.19(\mathrm{e})$ & $136.50(\mathrm{e})$ & $176.83(\mathrm{e})$ \\
\hline RC-A Rear & 129 & 3.58 & 0.11 & 4.61 & 14.18 & 41.11 \\
\hline RC-B Front & 177 & 3.89 & 0.14 & 5.03 & 15.44 & 60.61 \\
\hline RC-B Rear & 150 & 2.58 & 0.11 & 4.95 & 17.11 & 111.02 \\
\hline A Buell Front & 144 & 2.61 & 0.12 & 4.14 & 13.29 & 51.71 \\
\hline B Buell Front & 317 & 5.75 & 0.20 & 2.49 & 9.30 & 39.43 \\
\hline
\end{tabular}
(a) $\mathrm{LOI}=$ loss on ignition
(b) $\mathrm{D}(\mathrm{v}, 0.1)=$ diameter below which $10 \%$ of the sample lies, $\mathrm{m}$
(c) $\mathrm{D}(\mathrm{v}, 0.5)=$ diameter below which $50 \%$ of the sample lies, $\mathrm{m}$
(d) $\mathrm{D}(\mathrm{v}, 0.9)=$ diameter below which $90 \%$ of the sample lies, $\mathrm{m}$
(e) analysis of $<147 \mathrm{~m}$ portion of sample (see Table 5)
(f) average of two determinations 
TABLE 4

ANALYSES OF SET 3 (FEBRUARY 1999)

\begin{tabular}{|c|c|c|c|c|c|c|}
\hline \multirow[b]{2}{*}{ Sample ID } & \multirow[b]{2}{*}{$\begin{array}{r}\text { Ammonia, } \\
\mathrm{g} / \mathrm{g}\end{array}$} & \multirow[b]{2}{*}{$\begin{array}{r}\text { LOI (a), wt } \\
\% \\
\end{array}$} & \multirow[b]{2}{*}{$\begin{array}{r}\text { S (tot), } \\
\text { wt } \%\end{array}$} & \multicolumn{3}{|c|}{ particle size, $\quad \mathbf{m}(\mathbf{f})$} \\
\hline & & & & $D(v, 0.1)(b)$ & $\mathrm{D}(\mathrm{v}, 0.5)(\mathrm{c})$ & $D(v, 0.9)(d)$ \\
\hline A Air Heater & 38.5 & 3.17 & 0.12 & $52.16(\mathrm{e})$ & $101.32(\mathrm{e})$ & $166.40(\mathrm{e})$ \\
\hline B Air Heater & 616 & 10.54 & 0.37 & 86.74(e) & $133.43(\mathrm{e})$ & $176.07(\mathrm{e})$ \\
\hline RC-A Front & 129 & 3.58 & 0.12 & 6.63 & 15.79 & 43.46 \\
\hline RC-A Rear & 157 & 3.82 & 0.12 & 6.48 & 20.87 & 97.35 \\
\hline RC-B Front & 190 & 3.14 & 0.12 & 7.78 & 26.68 & 141.86 \\
\hline RC-B Rear & 85.2 & 5.91 & 0.13 & $22.44(\mathrm{e})$ & $107.60(\mathrm{e})$ & $187.40(\mathrm{e})$ \\
\hline A Buell Front & 194 & 6.63 & 0.18 & 3.44 & 11.81 & 53.27 \\
\hline B Buell Front & 281 & 5.58 & 0.16 & 6.04 & 21.57 & 106.47 \\
\hline
\end{tabular}
(a) $\mathrm{LOI}=$ loss on ignition
(b) $\mathrm{D}(\mathrm{v}, 0.1)=$ diameter below which $10 \%$ of the sample lies, $\mathrm{m}$
(c) $\mathrm{D}(\mathrm{v}, 0.5)=$ diameter below which $50 \%$ of the sample lies, $\mathrm{m}$
(d) $\mathrm{D}(\mathrm{v}, 0.9)=$ diameter below which $90 \%$ of the sample lies, $\mathrm{m}$
(e) analysis of $<147 \mathrm{~m}$ portion of sample (see Table 5)
(f) average of two determinations 
TABLE 5

SCREEN ANALYSES OF AIR HEATER SAMPLES FROM

JANUARY 19, 1999, AND FEBRUARY 25, 1999, SAMPLE SETS

\begin{tabular}{|c|c|c|c|c|c|c|}
\hline \multirow{2}{*}{$\begin{array}{c}\text { Screen Fraction, } \\
\text { Tyler Standard } \\
\text { Screen Sizes }\end{array}$} & \multirow{2}{*}{$\begin{array}{l}\text { Equivalent } \\
\text { Screen } \\
\text { Apertures ( m) }\end{array}$} & \multicolumn{2}{|c|}{ January 19, 1999} & \multicolumn{3}{|c|}{ February 25, 1999} \\
\hline & & $\begin{array}{c}\text { A Air Heater, } \\
\text { wt } \%\end{array}$ & $\begin{array}{c}\text { B Air } \\
\text { Heater, wt } \\
\%\end{array}$ & $\begin{array}{c}\text { A Air Heater, } \\
\text { wt } \%\end{array}$ & $\begin{array}{c}\text { B Air Heater, } \\
\text { wt } \%\end{array}$ & $\underset{\%}{\text { RC Out } B, \text { wt }}$ \\
\hline+28 & +589 & 0.5 & 1.3 & 5.8 & 4.1 & 0.6 \\
\hline $28 \times 48$ & $589-295$ & 2.5 & 6.1 & 6.4 & 9.3 & 5.4 \\
\hline $48 \times 100$ & 295-147 & 15.0 & 35.2 & 25.2 & 37.5 & 23.8 \\
\hline $100 \times 200$ & 147-74 & 31.6 & 47.4 & 34.4 & 37.8 & 30.2 \\
\hline $200 \times 325$ & $74-43$ & 20.8 & 8.2 & 16.3 & 8.1 & 14.6 \\
\hline-325 & -43 & 29.6 & 1.8 & 11.9 & 32 & 25.4 \\
\hline
\end{tabular}




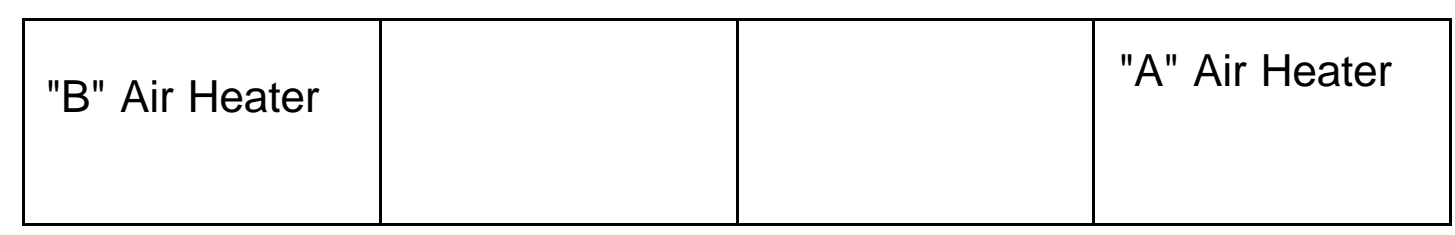

Air Heater Drop Out Hoppers

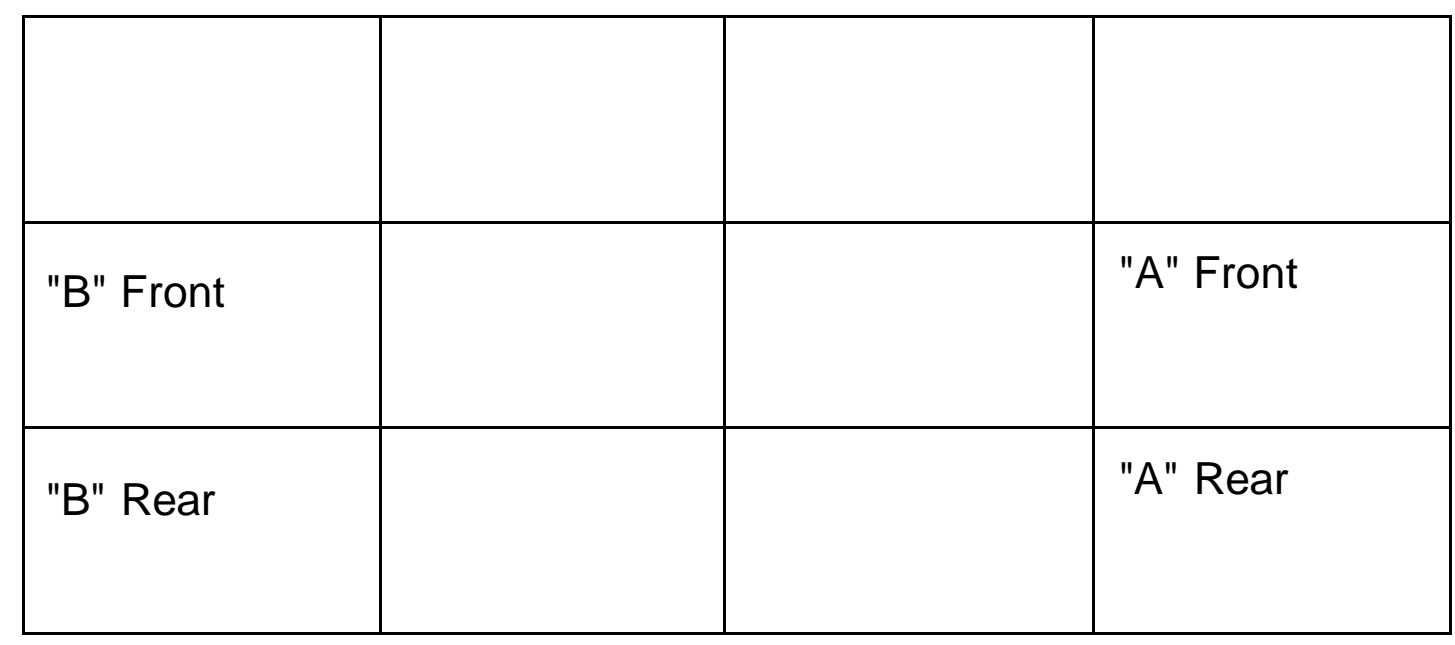

Research Cottrell (RC) Precipitator Hoppers

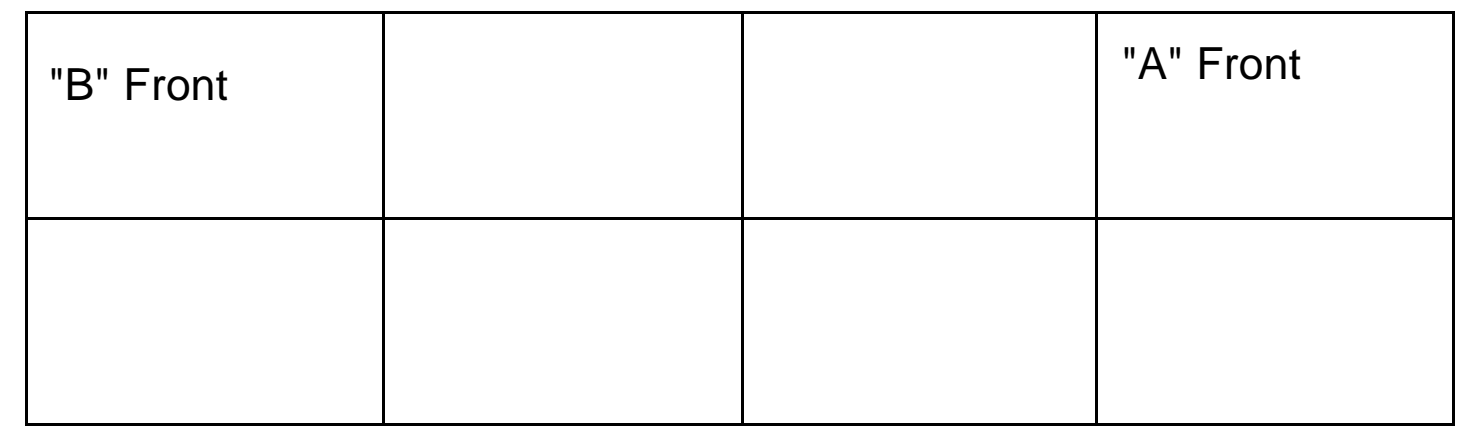

Buell Precipitator Hoppers

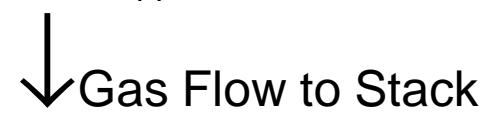

Figure 1. Seward Station Unit \#5 Location Plan for Fly Ash Samples 


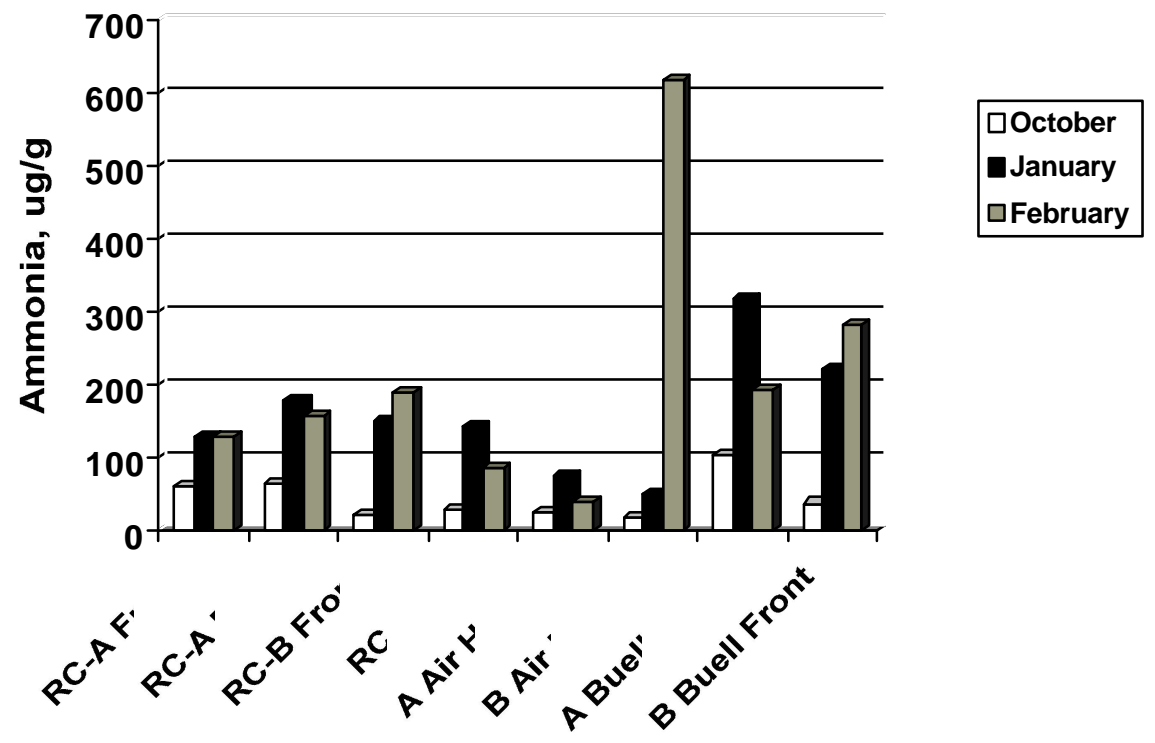

Sampling Loaction

Figure 2. Ammonia Content vs. Sampling Location.

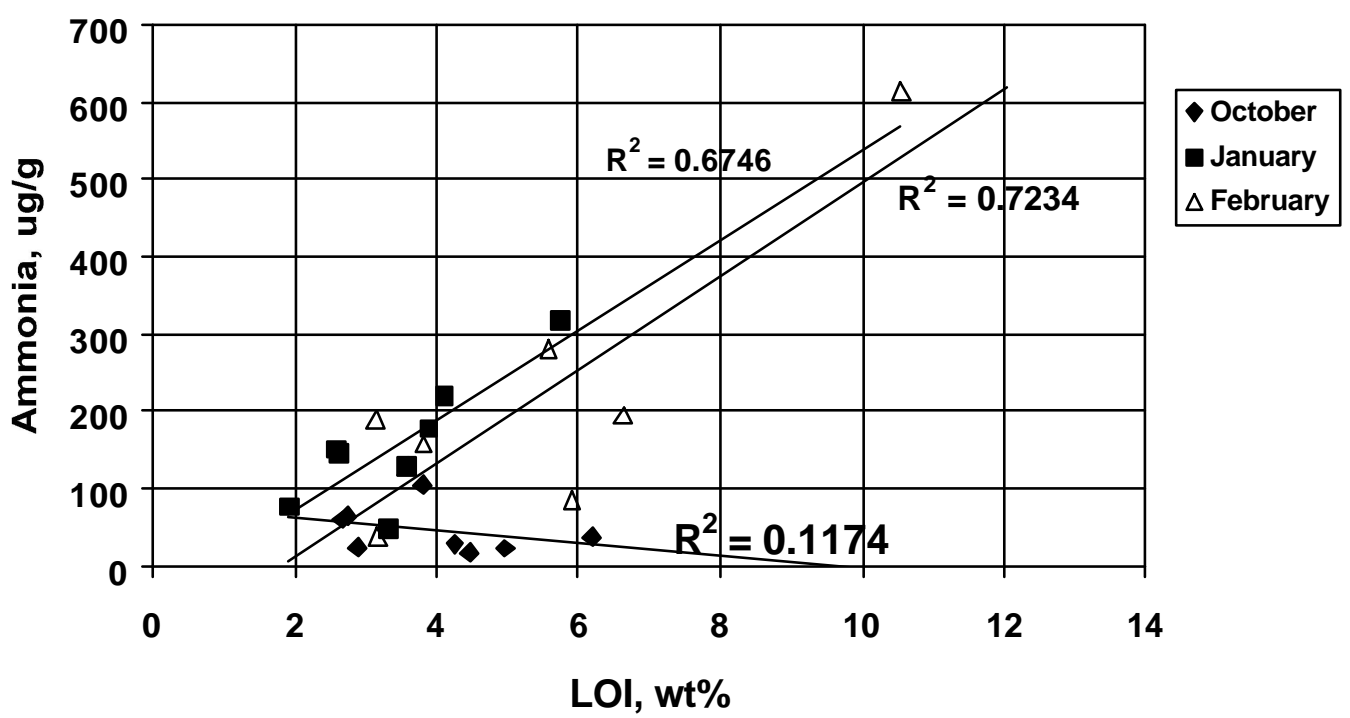

Figure 3. Ammonia Content vs Loss on Ignition. 


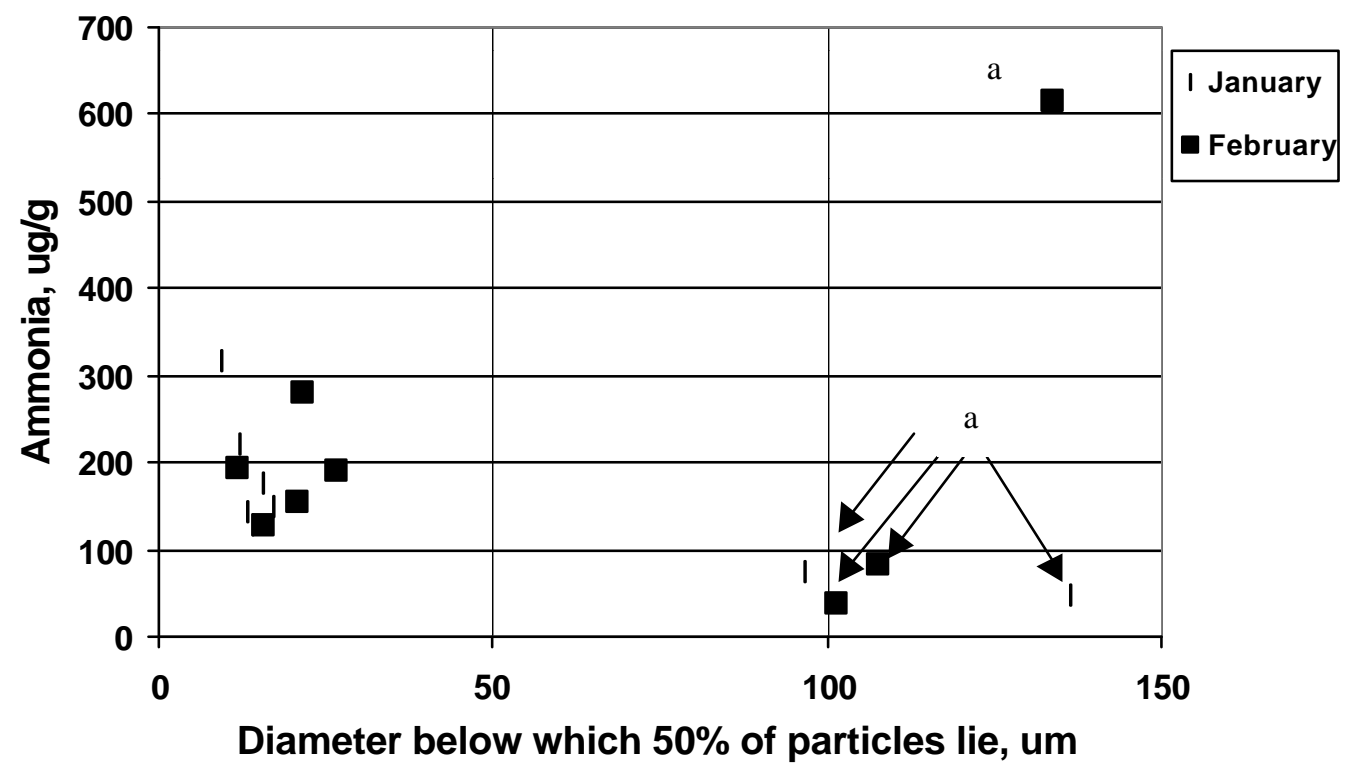

Figure 4a. Ammonia Content vs. Diameter Below Which $50 \%$ of Particles Lie. (a. Screened prior to analysis in Malvern instrument).

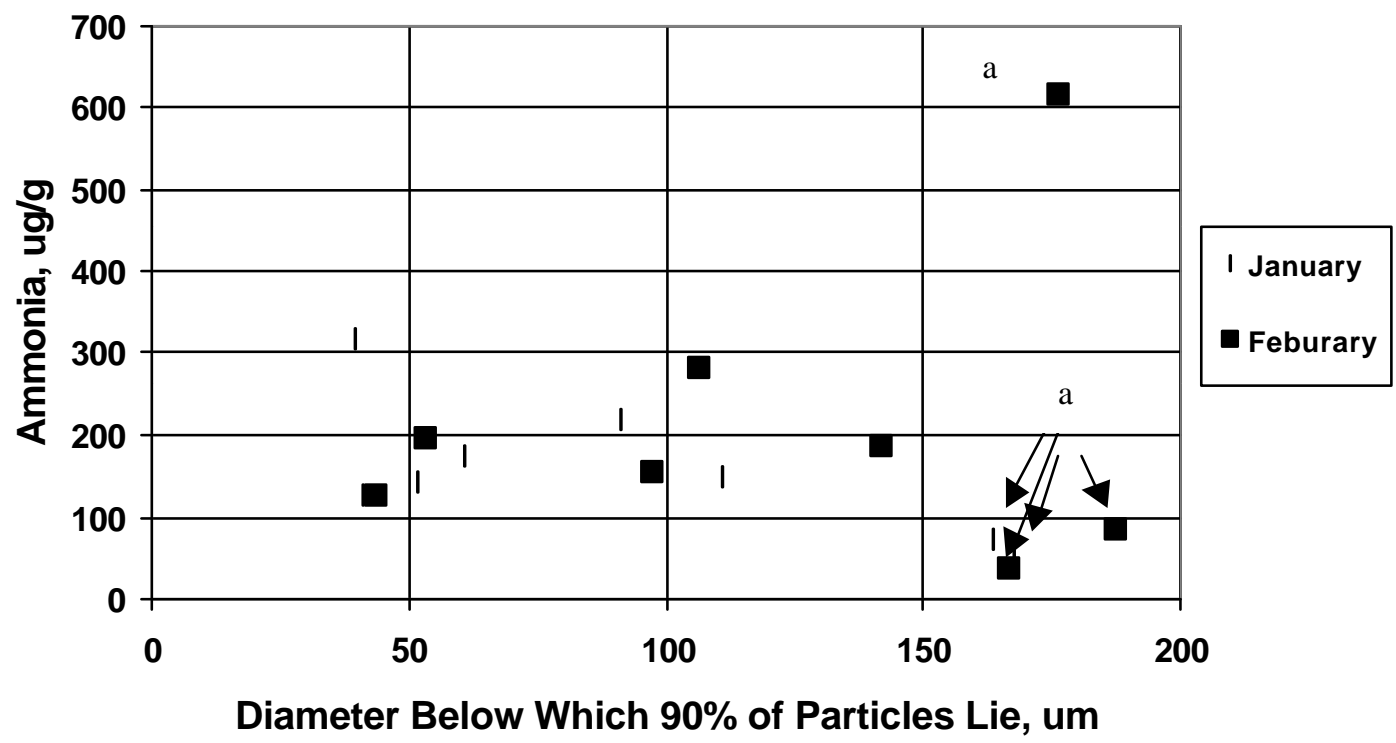

Figure 4b. Ammonia Content vs. Diameter Below Which $90 \%$ of Particles Lie. (a. Screened prior to analysis in Malvern instrument.) 


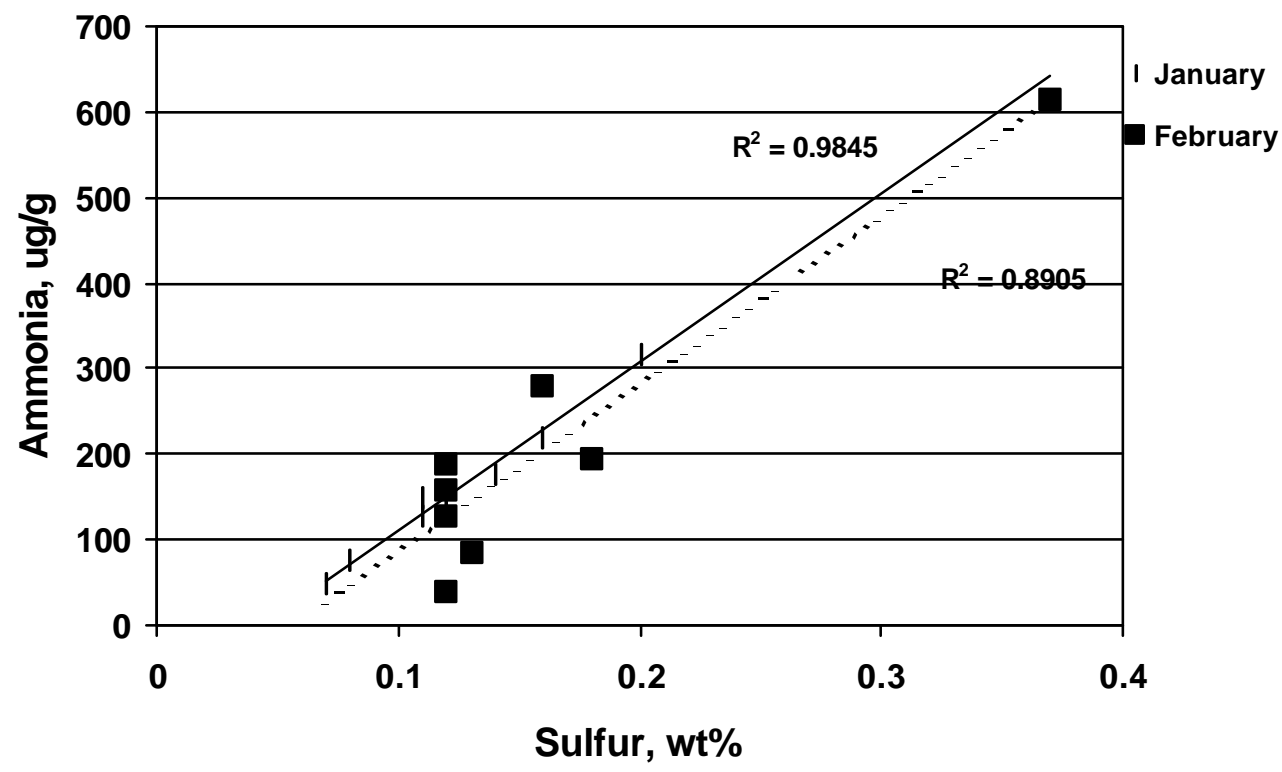

Figure 5. Ammonia Content vs. Sulfur Content. 


\section{APPENDIX E}




\section{CONSOL Inc.}

STANDARD METHOD No. 247

TITLE: $\quad$ The Determination of Ammonia in Fly Ash Using an Ammonia Specific Ion Electrode

DATE: $\quad$ April 1, 1998

CHANGE: New

\section{Scope}

This test method is applicable to the determination of soluble ammonia in fly ash. Results generated by this procedure are comparable to results generated by CONSOL Standard Method \# 221, "Ion Chromatographic Determination of Ammonia lons in Aqueous Solution."

\section{Principle}

The Ammonia in the test sample is solubilized with deionized water and is quantitatively determined potentiometrically using an ammonia specific ion electrode. The electrode employs a hydrophobic gas-permeable membrane to partition the sample solution containing the ammonium ions from the electrode internal solution of ammonium chloride. Ammonia dissolved in the sample solution diffuses through the membrane until the partial pressure of ammonia is the same on both sides. In any given test sample, the partial pressure of ammonia is proportional to its concentration.

\section{Apparatus Required}

1. Electrometer - A specific ion meter capable of calibration directly in concentration or a pH meter with expanded millivolt scale capable of $0.1 \mathrm{mV}$ resolution between $700 \mathrm{mV}$ and $+700 \mathrm{mV}$.

2. Ammonia Specific lon Electrode (An Orion model 95-12 was used in the development of this test procedure.)

3. Magnetic stirrer with teflon coated stirring bar.

4. Balance, sensitive to $0.1 \mathrm{mg}$.

5. Filter funnels, $110 \mathrm{~mm}$.

6. Beakers, $150 \mathrm{~mL}$. 
7. Volumetric flasks, $100 \mathrm{ml}$ and $1 \mathrm{~L}$.

8. Filter paper, Whatman \#40, $15 \mathrm{~cm}$.

9. Pipets, assorted.

\section{Reagents Required}

The chemicals listed below must be reagent grade and must conform to the specifications of the Committee on Analytical Reagents of the American Chemical Society.

1. Sodium hydroxide, $1 \mathrm{~N}$. Dissolved $40 \mathrm{~g} \mathrm{NaOH}$ in $80 \mathrm{~mL}$ of deionized water and dilute to $100 \mathrm{~mL}$.

2. Ammonia standard solution, $1000 \mathrm{mg} / \mathrm{L}$. (commercially available)

3. Deionized water

\section{Sample Preparation}

1. Weigh approximately $1 \mathrm{gram}$ (weighed to the nearest $0.1 \mathrm{mg}$ ) of the test sample into a clean dry $150 \mathrm{~mL}$ beaker.

2. Add approximately $60 \mathrm{~mL}$ of deionized water to the contents of the beaker.

3. Place the beaker into the ultrasonic bath and sonicate for 15 minutes

4. Remove the beaker from the ultrasonic bath and carefully dry the outside.

Quantitatively transfer the contents of the beaker into the filter apparatus. Allow the filtrate to drain into a $100 \mathrm{~mL}$ volumetric flask. Wash the residue on the filter paper several times with small increments of deionized water. Dilute to volume and mix well.

\section{Electrode Calibration}

The following procedure describes the measurement process using an electrometer with direct concentration readout capability.

1. Assemble and prepare the electrode according to manufacturers instructions then connect it to the electrometer. 
2. Prepare two calibration solutions by serial dilution of the $1000 \mathrm{ppm}$ ammonia standard. The calibration samples should bracket the expected sample range and should differ in concentration by a factor of ten.

3. Measure $50 \mathrm{~mL}$ of the more dilute calibration standard into a $150 \mathrm{~mL}$ beaker. Add 1 $\mathrm{mL}$ of $1.0 \mathrm{~N} \mathrm{NaOH}$ solution and a teflon coated magnetic stirring bar. Place the beaker containing the calibration solution onto the magnetic stirrer. (Stir thoroughly but avoid creating air bubbles that may become entrained on the electrode membrane.)

4. Rinse the electrode with deionized water, blot dry and immerse it into the calibration solution. Wait for the electrometer reading to stabilize (approximately 2 minutes) then adjust the meter to display the value of calibration solution as described in the electrometer instruction manual.

5. Measure $50 \mathrm{~mL}$ of the more concentrated calibration standard into a $150 \mathrm{~mL}$ beaker, add $1 \mathrm{~mL}$ of $1.0 \mathrm{NaOH}$ solution and a teflon coated magnetic stirring bar. Place the beaker containing the calibration solution onto the magnetic stirrer and repeat step 4.

The electrode should be calibrated daily and the calibration should be verified by analyzing a calibration solution at least once for every two hours of operation. If the results for the calibration solution are not within $5 \%$ of the expected value, recalibrate the electrode (steps 1 through 5).

\section{Analyses Procedure}

1. Measure $50 \mathrm{~mL}$ of the sample solution into a $150 \mathrm{~mL}$ beaker. Add $1 \mathrm{~mL}$ of $1.0 \mathrm{~N}$ $\mathrm{NaOH}$ and a teflon coated stirring bar. Stir the solution. Rinse the electrode with deionized water, blot dry and immerse into the sample solution. Wait for the electrometer to stabilize. The concentration of ammonia in the sample solution will be displayed on the meter.

2. Calculate the concentration of ammonia in the test sample according to the following equation:

$$
\begin{aligned}
\text { Ammonia }(\mathrm{ppm})= & \mathrm{NH}_{3} \text { in Solution (Meter Reading) } \\
& \text { sample weight (in grams) }
\end{aligned}
$$

If using a meter that responds in millivolts rather than concentration, prepare a calibration curve by plotting on semi-logarithmic graph paper, the millivolt values on the linear axis and the concentrations of the calibration solutions on the logarithmic axis. Then determine the concentration of solutions from the calibration curve. 


\section{General Notes on Electrode Use}

1. Sample solutions and calibration s solutions must be kept at the same temperature. A 1 degree ( C ) difference in temperature will give rise to about a $2 \%$ measurement error.

2. Between measurements, keep the electrode tip immersed in a $0.01 \mathrm{~N} \mathrm{NaOH}$ solution that contains 10 parts per million ammonia.

3. For overnight or one week periods, the electrode tip should be immersed in a 1000 parts per million ammonia solution. If storing for longer periods, disassemble the electrode completely, rinse all parts thoroughly with deionized water, dry and reassemble. For reuse, follow manufacturer's instruction for reassembly.

4. The electrode membrane may last from 1 week to several months. Membrane failure is characterized by a shift in the electrode potential, drift or poor response. Membrane failure may be apparent on visual inspection as dark spots or discoloration of the membrane. Normal electrode response is characterized by a 54 to $-60 \mathrm{mV}$ change for every 10 fold change in ammonia concentration. 